\title{
Evaluation of observed and modelled aerosol lifetimes using radioactive tracers of opportunity and an ensemble of 19 global models
}

\author{
N. I. Kristiansen ${ }^{1}$, A. Stohl ${ }^{1}$, D. J. L. Olivié ${ }^{2}$, B. Croft $^{3}$, O. A. Søvde ${ }^{4}$, H. Klein ${ }^{2}$, T. Christoudias ${ }^{5}$, D. Kunkel ${ }^{6}$, \\ S. J. Leadbetter ${ }^{7}$, Y. H. Lee ${ }^{8}$, K. Zhang ${ }^{9}$, K. Tsigaridis ${ }^{10}$, T. Bergman ${ }^{11}$, N. Evangeliou ${ }^{1,12}$, H. Wang ${ }^{9}$, P.-L. Ma ${ }^{9}$, \\ R. C. Easter $^{9}$, P. J. Rasch $^{9}$, X. Liu ${ }^{13}$, G. Pitari ${ }^{14}$, G. Di Genova ${ }^{14}$, S. Y. Zhao ${ }^{15}$, Y. Balkanski ${ }^{12}$, S. E. Bauer ${ }^{10}$,

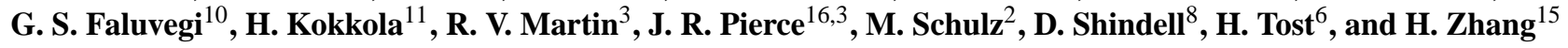 \\ ${ }^{1}$ NILU - Norwegian Institute for Air Research, Kjeller, Norway \\ ${ }^{2}$ Norwegian Meteorological Institute, Oslo, Norway \\ ${ }^{3}$ Department of Physics and Atmospheric Science, Dalhousie University, Halifax, Canada \\ ${ }^{4}$ Center for International Climate and Environmental Research - Oslo (CICERO), Oslo, Norway \\ ${ }^{5}$ The Cyprus Institute, Nicosia, Cyprus \\ ${ }^{6}$ Institute for Atmospheric Physics, Johannes Gutenberg University of Mainz, Mainz, Germany \\ ${ }^{7}$ Met Office, Exeter, UK \\ ${ }^{8}$ Earth and Ocean Sciences, Nicholas School of the Environment, Duke University, Durham, NC, USA \\ ${ }^{9}$ Pacific Northwest National Laboratory (PNNL), Richland, WA, USA \\ ${ }^{10}$ Center for Climate Systems Research, Columbia University, and NASA Goddard Institute for Space Studies, New York, \\ NY, USA \\ ${ }^{11}$ Finnish Meteorological Institute, Kuopio, Finland \\ ${ }^{12}$ Laboratoire des Sciences du Climat et de l'Environnement, CEA-CNRS-UVSQ, Gif-sur-Yvette, France \\ ${ }^{13}$ Department of Atmospheric Science, University of Wyoming, Laramie, WY, USA \\ ${ }^{14}$ University of L'Aquila, L'Aquila, Italy \\ ${ }^{15}$ Laboratory for Climate Studies, National Climate Center, Chinese Meteorological Administration, Beijing, China \\ ${ }^{16}$ Department of Atmospheric Science, Colorado State University, Fort Collins, CO, USA
}

Correspondence to: N. I. Kristiansen (nik@nilu.no)

Received: 5 August 2015 - Published in Atmos. Chem. Phys. Discuss.: 9 September 2015

Revised: 29 February 2016 - Accepted: 2 March 2016 - Published: 17 March 2016

\begin{abstract}
Aerosols have important impacts on air quality and climate, but the processes affecting their removal from the atmosphere are not fully understood and are poorly constrained by observations. This makes modelled aerosol lifetimes uncertain. In this study, we make use of an observational constraint on aerosol lifetimes provided by radionuclide measurements and investigate the causes of differences within a set of global models. During the Fukushima Dai-Ichi nuclear power plant accident of March 2011, the radioactive isotopes cesium-137 $\left({ }^{137} \mathrm{Cs}\right)$ and xenon-133 $\left({ }^{133} \mathrm{Xe}\right)$ were released in large quantities. Cesium attached to particles in the ambient air, approximately according to their available
\end{abstract}

aerosol surface area. ${ }^{137} \mathrm{Cs}$ size distribution measurements taken close to the power plant suggested that accumulationmode (AM) sulfate aerosols were the main carriers of cesium. Hence, ${ }^{137} \mathrm{Cs}$ can be used as a proxy tracer for the AM sulfate aerosol's fate in the atmosphere. In contrast, the noble gas ${ }^{133} \mathrm{Xe}$ behaves almost like a passive transport tracer. Global surface measurements of the two radioactive isotopes taken over several months after the release allow the derivation of a lifetime of the carrier aerosol. We compare this to the lifetimes simulated by 19 different atmospheric transport models initialized with identical emissions of ${ }^{137} \mathrm{Cs}$ that were assigned to an aerosol tracer with each model's default prop- 
erties of AM sulfate, and ${ }^{133} \mathrm{Xe}$ emissions that were assigned to a passive tracer. We investigate to what extent the modelled sulfate tracer can reproduce the measurements, especially with respect to the observed loss of aerosol mass with time. Modelled ${ }^{137} \mathrm{Cs}$ and ${ }^{133} \mathrm{Xe}$ concentrations sampled at the same location and times as station measurements allow a direct comparison between measured and modelled aerosol lifetime. The e-folding lifetime $\tau_{\mathrm{e}}$, calculated from station measurement data taken between 2 and 9 weeks after the start of the emissions, is 14.3 days ( $95 \%$ confidence interval 13.1-15.7 days). The equivalent modelled $\tau_{\mathrm{e}}$ lifetimes have a large spread, varying between 4.8 and 26.7 days with a model median of $9.4 \pm 2.3$ days, indicating too fast a removal in most models. Because sufficient measurement data were only available from about 2 weeks after the release, the estimated lifetimes apply to aerosols that have undergone long-range transport, i.e. not for freshly emitted aerosol. However, modelled instantaneous lifetimes show that the initial removal in the first 2 weeks was quicker (lifetimes between 1 and 5 days) due to the emissions occurring at low altitudes and co-location of the fresh plume with strong precipitation. Deviations between measured and modelled aerosol lifetimes are largest for the northernmost stations and at later time periods, suggesting that models do not transport enough of the aerosol towards the Arctic. The models underestimate passive tracer $\left({ }^{133} \mathrm{Xe}\right)$ concentrations in the Arctic as well but to a smaller extent than for the aerosol $\left({ }^{137} \mathrm{Cs}\right)$ tracer. This indicates that in addition to too fast an aerosol removal in the models, errors in simulated atmospheric transport towards the Arctic in most models also contribute to the underestimation of the Arctic aerosol concentrations.

\section{Introduction}

Aerosols play an important role in air quality and influence the global climate (Friedlander, 1977; Seinfeld and Pandis, 1998; Ramanathan et al., 2001) but the processes affecting their removal from the atmosphere are not fully understood and are poorly constrained by observations. Generally, aerosol concentrations are affected by emissions, transport, removal, and physico-chemical transformation (e.g. Pöschl, 2005), and the atmospheric lifetime of aerosols is a function of the various removal processes, such as dry deposition by impaction and sedimentation, as well as wet deposition. For accumulation-mode (AM) aerosols (0.1-2 $\mu$ m diameter), the dominant removal process is wet deposition. The uncertainties and lack of observational constraints on these removal processes affect the ability to model aerosol concentrations correctly and make modelled aerosol lifetimes uncertain. The uncertainty in the effects of aerosols on climate further affects the ability to diagnose how sensitive the climate is to greenhouse gas emissions (e.g. Andreae, 2007).
Observation-based estimates of aerosol lifetimes are sparse due to the difficulty of obtaining measurements that cover a sufficient geographical area and time period for robust analysis. Reported observation-based aerosol lifetimes range from a few days to about a month in the troposphere (Williams et al., 2002; Paris et al., 2009; Schmale et al., 2011). Other aerosol lifetime estimates are derived from radionuclides produced by cosmic rays, radon decay, or nuclear bomb tests, and vary from 4 days to more than a month (Giorgi and Chameides, 1986), reflecting the different origin (e.g. surface or stratospheric) of radionuclide tracers. Aerosol residence times of about 4 days in the lower troposphere and about 12 days in the middle to upper troposphere may be seen as typical (Moore et al., 1973), but higher values of 8 days for the lower troposphere have been reported as well (Papastefanou, 2006). Following the Chernobyl nuclear accident, the exponential decline of the radionuclide concentrations indicated a residence time of 7 days (Cambray et al., 1987). Models report global average residence times of AM aerosol in the atmosphere on the order of 3-7 days for species emitted near the surface (Chin et al., 1996; Feichter et al., 1996; Stier et al., 2005; Berglen et al., 2004; Liu et al., 2005; Bourgeois and Bey, 2011; Chung and Seinfeld, 2002; Koch and Hansen, 2005; Textor et al., 2006). The differences in reported lifetimes from observations and models can partly be attributed to the applied definition of lifetime (i.e. characteristic time of exponential decay vs. ratio of burden to deposition or emissions). These lifetime definitions are only equivalent if the decay has a constant e-folding time over the considered time period (Croft et al., 2014). Several definitions of lifetime and residence time (the ratio of burden to deposition/emission/production) exist but the terminologies are often used inconsistently. We encourage future studies to give clear information about which lifetime definitions that are used.

Many modelling studies have analysed the global distribution, transport, and lifetime of aerosols, particularly within the Aerosol Comparisons between Observations and Models (AeroCom) initiative (e.g. Textor et al., 2006; Koch et al., 2009; Samset et al., 2014). It has been demonstrated that large differences exist for aerosol dispersal and removal between models. Samset et al. (2014) found that, compared to aircraft measurements, models seem to overestimate black carbon (BC) aerosol concentrations in the middle and upper troposphere, and thus, a short aerosol lifetime appears necessary to reproduce such observations. On the other hand, the models generally underestimate the aerosol concentrations closer to the surface, and this would get worse with a shorter model lifetime. In particular, models struggle to capture the high aerosol concentrations in the Artic related to the Arctic haze season (e.g. Shindell et al., 2008; Koch et al., 2009). A general underestimation of surface aerosol concentrations in the Arctic is found during the Arctic haze season, while an overestimation is often found in the summer (e.g. Eckhardt et al., 2015). Models underestimate poleward transport, re- 
move aerosols too efficiently, or do not confine pollution sufficiently to the lowest model levels due to excessive vertical diffusion (Koch et al., 2009), but it is not clear which is the main cause. It has also not been fully quantified how these model issues evolve during transport to the Arctic. Browse et al. (2012) and H. Wang et al. (2013) found that scavenging parameterizations play a significant role in modelling Arctic aerosol concentrations. In particular, slow scavenging by ice clouds in winter and enhanced scavenging by drizzle in summer are important for modelling the annual cycle of Arctic aerosol concentrations. Using a source-tagging technique, $\mathrm{H}$. Wang et al. (2014) found that the annual mean lifetime of Arctic AM BC aerosol has very strong source-region dependence, varying by a factor of 4 . Zhang et al. (2015) further showed that the lifetime also depends on season and emission type. Substantially lower BC lifetime is found in summer, likely due to relatively strong wet removal, than in other seasons, and open-fire emissions that have higher initial injection heights which lead to generally longer lifetime than emissions from the surface.

In this study, we evaluate modelled aerosol lifetimes slightly differently than in previous studies. We use a unique single event with relatively well-known emissions to determine the lifetime of aerosols in the atmosphere. Previous studies report the mean lifetime of aerosols from simulations with higher uncertainty in the emission terms. Specifically, emissions and lifetimes are sometimes tuned to obtain what are thought to be "reasonable" concentrations. In this exercise, we use emissions of radionuclides from the Fukushima Dai-Ichi nuclear power plant (FD-NPP) accident in March 2011 as "tracers of opportunity". The cesium $\left({ }^{137} \mathrm{Cs}\right)$ released during the accident attached to the particles in the ambient air, approximately in proportion to their surface area (Papastefanou, 2008). The peak of the aerosol surface area distribution is generally in the AM, which in the area of FDNPP is typically dominated by sulfate. Kaneyasu et al. (2012) performed measurements close to FD-NPP and confirmed that ${ }^{137} \mathrm{Cs}$ was attached to or included in aerosols (internally mixed with other aerosol components), and their ${ }^{137} \mathrm{Cs}$ size distribution measurements showed that AM sulfate aerosols were the main transport carriers of cesium. They further explained that elemental carbon (EC) or BC particles were unlikely to be the transport carriers because flaming fires did not continue during the FD-NPP accident, large-scale forest fires were not reported around FD-NPP, and because the local residents had refrained from the burning of firewood in fear of the re-emission of radionuclides since the accident. However, they could not exclude the possibility that water-insoluble organic carbon (OC) could have acted as a transport medium of cesium. Even though it is possible that some of the ${ }^{137} \mathrm{Cs}$ attached to other aerosol than sulfate, these aerosol components were likely mixed internally with the dominant AM sulfate aerosol and therefore should have similar removal properties. Miyamoto et al. (2014) reported ${ }^{137} \mathrm{Cs}$ size distribution measurements taken in an earlier phase (6 days after the accident) and closer to FD-NPP, which showed an activity median aerodynamic diameter (AMAD) of ${ }^{137} \mathrm{Cs}$ of around $1.5-1.6 \mu \mathrm{m}$, in agreement with the results of Kaneyasu et al. (2012). Masson et al. (2013) found that after long-range transport to Europe, the AMAD of ${ }^{137} \mathrm{Cs}$ ranged between 0.25 and $0.71 \mu \mathrm{m}$, thus again in the AM of the ambient aerosols. Hence, ${ }^{137} \mathrm{Cs}$ can be used as a proxy tracer for the AM sulfate aerosol's fate in the atmosphere.

Cesium from FD-NPP was measured in the Northern Hemisphere for more than 3 months after its release and traced the fate of its carrier-aerosol in the atmosphere. These measurements provided a unique opportunity to estimate the lifetime of AM aerosols in the atmosphere, as presented by Kristiansen et al. (2012). In that study, measurements of the two radionuclides xenon $\left({ }^{133} \mathrm{Xe}\right)$ and cesium $\left({ }^{137} \mathrm{Cs}\right)$ were used, both released in large quantities from FD-NPP. The noble gas xenon $\left({ }^{133} \mathrm{Xe}\right)$ was used as a passive transport tracer. Notice that both radionuclides have very low background concentrations caused by emissions from nuclear facilities (Wotawa et al., 2010) or, in the case of ${ }^{137} \mathrm{Cs}$, resuspension of deposited radiocesium. Background values were subtracted from all measured values, as described by Kristiansen et al. (2012). These authors used the measured ratios of the aerosol $\left({ }^{137} \mathrm{Cs}\right)$ to the passive tracer $\left({ }^{133} \mathrm{Xe}\right)$ enhancements in the surface concentrations, to compensate for variability in transport, and estimated an AM aerosol lifetime of 10-14 days. This is longer than the mean lifetimes of AM aerosols obtained from most aerosol models (typically in the range of 3-7 days). The disagreement could be partly due to the fact that the emissions were from a single location and during a specific season, the measurements were all groundbased, and thus the data were not fully representative of the global and annual mean aerosol lifetime, as well as using definitions of lifetime that were not equivalent under the considered conditions (Croft et al., 2014). In the current study, we try to resolve this issue and investigate to what extent aerosol models can reproduce the observations, especially with respect to the observed loss of aerosol mass with time.

We use the term "aerosol lifetime" throughout the paper to indicate the lifetime of AM aerosol and primarily sulfate. We assume that the ${ }^{137} \mathrm{Cs}$ attached mostly to the dominant $\mathrm{AM}$ sulfate aerosol, confirmed by measurements. The lifetimes apply to aerosols that have undergone long-range transport (after about 2-3 weeks); i.e. the results presented cannot directly constrain the lifetime of freshly emitted aerosols.

The paper is organized as follows. In Sect. 2 we describe the measurements used in the study, followed by an overview of all participating models in Sect. 3. The methods are described in Sect. 4, and the main results are presented in Sect. 5. In Sect. 6 we further discuss some important aspects of the results and compare our results to other recent studies. Main conclusions are summarized in Sect. 7. The paper also includes supplementary information in three Appendices, A to $\mathrm{C}$. 


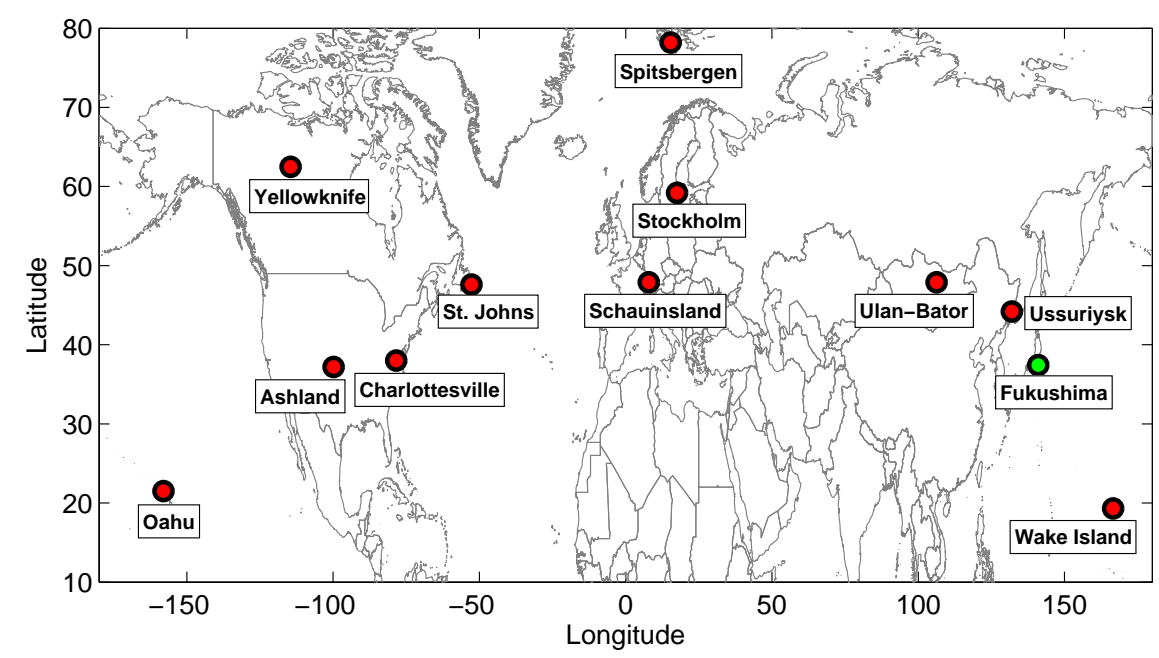

Figure 1. Measurement station network. CTBTO stations (red markers) measuring particulates $\left({ }^{137} \mathrm{Cs}\right)$ and noble gases $\left({ }^{133} \mathrm{Xe}\right)$. The position of the Fukushima Dai-Ichi nuclear power plant (FD-NPP) is shown by a green marker.

\section{Observations}

We have used atmospheric surface measurements of activity concentrations of the noble gas ${ }^{133} \mathrm{Xe}$ and the aerosol-bound radionuclide ${ }^{137} \mathrm{Cs}$ available from several stations (Fig. 1) operated by the Comprehensive Nuclear-Test-Ban Treaty Organization (CTBTO). For collecting particulate radionuclides, about $20000 \mathrm{~m}^{3}$ of air is blown through a filter over a period of $24 \mathrm{~h}$. The different radionuclides are measured with high-resolution germanium detectors (Schulze et al., 2000; Medici, 2001). The minimum detectable activity concentration of ${ }^{137} \mathrm{Cs}$ is $1 \mu \mathrm{Bq} \mathrm{m}^{-3}$. During the International Noble Gas Experiment (INGE), noble gas measurement systems have been set up worldwide (Wernsberger and Schlosser, 2004; Saey and de Geer, 2005) at CTBTO stations. The collection period of the xenon samples is typically $12 \mathrm{~h}$. The most prevalent and important isotope is ${ }^{133} \mathrm{Xe}$, which is measured with an accuracy of about $0.1 \mathrm{mBq} \mathrm{m}^{-3}$. All measured radionuclide concentrations were corrected for radioactive decay relative to the time of the earthquake on 11 March 05:46 UTC that triggered the nuclear accident. The measurements were further converted from activity per norm cubic metre at standard temperature and pressure $(273.15 \mathrm{~K}$ and $101325 \mathrm{~Pa}$ ) to activity per cubic metre (using meteorological analysis data) for comparison with the model results. The measurements and their uncertainties are described in more detail by Stohl et al. (2012a) and Kristiansen et al. (2012).

\section{Model simulations}

A total of 19 atmospheric transport models have simulated the transport and removal of the radioactive isotopes released during the FD-NPP accident. The models are classified as either Lagrangian particle dispersion models (LPDMs), aerosol transport models (ATMs; models which rely entirely on meteorological input data) and aerosol circulation models (ACMs; models which calculate their own meteorology or are nudged towards (re)analysis data). Table 1 shows an overview of the models included in the experiment including their type, meteorology, and model resolutions. More details on each model's treatment of aerosols are given in Appendix A, Table A1.

All model simulations were initiated with identical emissions of cesium $\left({ }^{137} \mathrm{Cs}\right)$ and xenon $\left({ }^{133} \mathrm{Xe}\right)$ as determined from inverse modelling by Stohl et al. (2012a). The simulations extended from 11 March until at least 5 June 2011 for when the last measurement of the radionuclides were taken. A total of $36.6 \mathrm{PBq}$ of ${ }^{137} \mathrm{Cs}$ and $15.3 \mathrm{EBq}$ of ${ }^{133} \mathrm{Xe}$ were released by all models. The emission rates vary significantly over the emission period considered (11 March20 April 2011) but the major emissions of the radionuclides occurred over about 5 days (11-15 March 2011). The emissions of cesium continued until 20 March after which they dropped significantly. The releases were divided into three vertical layers between 0 and $1000 \mathrm{~m}$ above ground level (Stohl et al., 2012a). Croft et al. (2014) have shown that the e-folding lifetimes derived from their GEOS-Chem model simulations of the Fukushima emissions do not depend very much on the exact specification of the emissions (e.g. their altitude, location, and time). This is because radionuclides could be measured in the atmosphere for several months, long after the emissions had practically ceased (Kristiansen et al., 2012). Therefore, after the end of the emissions the decrease in measured concentrations can be attributed solely to aerosol removal. Biases in the emissions affect the absolute model-simulated values, but not the lifetime estimate. In the analysis, it might be expected that the FLEXPART model will perform relatively well since the source terms used by all 
Table 1. List of models. ATMs: aerosol transport models (models which rely entirely on meteorological input data), ACMs: aerosol circulation models (models which calculate their own meteorology or are nudged towards (re)analysis data), LPDMs: Lagrangian particle dispersion models, *AEROCOM Phase II models.

\begin{tabular}{|c|c|c|c|c|c|}
\hline & Model & Type & Meteorology & $\begin{array}{l}\text { Model output resolution } \\
\mathrm{H}: \text { horizontal (degrees lat } \times \text { long) } \\
\text { V: vertical, T: temporal }\end{array}$ & References \\
\hline 1 & NorESM & $\mathrm{ACM}$ & Internal (generated online) & $\begin{array}{l}\mathrm{H}: 1.875^{\circ} \times 2.5^{\circ} \\
\mathrm{V}: 26 \text { levels up to } \sim 2.2 \mathrm{hPa} . \\
\mathrm{T}: 3 \mathrm{~h} \text { mean }(\text { model calc. } 30 \mathrm{~min})\end{array}$ & $\begin{array}{l}\text { Kirkevåg et al. (2013), } \\
\text { Iversen et al. (2013), } \\
\text { Bentsen et al. (2013) }\end{array}$ \\
\hline 2 & GISS-ModelE2-TOMAS* & $\mathrm{ACM}$ & $\begin{array}{l}\text { NCEP reanalysis horizontal } \\
\text { winds every } 6 \mathrm{~h}\end{array}$ & $\begin{array}{l}\mathrm{H}: 2.0^{\circ} \times 2.5^{\circ} \\
\mathrm{V}: 40 \text { levels up to } 0.1 \mathrm{hPa} \\
\mathrm{T}: 3 \mathrm{~h} \text { mean }(\text { model calc. } 30 \mathrm{~min})\end{array}$ & $\begin{array}{l}\text { Adams and Seinfeld (2002); } \\
\text { Lee et al. (2015) }\end{array}$ \\
\hline 3 & GISS-ModelE* & $\mathrm{ACM}$ & $\begin{array}{l}\text { NCEP reanalysis horizontal } \\
\text { winds every } 6 \mathrm{~h}\end{array}$ & $\begin{array}{l}\mathrm{H}: 2.0^{\circ} \times 2.5^{\circ} \\
\mathrm{V}: 40 \text { levels up to } 0.1 \mathrm{hPa} \\
\mathrm{T}: 3 \mathrm{~h} \text { mean }(\text { model calc. } 30 \mathrm{~min})\end{array}$ & $\begin{array}{l}\text { Koch et al. (2006); } \\
\text { Tsigaridis et al. (2013); } \\
\text { Schmidt et al. (2014) }\end{array}$ \\
\hline 4 & ULAQ-CCM & $\mathrm{ACM}$ & Internal (generated online) & $\begin{array}{l}\mathrm{H}: 5.0^{\circ} \times 6.0^{\circ}(\mathrm{T} 21) \\
\mathrm{V}: 126 \text { levels up to mesosphere } \\
\mathrm{T}: 45 \mathrm{~min}\end{array}$ & Pitari et al. (2014) \\
\hline 5 & BCC_AGCM_2.0.1_CAM* & $\mathrm{ACM}$ & $\begin{array}{l}\text { Online coupled. NCEP/NCAR } \\
\text { reanalysis as initial field }\end{array}$ & $\begin{array}{l}\mathrm{H}: 2.8^{\circ} \times 2.8^{\circ} \\
\mathrm{V}: 26 \text { levels up to } 2.9 \mathrm{hPa} \\
\mathrm{T}: 3 \mathrm{~h}(\text { model calc. } 20 \mathrm{~min})\end{array}$ & $\begin{array}{l}\text { Gong et al. (2003); } \\
\text { H. Zhang et al. (2012); } \\
\text { H. Zhang et al. (2014) }\end{array}$ \\
\hline 6 & LMDZORINCA & $\mathrm{ACM}$ & $\begin{array}{l}\text { Nudged to ERA-Interim reanal- } \\
\text { ysis wind fields every } 6 \mathrm{~h} \text { with a } \\
\text { relaxation time of } 10 \text { days }\end{array}$ & $\begin{array}{l}\mathrm{H}: 2.5^{\circ} \times 1.27^{\circ} \\
\mathrm{V}: 39 \text { levels up to } \sim 78 \mathrm{~km} \\
\mathrm{~T}: 3 \mathrm{~h} \text { mean }\end{array}$ & Evangeliou et al. (2013) \\
\hline 7 & $\mathrm{CAM}^{*}$ & $\mathrm{ACM}$ & $\begin{array}{l}\text { ERA-Interim reanalysis every } \\
6 \mathrm{~h} \text { (re-gridded to the model } \\
\text { grid resolution) }\end{array}$ & $\begin{array}{l}\mathrm{H}: 1.9^{\circ} \times 2.5^{\circ} \\
\mathrm{V}: 56 \text { levels up to } 1.9 \mathrm{hPa} \\
\mathrm{T}: 30 \mathrm{~min}\end{array}$ & $\begin{array}{l}\text { Liu et al. (2012); } \\
\text { Ma et al. (2013) }\end{array}$ \\
\hline 8 & CAM5_PNNL ${ }^{*}$ & $\mathrm{ACM}$ & Same as CAM5 & Same as CAM5 & H. Wang et al. (2013) \\
\hline 9 & CAM5_NDG & $\mathrm{ACM}$ & $\begin{array}{l}\text { ERA-Interim reanalysis hori- } \\
\text { zontal winds (re-gridded to the } \\
\text { model grid) at every model time } \\
\text { step, with a relaxation timescale } \\
\text { of } 6 \mathrm{~h}\end{array}$ & $\begin{array}{l}\mathrm{H}: 1.9^{\circ} \times 2.5^{\circ} \\
\mathrm{V}: 30 \text { levels up to } 3.6 \mathrm{hPa} \\
\mathrm{T}: 30 \mathrm{~min}\end{array}$ & $\begin{array}{l}\text { Liu et al. (2012); } \\
\text { K. Zhang et al. (2014) }\end{array}$ \\
\hline 10 & $\begin{array}{l}\text { ECHAM5-MESSy- } \\
\text { Atmospheric Chemistry } \\
\text { Model, v1.92 (EMAC-1) }\end{array}$ & $\mathrm{ACM}$ & $\begin{array}{l}\text { ERA-Interim every } 6 \mathrm{~h} \text { on the } \\
\text { model grid resolution. Nudged } \\
\text { variables are divergence and } \\
\text { vorticity of the wind, tempera- } \\
\text { ture, and the logarithm of the } \\
\text { surface pressure }\end{array}$ & $\begin{array}{l}\mathrm{H}: 1.1^{\circ} \times 1.1^{\circ} \\
\mathrm{V}: 31 \text { levels up to } 10 \mathrm{hPa} \\
\mathrm{T}: 3 \mathrm{~h}(\text { model calc. } 6 \mathrm{~min})\end{array}$ & $\begin{array}{l}\text { Christoudias and Lelieveld } \\
\text { (2013) }\end{array}$ \\
\hline 11 & $\begin{array}{l}\text { ECHAM5-MESSy- } \\
\text { Atmospheric Chemistry } \\
\text { Model, v2.50 (EMAC-2) }\end{array}$ & $\mathrm{ACM}$ & $\begin{array}{l}\text { ERA-Interim every } 6 \mathrm{~h} \text { on the } \\
\text { model grid resolution. Nudged } \\
\text { variables are divergence and } \\
\text { vorticity of the wind, tempera- } \\
\text { ture, and the logarithm of the } \\
\text { surface pressure }\end{array}$ & $\begin{array}{l}\mathrm{H}: 1.9^{\circ} \times 1.9^{\circ} \\
\mathrm{V}: 31 \text { levels up to } 10 \mathrm{hPa}(\sim 30 \mathrm{~km}) \\
\mathrm{T}: 1 \mathrm{~h}(\text { model calc. } 15 \mathrm{~min})\end{array}$ & $\begin{array}{l}\text { Kunkel (2012); } \\
\text { Kunkel et al. (2013) }\end{array}$ \\
\hline 12 & ECHAM5-HAM2* & $\mathrm{ACM}$ & $\begin{array}{l}\text { Nudged towards ERA-Interim } \\
\text { reanalysis at every time step. } \\
\text { Relaxation timescales are } 6 \mathrm{~h} \\
\text { for vorticity, } 48 \mathrm{~h} \text { for diver- } \\
\text { gence, } 24 \mathrm{~h} \text { for temperature, and } \\
24 \mathrm{~h} \text { for surface pressure }\end{array}$ & $\begin{array}{l}\mathrm{H}: 2.8^{\circ} \times 2.8^{\circ} \\
\mathrm{V}: 19 \text { levels (top layer centre at } 10 \mathrm{hPa} \text {, } \\
\text { including stratosphere) } \\
\mathrm{T}: 30 \mathrm{~min}\end{array}$ & K. Zhang et al. (2012) \\
\hline 13 & ECHAM5-SALSA* & $\mathrm{ACM}$ & $\begin{array}{l}\text { ERA-Interim data at } 6 \mathrm{~h} \text { inter- } \\
\text { vals }\end{array}$ & $\begin{array}{l}\mathrm{H}: 1.9^{\circ} \times 1.9^{\circ} \\
\mathrm{V}: 31 \text { levels up to } 10 \mathrm{hPa}(\sim 30 \mathrm{~km}) \\
\mathrm{T}: 1 \mathrm{~h} \text { mean }(\text { model calc. } 12 \mathrm{~min})\end{array}$ & $\begin{array}{l}\text { Bergman et al. (2012); } \\
\text { Laakso et al. (2016) }\end{array}$ \\
\hline 14 & GEOS-Chem v09-01-03 & ATM & $\begin{array}{l}\text { GMAO GEOS-5.2.0 assimi- } \\
\text { lated meteorology, } 0.67 \times 0.5 \\
\text { degree horizontal grid, } 6 \mathrm{~h} \text {, } \\
\text { re-gridded to model resolution }\end{array}$ & $\begin{array}{l}\mathrm{H}: 2.0^{\circ} \times 2.5^{\circ} \\
\mathrm{V}: 47 \text { levels up to } 0.01 \mathrm{hPa} \\
\mathrm{T}: 1 \mathrm{~h}\end{array}$ & $\begin{array}{l}\text { www.geos-chem.org; } \\
\text { Croft et al. (2014); } \\
\text { Bey et al. (2001) }\end{array}$ \\
\hline
\end{tabular}


Table 1. Continued.

\begin{tabular}{|c|c|c|c|c|c|}
\hline & Model & Type & Meteorology & $\begin{array}{l}\text { Model output resolution } \\
\text { H: horizontal (degrees lat } \times \text { long) } \\
\text { V: vertical, T: temporal }\end{array}$ & References \\
\hline 15 & EEMEP v2533 & ATM & $\begin{array}{l}\text { ECMWF IFS cycle } 36,3 \mathrm{~h} \text { fore- } \\
\text { casts }\end{array}$ & $\begin{array}{l}\mathrm{H}: 1.0^{\circ} \times 1.0^{\circ} \\
\mathrm{V}: 20 \text { levels up to } 100 \mathrm{hPa}(\sim 14 \mathrm{~km}) \\
\mathrm{T}: 30 \text { min }\end{array}$ & $\begin{array}{l}\text { http://www.emep.int/mscw/ } \\
\text { models.html }\end{array}$ \\
\hline 16 & OsloCTM2* & ATM & $\begin{array}{l}\text { ECMWF IFS cycle } 36,3 \mathrm{~h} \text { fore- } \\
\text { casts }\end{array}$ & $\begin{array}{l}\mathrm{H}: 2.8^{\circ} \times 2.8^{\circ} \\
\text { V: } 60 \text { levels up to } 0.1 \mathrm{hPa} \\
\text { T: } 1 \mathrm{~h}\end{array}$ & $\begin{array}{l}\text { Søvde et al. (2008); } \\
\text { Berglen et al. (2004) }\end{array}$ \\
\hline 17 & OsloCTM3 & ATM & $\begin{array}{l}\text { ECMWF IFS cycle } 36,3 \mathrm{~h} \text { fore- } \\
\text { casts }\end{array}$ & $\begin{array}{l}\mathrm{H}: 1.1^{\circ} \times 1.1^{\circ} \\
\mathrm{V}: 60 \text { levels up to } 0.1 \mathrm{hPa} \\
\mathrm{T}: 1 \mathrm{~h}\end{array}$ & Søvde et al. (2012) \\
\hline 18 & NAME III & LPDM & $\begin{array}{l}\text { Met Office Unified Model anal- } \\
\text { ysis, } 0.35^{\circ} \times 0.23^{\circ} \text { and } 3 \mathrm{~h} \text { res- } \\
\text { olution. }\end{array}$ & $\begin{array}{l}\mathrm{H}: 1.0^{\circ} \times 1.0^{\circ} \\
\text { V: } 2 \mathrm{~km}(\text { upper level at } 20 \mathrm{~km}) \\
\text { T: } 3 \mathrm{~h} \text { mean }\end{array}$ & $\begin{array}{l}\text { Leadbetter et al. (2015); } \\
\text { Webster and Thomson (2014) }\end{array}$ \\
\hline 19 & FLEXPART $\vee 9.0$ & LPDM & $\begin{array}{l}\text { National Centers for Envi- } \\
\text { ronmental Prediction (NCEP) } \\
\text { Global Forecast System (GFS) } \\
\text { analyses, } 0.5^{\circ} \times 0.5^{\circ} \text { and } 3 \mathrm{~h} \\
\text { resolution }\end{array}$ & $\begin{array}{l}\mathrm{H}: 2.0^{\circ} \times 2.0^{\circ} \\
\text { V: } 100 \mathrm{~m} \text { surf conc. }+ \text { total column } \\
\text { T: } 3 \mathrm{~h} \text { mean }\end{array}$ & Stohl et al. $(2005,2012 a)$ \\
\hline
\end{tabular}

models were estimated using inverse modelling with the help of FLEXPART. However, the source term was constrained using measurements from several other stations than those utilized in the current study, and both airborne and deposition data.

The cesium was treated as sulfate aerosols in the model simulations; i.e. it underwent the same wet and dry deposition as AM sulfate aerosols. Xenon was treated as a passive tracer without wet and dry removal processes. In order to evaluate the removal of aerosols due to wet and dry deposition processes only, no radioactive decay of ${ }^{137} \mathrm{Cs}$ (halflife 30 years) and ${ }^{133} \mathrm{Xe}$ (half-life 5.25 days) was simulated by the models or the model simulation was decay-corrected to the start of the nuclear accident (11 March 05:46 UTC). Both the emissions used for the model simulations and the atmospheric concentration measurements were also decaycorrected. Modelled cesium and xenon concentrations were sampled at the location of the 11 CTBTO sites (Fig. 1), at times when measurements were available. This allows a direct comparison to the measurements and observation-based lifetime evaluations (Kristiansen et al., 2012). Modelled total atmospheric burdens as a function of time were also calculated and evaluated.

The transport of the radioactive cloud across the Northern Hemisphere is illustrated in Fig. 2, as simulated by the FLEXPART model using meteorological analysis data from the Global Forecast System (GFS) model of the National Centers for Environmental Prediction (NCEP), in the weeks following the initial release at FD-NPP. While transport patterns depend on the meteorological data set used (e.g. some models generate their own meteorology), it can be seen that 3-4 weeks after the start of the emissions, the radionuclides were already distributed fairly homogeneously over the entire Northern Hemisphere.

\section{Methods}

We use the same basic approaches as in Kristiansen et al. (2012) to evaluate measured and modelled loss of aerosol mass with time, i.e. aerosol lifetimes. Measured aerosol lifetimes, derived directly from the decay of station measurements of cesium $\left({ }^{137} \mathrm{Cs}\right)$ and xenon $\left({ }^{133} \mathrm{Xe}\right)$ (Kristiansen et al., 2012), are compared to modelled aerosol lifetimes determined in exactly the same way from modelled station concentrations for the same time periods as the observations. To reduce the variability caused by atmospheric transport, we normalize the ${ }^{137} \mathrm{Cs}$ values by the ${ }^{133} \mathrm{Xe}$ values; i.e. the ratio of the aerosol $\left({ }^{137} \mathrm{Cs}\right)$ to the passive tracer $\left({ }^{133} \mathrm{Xe}\right)$ is used throughout all lifetime evaluations. This largely compensates for variability in transport, but not completely because the source terms for ${ }^{137} \mathrm{Cs}$ and ${ }^{133} \mathrm{Xe}$ are not perfectly correlated. Additionally, we use global burdens estimated from measurement data as in Kristiansen et al. (2012) and compare these to modelled global burdens.

Several definitions of atmospheric lifetime exist. In Kristiansen et al. (2012), the e-folding lifetime was used as a measure of aerosol lifetime. Croft et al. (2014) document, compare, and explain differences between global mean aerosol lifetime, the definition typically reported for aerosol and climate model simulations, and e-folding times from their GEOS-Chem transport simulations of the FD-NPP accident emissions. They show that the two definitions are not directly comparable for the FD-NPP case. The lifetime results for the former definition were heavily influenced by 

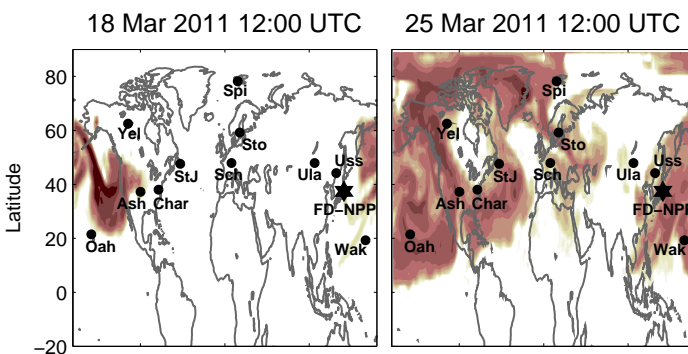

08 Apr 2011 12:00 UTC
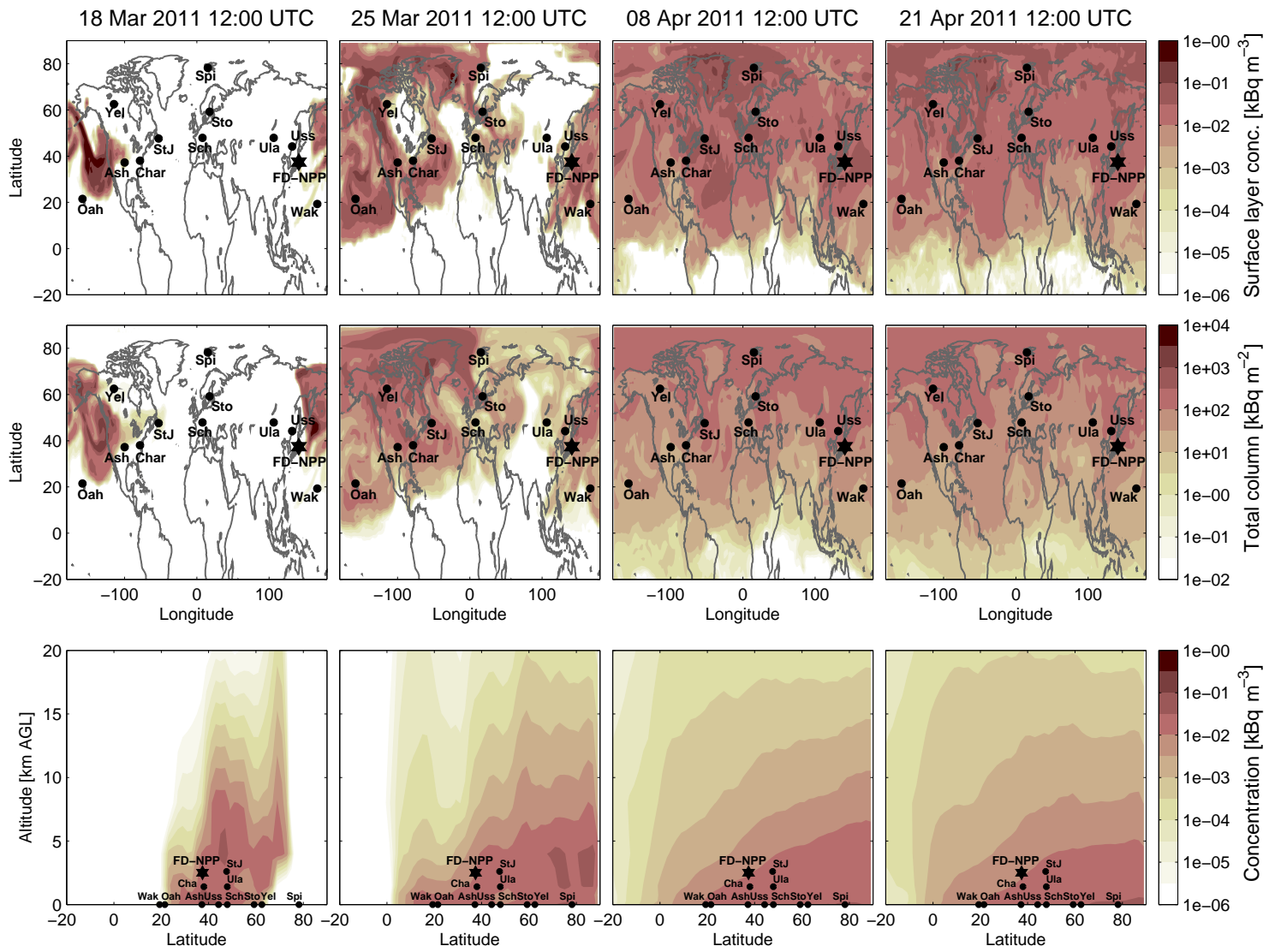

Figure 2. The transport of the radioactive plume of ${ }^{133}$ Xe released from the Fukushima Dai-Ichi nuclear power plant (FD-NPP; black star) as simulated by the FLEXPART model using GFS meteorological data. ${ }^{133}$ Xe surface concentrations (upper panel), total atmospheric columns (middle panel), and zonal mean vertical distribution (lower panel) for 18, 25 March, 8 and 22 April 2011 (1, 2, 4, and 6 weeks, respectively, after the start of the initial release on 11 March). The 11 CTBTO stations are marked with black points (please note that the points in the lower panel do not reflect the real station elevations).

initial quick removal, giving a much shorter lifetime than the e-folding lifetime for the hemispherically relatively wellmixed phase starting about 3 weeks after the main emissions. They also show that the global mean aerosol lifetime strongly depends on the altitude where emissions are assumed to occur, while the e-folding lifetime is relatively insensitive to emissions parameters such as altitude, location, and time, suggesting that e-folding times allow a robust comparison between modelled and measurement-based lifetimes. For the purpose of this study we consider lifetime as equivalent to residence time.

In this exercise, we will use the e-folding lifetime (as in Kristiansen et al., 2012) and the instantaneous lifetime (as in Croft et al., 2014) as means of evaluation. The two lifetimes are typically used to evaluate exponentially decreasing aerosol concentrations after an emissions pulse.

The e-folding lifetime is defined as

$\tau_{\mathrm{e}}=\frac{-t_{i}}{\ln \frac{C\left(t_{i}\right)}{C\left(t_{0}\right)},}$ where $C\left(t_{i}\right)$ is the concentration at time $t_{i}, C\left(t_{0}\right)$ the initial concentration at time $t_{0}$, and $t_{i}$ is the time since $t_{0}$. Instantaneous lifetime is defined as

$\tau_{\text {inst }}=\frac{t_{(i-1)}-t_{i}}{\ln \frac{C\left(t_{i}\right)}{C\left(t_{i-1}\right)}}$,

where $t_{i}$ and $t_{i-1}$ are adjacent time steps, here in this study separated by 1 day.

Further, we calculate the mean and median of all the modelled lifetimes. These are calculated from the lifetimes obtained for each model. Since the distribution of the modelled lifetime data is not symmetric but has outliers, the mean is not the best representative of the centre of the data, and therefore the median is preferred. The variability is given as the standard deviation (SD) from the mean, and the median absolute deviation (MAD) from the median. The MAD is defined as the median of the absolute deviations from the data's median:

$\operatorname{MAD}=\operatorname{median}\left(\left|\tau_{i}-\operatorname{median}\left(\tau_{i}\right)\right|, i=1, \ldots, N\right)$, 
where $N$ is the total number of models and $\tau_{i}$ is the lifetime (either e-folding or instantaneous) obtained from model $i$.

\section{Results}

\subsection{Direct comparison of measured and modelled aerosol lifetimes}

Here we present a direct comparison of measured and modelled aerosol lifetimes based on an observational constraint provided by radionuclide measurements of the FD-NPP emissions. We investigate the causes of differences between the measurements and models. The measured and modelled aerosol lifetimes are estimated from the ratios of the aerosol $\left({ }^{137} \mathrm{Cs}\right)$ to the passive tracer $\left({ }^{133} \mathrm{Xe}\right)$ surface concentrations (Sect. 4) at 11 CTBTO measurement sites (Sect. 3) as shown in Fig. 3. Both the measurements and all model simulations show a decrease in these ratios with time due to the removal of aerosols. The aerosol lifetimes are estimated by fitting an exponential decay model (grey lines in Fig. 3) to the daily median ratios over all stations (black triangles; $\omega$ in Fig. 3), between 15 and 65 days after the start of the emissions on 11 March. During this time period, measurement data exist from at least five stations each day; i.e. the daily median value $\omega$ is calculated from at least five values. The data density before day 15 and after day 65 is quite sparse and there are sampling biases. Before day 15 , the measurements are mainly from the closest stations as the plume has not yet reached all sites and mixed through the Northern Hemisphere. After day 65, valid measurement data become sparse because concentrations start to drop below the detection limit and all data below the detection limit were discarded. The remaining valid data after day 65 are mainly from Yellowknife and Spitsbergen with values near the detection limit. If these periods were considered, the lifetimes would be biased high, possibly due to a latitude effect, discussed later.

The measured aerosol $\left({ }^{137} \mathrm{Cs}\right)$ to the passive tracer $\left({ }^{133} \mathrm{Xe}\right)$ ratios decay with an e-folding lifetime $\tau_{\mathrm{e}}$ (Eq. 1) of 14.3 days (Fig. 3 and Table 2) with a $95 \%$ confidence interval of 13.1-15.7 days (Appendix B and Table B1). The equivalent modelled $\tau_{\mathrm{e}}$ lifetimes vary between 4.8 and 26.7 days with a model mean ( \pm standard deviation) of $10.7 \pm 5.5$, and a model median ( \pm MAD, Eq. 3) of $9.4 \pm 2.3$ days (Table 2 ). Thus, the model mean and median lifetimes are shorter than the lifetime based on the measurements, indicating too quick a removal of the aerosols in the models. However, some individual models have longer lifetimes than measured, and the model mean \pm standard deviation encompasses the measured lifetime. Large variations in the modelled lifetimes are expected due to differences in the simulated transport and especially tropospheric removal.

Table 2 shows the lifetime estimates using data only from stations below and above $50^{\circ} \mathrm{N}$ separately. Both measured and mean modelled lifetimes are shorter below $50^{\circ} \mathrm{N}$ than at high latitudes, suggesting less efficient aerosol removal at high latitudes during the time period investigated (March-June). However, a few models (NorESM, ULAQCCM, EMAC-1, EMAC-2, and NAME) also have somewhat shorter lifetimes at higher latitudes than at lower latitudes, and two models (CAM5 and FLEXPART) show no change in lifetime with latitude. H. Wang et al. (2013) found that CAM5, with the shortest lifetimes of all models, overestimates aerosol wet removal by super-cooled liquid in mixedphase clouds, which was improved in CAM5_PNNL. There is a larger spread in model lifetimes and larger deviations from the measurements at high latitudes compared to at lower latitudes, indicating larger uncertainties in the simulation of aerosols at higher latitudes. Similarly, lifetime estimates from the earlier phases (25-45 days after the start of the release, a period when the major emissions were over) are compared to those for later time periods (days 45-65) (Table 2). Both the measurements and the median model give slightly longer lifetimes (by about 0.3-1.0 days) for the earlier phases than for later time periods. This is perhaps unexpected as the radionuclides are initially located in the lower troposphere where they are strongly affected by precipitation scavenging and dry deposition, and later when the radionuclides are mostly located in the relatively dry upper troposphere (or even stratosphere), the removal processes are much less effective which would yield an increase in lifetime. However, since the data used to derive the lifetimes are ground-based and thus biased towards that part of the aerosol population residing in the lower troposphere, neither the measurements nor the models may fully reflect the increase in lifetime due to transport in the upper troposphere. Differences in lifetime between tracers emitted near the surface and those coming from the stratosphere may be substantial, as discussed in Kristiansen et al. (2012). Furthermore, most of the radionuclides were uplifted immediately after the release (Stohl et al., 2012a) and thus quite well mixed in the troposphere already for the earlier time period (days 25-45), as also shown in Fig. 2. In addition, station data from the later time periods (day 45-65) include fewer data points in the calculations than in the earlier phases. Lastly, there are larger variations in the modelled lifetimes for the later phase, and a larger model to measurement deviation, indicating larger uncertainty in the modelled lifetimes for the later phase than for the earlier phase.

In summary, both the mean and median modelled aerosol lifetimes are somewhat shorter than the observed aerosol lifetime, although they mostly agree within the standard deviations of the modelled lifetimes. The underestimation of lifetimes by the models is smaller than what was indicated by Kristiansen et al. (2012) based on reported mean modelled lifetimes from the literature, consistent with the findings of Croft et al. (2014). The deviations between observed and modelled aerosol lifetimes are largest for the northernmost stations and at later time periods, indicating higher uncer- 
Table 2. E-folding aerosol lifetimes (Eq. 1) estimated from the decay of the ratios between the aerosol $\left({ }^{137} \mathrm{Cs}\right)$ and the passive tracer $\left({ }^{133} \mathrm{Xe}\right)$ surface concentrations at 11 station locations. Variations in lifetime for different latitude regions (below and above $50^{\circ} \mathrm{N}$ ) and time periods are also given. Mean and median modelled lifetimes are calculated from the lifetimes obtained for each model and the variability is given as standard deviation (SD) and median absolute deviation (MAD, Eq. 3). The data are shown in Fig. $3.95 \%$ confidence intervals and $R^{2}$ statistics are given in Appendix B, Table B1. Values that are not statistically significant are marked with a star and were not considered for the mean and median calculations.

\begin{tabular}{llrrrrr}
\hline \multirow{2}{*}{ Model } & \multicolumn{5}{c}{ E-folding lifetime $\tau_{\mathrm{e}}$ (days) } \\
\cline { 3 - 7 } & & $\begin{array}{r}\text { Days 15-65 } \\
\text { All stations }\end{array}$ & $\begin{array}{r}\text { Days 15-65 } \\
\text { Stations } \\
\text { below } 50^{\circ} \mathrm{N}\end{array}$ & $\begin{array}{r}\text { Days 15-65 } \\
\text { Stations } \\
\text { above } 50^{\circ} \mathrm{N}\end{array}$ & $\begin{array}{r}\text { Days 25-45 } \\
\text { All stations }\end{array}$ & $\begin{array}{r}\text { Days 45-65 } \\
\text { All stations }\end{array}$ \\
& & & 11.2 & 9.0 & 10.1 & 10.9 \\
\hline 1 & NorESM & 10.5 & 9.3 & 10.1 & 9.5 & 10.2 \\
2 & GISS-ModelE2-TOMAS & 9.6 & 7.7 & 8.5 & 7.5 & 8.6 \\
3 & GISS-ModelE & 8.0 & 6.4 & 5.7 & 5.7 & 4.3 \\
4 & ULAQ-CCM & 6.0 & 17.7 & 18.5 & 17.9 & 12.6 \\
5 & BCC_AGCM & 16.7 & 10.0 & 16.1 & 6.9 & 17.5 \\
6 & LMDZORINCA & 11.5 & 5.1 & 5.1 & $14.6^{*}$ & 2.8 \\
7 & CAM5 & 12.5 & 12.7 & 18.7 & 14.7 & 15.1 \\
8 & CAM5_PNNL & 7.7 & 7.3 & 9.8 & 6.1 & 6.2 \\
9 & CAM5_NDG & 11.7 & 13.9 & 8.3 & 8.7 & 8.1 \\
10 & EMAC-1 & 8.1 & 8.1 & 7.8 & $19.9^{*}$ & 3.9 \\
11 & EMAC-2 & 6.4 & 6.3 & 8.8 & 5.7 & 6.2 \\
12 & ECHAM-HAM2 & 6.9 & 7.5 & 7.8 & 8.6 & $34.0^{*}$ \\
13 & ECHAM5-SALSA & 20.4 & 16.6 & 33.0 & 18.6 & 23.3 \\
14 & GEOS-Chem & 26.7 & 20.2 & $50.0^{*}$ & 15.6 & $23.6^{*}$ \\
15 & EEMEP & 11.2 & 11.1 & 19.9 & 10.8 & 8.3 \\
16 & OsloCTM2 & 8.8 & 9.1 & 9.3 & 13.0 & 7.8 \\
17 & OsloCTM3 & 9.4 & 11.0 & 8.7 & 7.3 & 4.5 \\
18 & NAME & 5.8 & 5.9 & 5.9 & 6.5 & 5.0 \\
19 & FLEXPART & $10.7 \pm 5.4$ & $10.4 \pm 4.2$ & $11.7 \pm 7.0$ & $10.1 \pm 4.3$ & $9.1 \pm 5.5$ \\
\hline & Model mean \pm SD & $9.4 \pm 2.3$ & $9.3 \pm 2.0$ & $8.9 \pm 1.2$ & $8.7 \pm 2.2$ & $8.1 \pm 3.1$ \\
& Model median \pm MAD & 13.5 & 15.0 & 15.0 & 14.7 \\
\hline
\end{tabular}

tainties in the simulation of aerosols and aerosol lifetimes at higher latitudes and later times.

\subsection{Model evaluation of latitudinal variations in transport and scavenging}

The previous section indicated that disagreements between the measurements and the models are largest at higher latitudes and at later time periods. This agrees with several previous studies (e.g. Shindell et al., 2008; Koch et al., 2009), which suggest that models do not capture the Arctic aerosol variations very well. In this study, we have the possibility to evaluate the models' abilities to simulate the aerosol concentrations and transport at different latitudes, by comparing the measured and modelled aerosol $\left({ }^{137} \mathrm{Cs}\right)$ and the passive transport tracer $\left({ }^{133} \mathrm{Xe}\right)$ data. In this way, we can directly explore how well the models are able to reproduce the observations at the northernmost stations (i.e. above $60^{\circ} \mathrm{N}$; Yellowknife $62.5^{\circ} \mathrm{N}$ and Spitsbergen $78^{\circ} \mathrm{N}$ ) compared to at lower latitudes. We also examine whether there are any temporal variations in the model-observation deviations. The analyses are limited by the low number of Arctic/subarctic stations and the particular season and time period (March-June 2011) of the measurements. Some indications may still be given which might help explain shortcomings with simulated scavenging and/or transport in the models, and if one is the more likely cause for deviations to observations.

We use the ratio of the modelled to measured surface concentrations as means of model score, where a ratio $>1$ indicates that the model over-predicts, and a ratio $<1$ represents under-predictions (Tables 3 and 4). Figure 4 shows the ratio of modelled to observed aerosol (green circles) and passive transport tracer (blue circles) concentrations as a function of latitude of the measurement stations. Generally, the models reproduce the observed passive tracer $\left({ }^{133} \mathrm{Xe}\right)$ values better than the observed aerosol $\left({ }^{137} \mathrm{Cs}\right)$ values, indicating that transport is reasonably well represented in the models. Scavenging affects only the aerosols, causing more variability and a larger extent of over- or under-prediction. On average, over all stations and models, the median ratio of modelled to measured passive tracer values is 0.79 (Table 3 ) and 

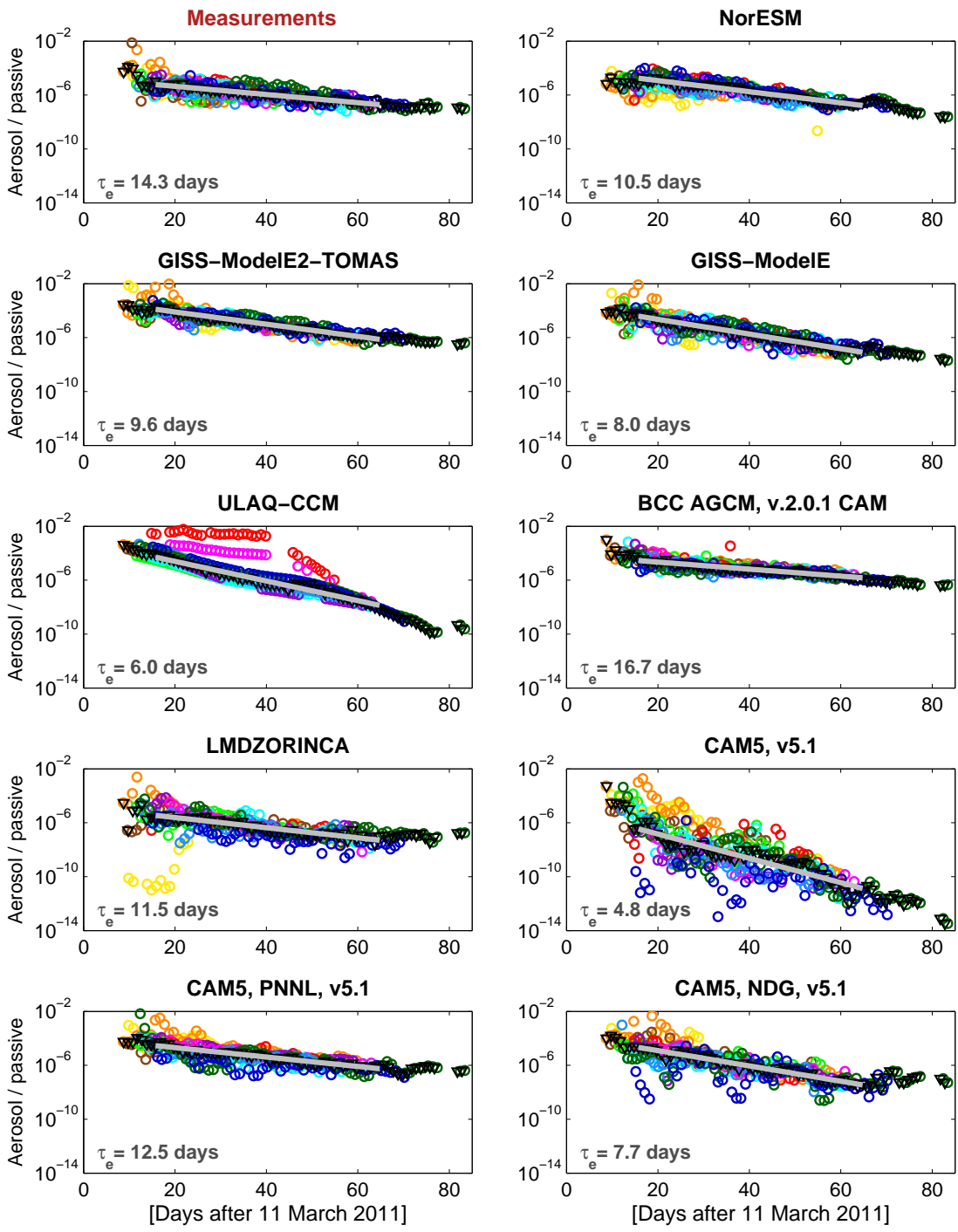

$\begin{array}{lllll}\text { Wake Island } & \text { Oahu } & \bigcirc & \text { Ashland } \\ \text { Schauinsland } O & \text { Ulanbator } & \text { Stockholm }\end{array}$

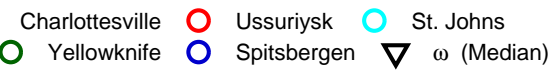

Figure 3.

for the aerosols 0.49 (Table 4), suggesting a general underprediction of both aerosol and passive tracer concentrations. The aerosol underestimation is consistent with the lifetime results from the previous section (Sect. 5.1) which showed that modelled aerosol lifetimes are too short compared to the measurements, and this would yield too much removal and thus under-predictions of the aerosol concentrations.

Furthermore, at the southernmost stations (Wake Island and Oahu) many models over-predict both the aerosol and passive tracer concentrations, whilst under-predicting both at the stations further north (Tables 3 and 4). The exception is Schauinsland $\left(48^{\circ} \mathrm{N}\right)$ where the models generally overpredict the passive tracer but under-predict the aerosol values. We find the largest under-prediction at the northernmost stations: Yellowknife for the passive tracer and Spitsbergen for the aerosol values. The modelled to measured aerosol ratios have a pronounced latitudinal trend, with ratios decreasing (i.e. larger under-predictions) with increasing latitude (Table 4 and Fig. 4). This indicates that there is too much aerosol removal occurring en route to the Arctic. There is also a slight decrease in modelled to measured passive tracer ratios with latitude (Table 3 and Fig. 4), suggesting that transport to the high latitudes is also not strong enough in the models, and this contributes to the aerosol underestimates at high latitudes. However, the main reason for the aerosol underestimates at high latitudes must be too efficient a simulated removal.

Finally, Fig. 4 illustrates the temporal variations of modelled to measured ratios. The values are medians over 14 day time periods and the size of the circles indicates the time; the 

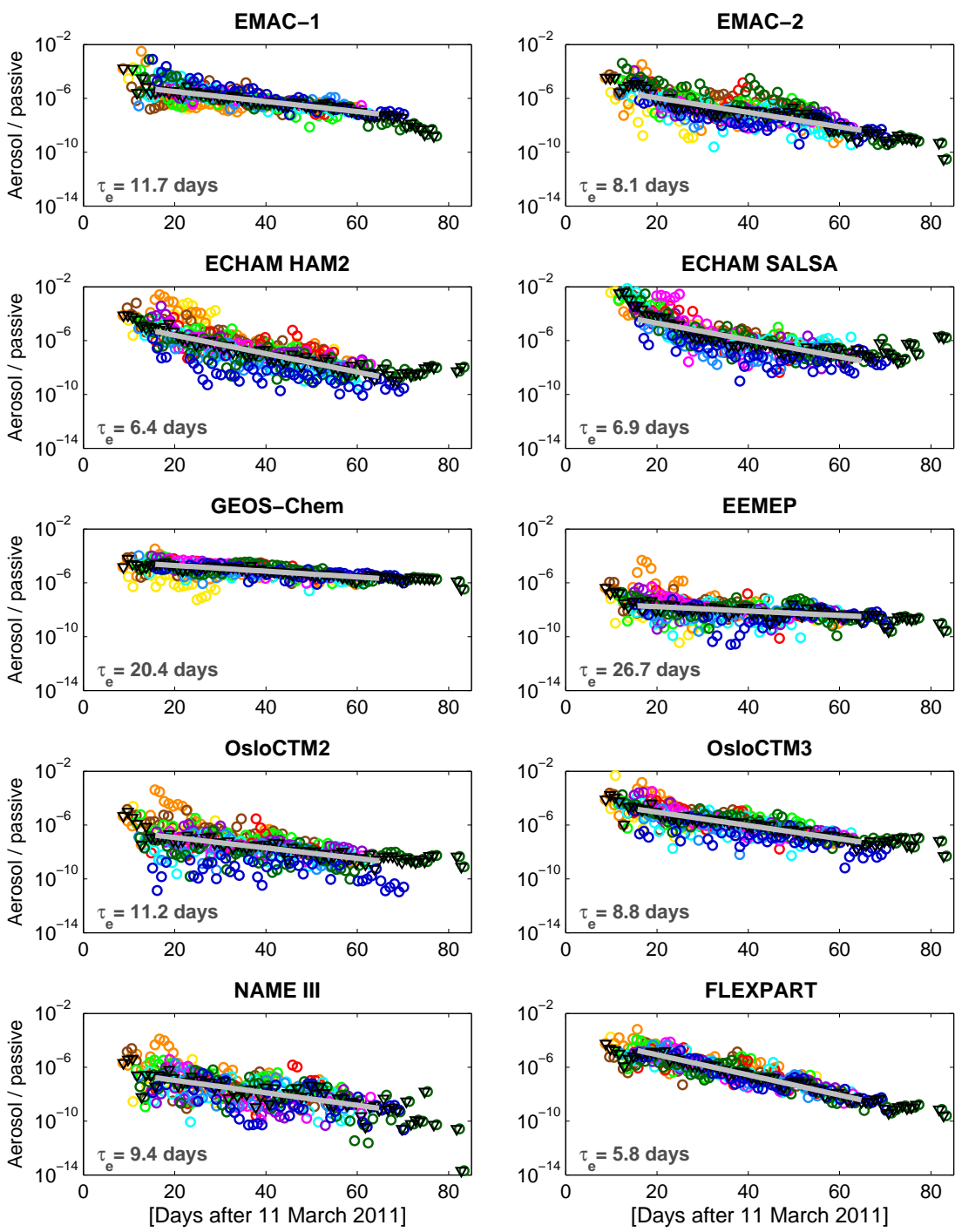

$\begin{array}{llll}\text { Wake Island } & \text { Oahu } & \text { Ashland } \\ \text { Schauinsland } & \text { Ulanbator } & \text { Stockholm }\end{array}$

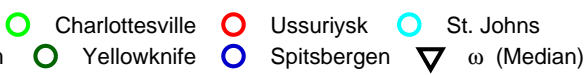

Figure 3. Time series of measured and modelled ratios of the aerosol $\left({ }^{137} \mathrm{Cs}\right)$ to the passive tracer $\left({ }^{133} \mathrm{Xe}\right)$ surface concentrations at 11 CTBTO station locations. $\omega$ values (median, black triangles) represent the daily median ratios (median concentration for each day over all stations). Fits of exponential decay models to the $\omega$ data are shown as grey lines with e-folding timescales $\tau_{\mathrm{e}}$ (Eq. 1) as indicated. The fits are made over days 15 to 65 for which data exist from at least five stations each day.

larger the circle, the later the time period. Particularly for the aerosol values, some models tend to show a stronger underestimation with time, also evident in the median model.

Our results suggest that modelling of both scavenging and transport are causes for disagreements with observations. Transport to the high latitudes is not strong enough in the models, and this contributes to the model underestimates also of the aerosol tracer at high latitudes. However, the modelled to observed ratios decrease much more strongly with latitude for the aerosol than for the passive tracer, and this indicates that a problem with the aerosol scavenging is the major reason for disagreement between the simulations and the mea- surements. Scavenging in the models depends strongly on the representation of clouds (temporal and spatial occurrence and dimensions) as well as on the amount of precipitation, which are likely to be the underlying issues. This helps explain the larger deviations between measured and modelled aerosol lifetimes for the northernmost stations and at later time periods as seen in the previous section (Table 2).

\subsection{Instantaneous lifetimes}

The time variations in aerosol lifetimes can be examined further by considering the instantaneous lifetimes, $\tau_{\text {inst }}$ (defined 
Table 3. Median ratio of the modelled to measured passive tracer $\left({ }^{133} \mathrm{Xe}\right)$ surface concentrations, for each model and each station as well as the model median and over all stations. Values greater than 1.2 (substantial over-predictions) are shown in red, and values less than 0.8 (substantial under-predictions) in blue.

\begin{tabular}{|c|c|c|c|c|c|c|c|c|c|c|c|c|c|}
\hline & $\begin{array}{c}\text { Station (latitude) / } \\
\text { model }\end{array}$ & \begin{tabular}{|l} 
Wak. \\
$\left(19^{\circ} \mathrm{N}\right)$
\end{tabular} & \begin{tabular}{|l|} 
Oah. \\
$\left(22^{\circ} \mathrm{N}\right)$
\end{tabular} & $\begin{array}{l}\text { Ash. } \\
\left(37^{\circ} \mathrm{N}\right)\end{array}$ & \begin{tabular}{|c|} 
Cha. \\
$\left(38^{\circ} \mathrm{N}\right)$
\end{tabular} & \begin{tabular}{|c} 
Uss. \\
$\left(44^{\circ} \mathrm{N}\right)$
\end{tabular} & \begin{tabular}{|c|} 
St. J \\
$\left(48^{\circ} \mathrm{N}\right)$
\end{tabular} & $\begin{array}{l}\text { Sha. } \\
\left(48^{\circ} \mathrm{N}\right)\end{array}$ & $\begin{array}{c}\text { Ula. } \\
\left(48^{\circ} \mathrm{N}\right)\end{array}$ & $\begin{array}{l}\text { Sto. } \\
\left(59^{\circ} \mathrm{N}\right)\end{array}$ & \begin{tabular}{|c|} 
Yel. \\
$\left(62^{\circ} \mathrm{N}\right)$
\end{tabular} & $\begin{array}{l}\text { Spi. } \\
\left(78^{\circ} \mathrm{N}\right)\end{array}$ & $\begin{array}{c}\text { All } \\
\text { stations }\end{array}$ \\
\hline 1 & NorESM & 1.58 & 1.22 & 0.76 & 0.80 & 0.54 & 0.47 & 1.19 & 0.61 & 0.47 & 0.48 & 0.58 & 0.61 \\
\hline 2 & GISS-ModelE2-TOMAS & 0.49 & 0.92 & 1.00 & 1.29 & 1.24 & 1.14 & 2.12 & 1.01 & 1.30 & 0.94 & 1.27 & 1.16 \\
\hline 3 & GISS-ModelE & 0.51 & 1.02 & 1.20 & 1.33 & 1.24 & 1.13 & 2.11 & 1.03 & 1.29 & 0.98 & 1.27 & 1.17 \\
\hline 4 & ULAQ-CCM & 13.09 & 4.14 & 0.73 & 0.46 & 0.80 & 0.43 & 0.60 & 0.56 & 0.37 & 0.66 & 0.58 & 0.61 \\
\hline 5 & BCC_AGCM2.0.1_CAM & 1.49 & 1.72 & 0.93 & 0.91 & 0.70 & 0.65 & 1.54 & 0.64 & 0.65 & 0.57 & 0.68 & 0.72 \\
\hline 6 & LMDZORINCA & 1.60 & 2.04 & 1.69 & 1.61 & 1.08 & 0.97 & 2.08 & 1.11 & 0.90 & 0.90 & 1.09 & 1.15 \\
\hline 7 & CAM5 & 0.70 & 1.10 & 0.91 & 0.96 & 0.85 & 0.83 & 1.37 & 0.80 & 0.88 & 0.71 & 0.90 & 0.86 \\
\hline 8 & CAM5_PNNL & 0.68 & 1.07 & 0.91 & 0.97 & 0.85 & 0.84 & 1.35 & 0.81 & 0.88 & 0.71 & 0.90 & 0.86 \\
\hline 9 & CAM5_NDG & 1.72 & 0.72 & 0.48 & 0.73 & 0.60 & 0.55 & 0.91 & 0.50 & 0.59 & 0.40 & 0.57 & 0.58 \\
\hline 10 & EMAC-1 & 0.23 & 0.30 & 0.35 & 0.33 & 0.94 & 0.66 & 1.18 & 0.76 & 0.85 & 0.60 & 0.93 & 0.70 \\
\hline 11 & EMAC-2 & 1.20 & 1.22 & 0.39 & 0.35 & 0.87 & 0.69 & 0.37 & 0.62 & 0.46 & 0.59 & 0.84 & 0.70 \\
\hline 12 & ECHAM-HAM2 & 0.65 & 0.90 & 0.68 & 0.71 & 0.68 & 0.65 & 1.18 & 0.65 & 0.69 & 0.55 & 0.72 & 0.68 \\
\hline 13 & ECHAM_salsa & 0.71 & 0.78 & 0.04 & 0.21 & 0.29 & 0.20 & 0.12 & 0.15 & 0.07 & 0.07 & 0.19 & 0.15 \\
\hline 14 & GEOS-Chem & 1.00 & 1.08 & 0.88 & 0.84 & 0.83 & 0.81 & 1.51 & 0.74 & 0.88 & 0.72 & 0.93 & 0.87 \\
\hline 15 & EEMEP & 2.13 & 2.15 & 1.45 & 1.70 & 1.45 & 1.30 & 2.36 & 1.33 & 1.51 & 1.21 & 1.52 & 1.48 \\
\hline 16 & OsloctM2 & 1.20 & 1.07 & 0.70 & 0.68 & 0.68 & 0.64 & 1.41 & 0.70 & 0.66 & 0.55 & 0.90 & 0.76 \\
\hline 17 & OsloctM3 & 1.05 & 1.24 & 0.79 & 0.82 & 0.72 & 0.63 & 1.49 & 0.77 & 0.67 & 0.60 & 0.76 & 0.77 \\
\hline 18 & NAME & 1.13 & 0.88 & 0.60 & 0.73 & 0.66 & 0.46 & 0.76 & 0.50 & 0.38 & 0.31 & 0.17 & 0.51 \\
\hline 19 & FLEXPART & 1.17 & 1.35 & 0.81 & 0.93 & 0.95 & 1.03 & 1.91 & 1.03 & 0.91 & 0.72 & 1.62 & 1.03 \\
\hline & Model median & 1.05 & 1.08 & 0.77 & 0.81 & 0.77 & 0.67 & 1.46 & 0.75 & 0.71 & 0.63 & 0.85 & 0.79 \\
\hline
\end{tabular}

Table 4. Same as Table 3 but for aerosol $\left({ }^{137} \mathrm{Cs}\right)$ surface concentrations.

\begin{tabular}{|c|c|c|c|c|c|c|c|c|c|c|c|c|c|}
\hline & $\begin{array}{c}\begin{array}{c}\text { Station (latitude) / } \\
\text { model }\end{array} \\
\end{array}$ & $\begin{array}{l}\text { Wak. } \\
\left(19^{\circ} \mathrm{N}\right)\end{array}$ & $\begin{array}{l}\text { Oah. } \\
\left(22^{\circ} \mathrm{N}\right)\end{array}$ & \begin{tabular}{|c|} 
Ash. \\
$\left(37^{\circ} \mathrm{N}\right)$
\end{tabular} & \begin{tabular}{|c|} 
Cha. \\
$\left(38^{\circ} \mathrm{N}\right)$
\end{tabular} & \begin{tabular}{|c|} 
Uss. \\
$\left(44^{\circ} \mathrm{N}\right)$
\end{tabular} & \begin{tabular}{|c|} 
St.J \\
$\left(48^{\circ} \mathrm{N}\right)$
\end{tabular} & \begin{tabular}{|c|} 
Sha. \\
$\left(48^{\circ} \mathrm{N}\right)$
\end{tabular} & \begin{tabular}{|c|} 
Ula. \\
$\left(48^{\circ} \mathrm{N}\right)$
\end{tabular} & \begin{tabular}{|l|}
$\begin{array}{l}\text { Sto. } \\
\left(59^{\circ} \mathrm{N}\right)\end{array}$ \\
\end{tabular} & \begin{tabular}{|c|} 
Yel. \\
$\left(62^{\circ} \mathrm{N}\right)$ \\
\end{tabular} & $\begin{array}{l}\text { Spi. } \\
\left(78^{\circ} \mathrm{N}\right)\end{array}$ & $\begin{array}{c}\text { All } \\
\text { stations }\end{array}$ \\
\hline 1 & NorESM & 0.34 & 1.04 & 5.42 & 2.00 & 0.97 & 0.51 & 1.13 & 1.70 & 0.61 & 0.60 & 1.28 & 1.13 \\
\hline 2 & GISS-ModelE2-TOMAS & 6.18 & 9.04 & 20.45 & 13.35 & 7.45 & 11.44 & 13.65 & 11.30 & 12.65 & 5.50 & 10.14 & 10.17 \\
\hline 3 & GISS-ModelE & 1.10 & 3.61 & 4.09 & 3.32 & 2.10 & 3.64 & 2.48 & 1.82 & 2.14 & 0.90 & 1.53 & 2.06 \\
\hline 4 & ULAQ-CCM & 60.73 & 3.60 & 2.20 & 0.41 & 367.45 & 0.08 & 0.19 & 46.43 & 0.39 & 0.19 & 0.80 & 0.80 \\
\hline 5 & BCC_AGCM2.0.1_CAM & 9.42 & 18.99 & 18.74 & 8.03 & 6.03 & 4.03 & 10.46 & 5.29 & 3.41 & 1.31 & 3.14 & 5.50 \\
\hline 6 & LMDZORINCA & 0.00 & 2.17 & 2.52 & 0.99 & 0.24 & 0.55 & 1.27 & 0.80 & 0.30 & 0.34 & 0.09 & 0.56 \\
\hline 7 & CAM5 & 0.95 & 0.54 & 0.08 & 0.02 & 0.00 & 0.00 & 0.00 & 0.00 & 0.00 & 0.00 & 0.00 & 0.00 \\
\hline 8 & CAM5_PNNL & 15.71 & 12.89 & 6.04 & 3.67 & 2.32 & 1.81 & 5.89 & 5.26 & 2.78 & 0.93 & 1.13 & 3.16 \\
\hline 9 & CAM5_NDG & 10.72 & 3.37 & 2.69 & 1.76 & 0.19 & 0.29 & 0.91 & 0.88 & 0.60 & 0.16 & 0.07 & 0.69 \\
\hline 10 & EMAC-1 & 0.01 & 0.11 & 0.29 & 0.06 & 0.32 & 0.34 & 0.67 & 0.58 & 0.71 & 0.14 & 0.51 & 0.33 \\
\hline 11 & EMAC-2 & 0.02 & 0.59 & 0.51 & 0.11 & 0.18 & 0.04 & 0.04 & 0.03 & 0.02 & 0.03 & 0.02 & 0.05 \\
\hline 12 & ECHAM-HAM2 & 5.43 & 1.80 & 0.87 & 0.28 & 0.11 & 0.02 & 0.20 & 0.15 & 0.03 & 0.02 & 0.00 & 0.11 \\
\hline 13 & ECHAM_salsa & 2.51 & 2.47 & 0.38 & 0.67 & 0.07 & 0.24 & 0.17 & 0.12 & 0.02 & 0.05 & 0.01 & 0.15 \\
\hline 14 & GEOS-Chem & 0.14 & 4.14 & 7.52 & 6.32 & 4.58 & 6.49 & 8.74 & 7.50 & 5.55 & 3.25 & 6.89 & 5.53 \\
\hline 15 & EEMEP & 0.00 & 0.05 & 0.03 & 0.02 & 0.01 & 0.01 & 0.02 & 0.02 & 0.01 & 0.01 & 0.01 & 0.01 \\
\hline 16 & OsloctM2 & 0.06 & 0.21 & 0.30 & 0.06 & 0.01 & 0.01 & 0.05 & 0.01 & 0.01 & 0.00 & 0.00 & 0.02 \\
\hline 17 & OslocTM3 & 0.69 & 2.73 & 4.96 & 2.62 & 0.63 & 0.51 & 1.28 & 1.19 & 0.39 & 0.34 & 0.08 & 0.76 \\
\hline 18 & NAME & 0.03 & 0.13 & 0.02 & 0.03 & 0.01 & 0.01 & 0.00 & 0.01 & 0.01 & 0.00 & 0.00 & 0.01 \\
\hline \multirow[t]{2}{*}{19} & \begin{tabular}{|l} 
FLEXPART \\
\end{tabular} & 2.54 & 2.81 & 1.00 & 0.64 & 0.21 & 0.19 & 0.57 & 0.42 & 0.46 & 0.03 & 0.17 & 0.35 \\
\hline & Model median & 0.91 & 1.67 & 1.99 & 0.64 & 0.41 & 0.19 & 0.74 & 0.78 & 0.32 & 0.15 & 0.13 & 0.49 \\
\hline
\end{tabular}

in Sect. 4). In this section we use global modelled data as opposed to the previous sections that focused on modelled concentrations at the measurement stations. The estimate of instantaneous lifetimes uses the global aerosol $\left({ }^{137} \mathrm{Cs}\right)$ and passive tracer $\left({ }^{133} \mathrm{Xe}\right)$ burdens as simulated by the models. Kristiansen et al. (2012) also provide an estimate for the burdens using the station measurements and a 1-D box model. This estimate is however limited by the assumption of a well-mixed state in the atmosphere and only valid approximately after about 3 weeks after the release until about 9 weeks (Appendix C). Therefore, global burdens estimated from the measurement data are only available for a limited time period. The global burdens are shown in Appendix $\mathrm{C}$ and Fig. C1. The modelled global aerosol $\left({ }^{137} \mathrm{Cs}\right)$ burdens 

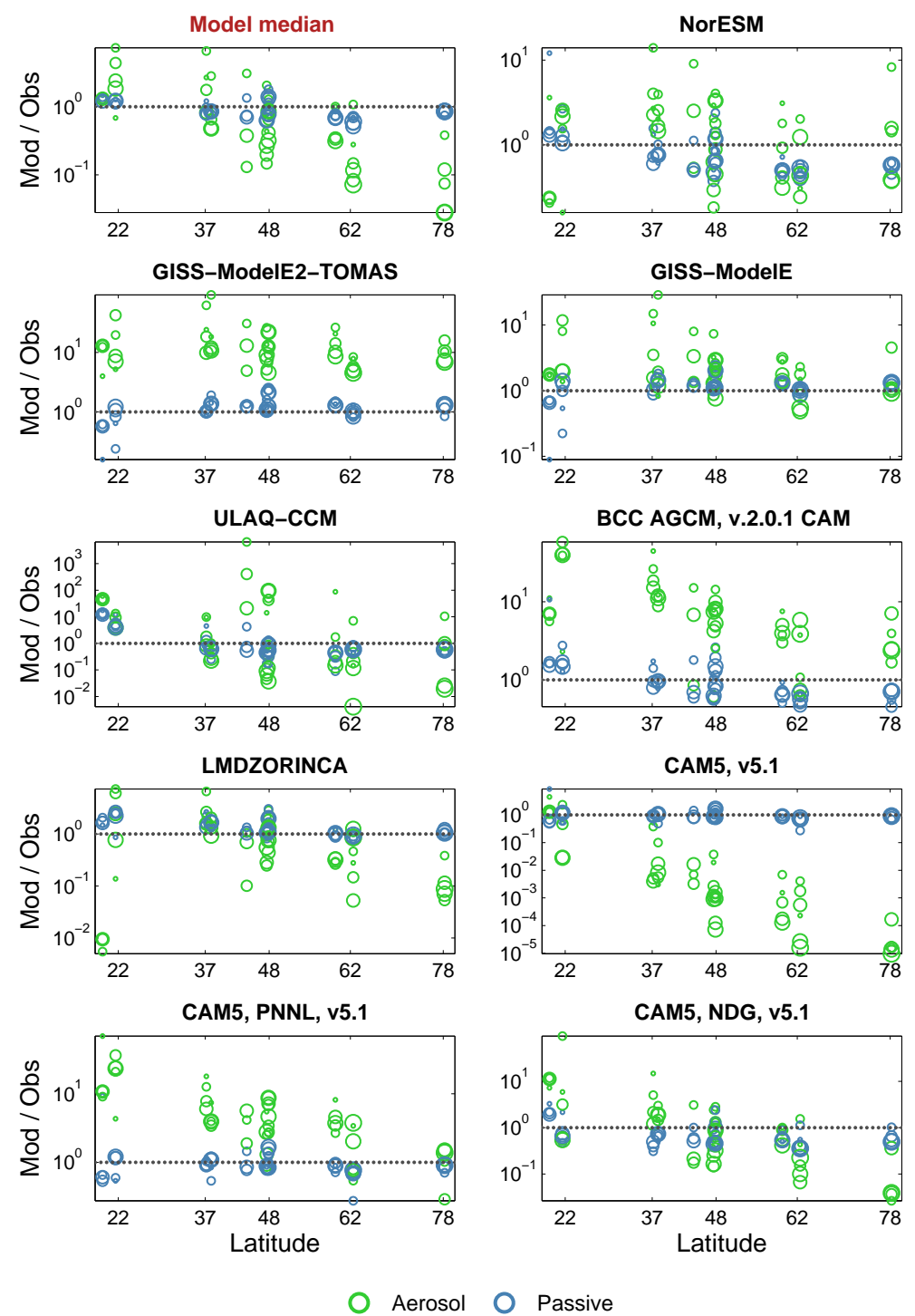

Figure 4.

increase initially due to continuous cesium emissions but decrease as the aerosols are removed from the atmosphere, while the passive tracer $\left({ }^{133} \mathrm{Xe}\right)$ global burdens stay approximately constant in the models after the xenon emissions cease. In the following, we analyse the instantaneous lifetimes obtained from the global burdens.

We use the ratios of the aerosol $\left({ }^{137} \mathrm{Cs}\right)$ to the passive tracer $\left({ }^{133} \mathrm{Xe}\right)$ global burdens, and calculate the instantaneous lifetimes (Eq. 2) from these ratios, as shown in Table 5 and Fig. 5. In the first week after the start of the release, the modelled instantaneous lifetimes are about 2 days (Table 5), much shorter than the e-folding lifetimes presented in Sect. 5.1 for later time periods. This illustrates that the initial removal was quicker, as previously suggested by Kristiansen et al. (2012) and illustrated in Croft et al. (2014). This is due to the emissions occurring at low altitudes and co- location of the plume with strong precipitation. After about 3 weeks, estimates for the instantaneous lifetimes from the measurement data are also possible and give a lifetime of 9.3-10.9 days, which is mostly longer than the median model lifetime of about 6.0-10.4 days (Table 5). After about 7 weeks (day 45-50), the instantaneous lifetimes reach some quasi-steady state with less variability (Fig. 5). The occurrence of this less variable steady state is related to the emissions. Between day 10 and 40 there are low-level emissions of ${ }^{137} \mathrm{Cs}$, about 1 order of magnitude less than during the highest emissions around day 5. Because the emission was a point source (and not global) and its geographical distribution is rather local, one continues to see the impact of single deposition events, making the instantaneous lifetime fluctuate considerably. On day 40 all emissions of ${ }^{137} \mathrm{Cs}$ end in the model simulations. The planetary boundary layer (PBL) 

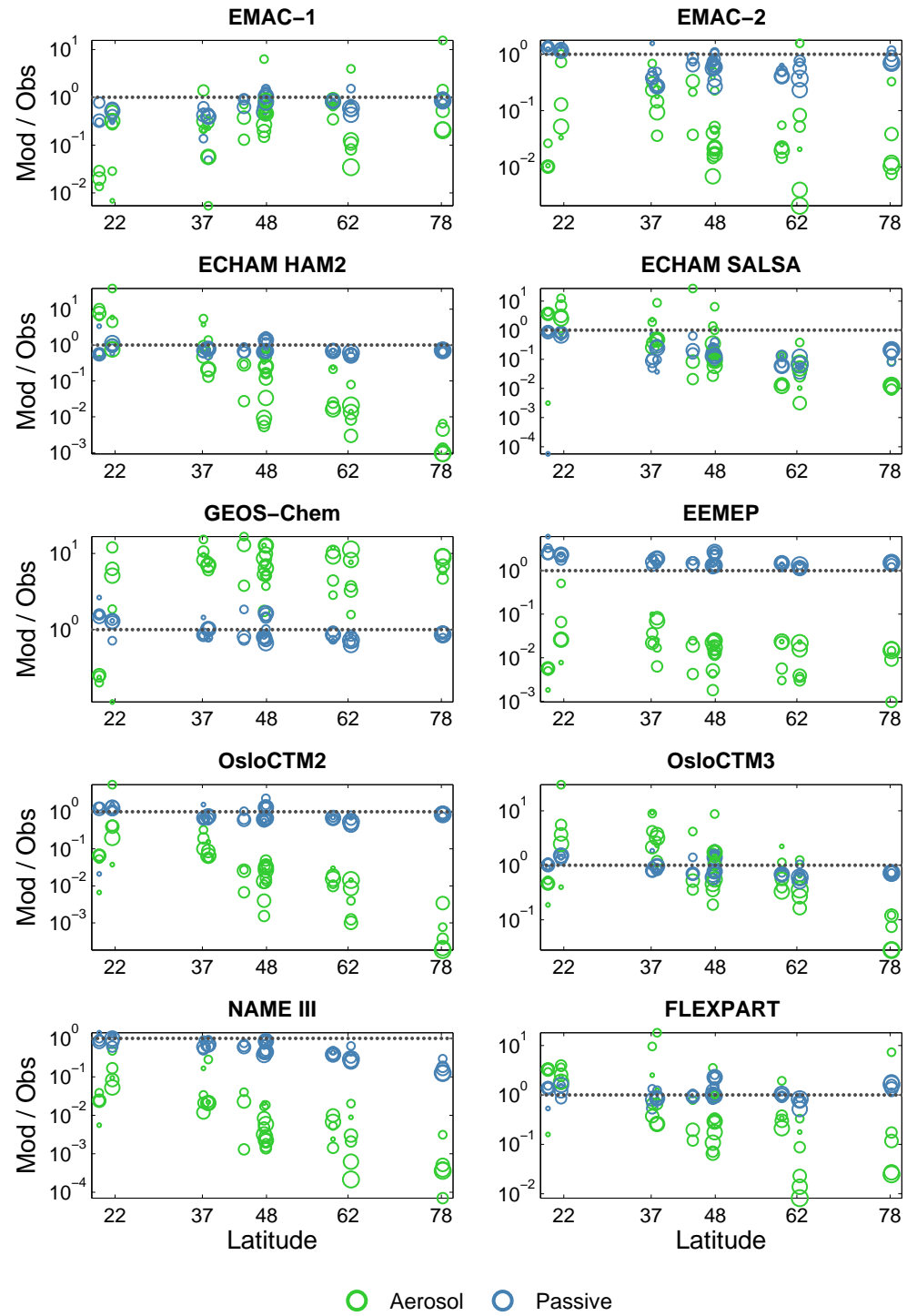

Figure 4. Ratio of modelled to observed aerosol (green) and passive tracer (blue) surface concentrations as a function of the latitude of the measurement station and time; values at each measurement station are the median values over 14 day time periods (11-24 March, 25 March7 April, 8-21 April, 22 April-5 May, 6-19 May, 20 May-2 June, 3-17 June 2011). The size of the circles indicate the time; the larger the circle, the later the time period. Values above the dotted 1-line are over-predicted by the model and values below 1 are under-predictions. Notice different scales on the $y$ axes.

is soon emptied of most ${ }^{137} \mathrm{Cs}$, and the remaining ${ }^{137} \mathrm{Cs}$ (mainly in the free troposphere) is more widely spread and gives rise to a more stable instantaneous lifetime, and thus a quasi-steady state with less variability. The modelled instantaneous lifetimes over days 49 to 63 (weeks 8-9; shaded area in Fig. 5) vary between 2.8 and 19.0 days with a model median of $10.4 \pm 2.5$ days. The median instantaneous lifetime for the same time period based on the measurements is $9.6 \pm 0.7$ days. In this period, the median modelled lifetimes are closer to, but slightly longer than those based on measurement data, in contrast to earlier phases. This could be due to more prominent modelled than real mixing into the strato- sphere where lifetimes are longer. This stratospheric mixing is not evident in the surface measurement data.

The further steady increase in the instantaneous lifetimes in the later phases after about day 65 (Fig. 5) is attributed to transport and mixing into regions where the lifetimes are longer, such as the upper troposphere and the stratosphere. After some time, the troposphere is mainly cleaned by wet scavenging while aerosols that have been transported into the stratosphere remain, as the removal there is inefficient, especially for AM aerosols for which also gravitational settling is very slow. The total aerosol mass and the lifetimes are then dominated by the stratospheric loading, giving a contin- 
Table 5. Median instantaneous lifetimes calculated from the ratios of the aerosol $\left({ }^{137} \mathrm{Cs}\right)$ to the passive tracer $\left({ }^{133} \mathrm{Xe}\right)$ global burdens during different time periods (weeks) after the start of the emissions (11 March 2011). The variability is given as the median absolute deviation (MAD, Eq. 3) for the individual models, as well as for the observations and the model median, while the standard deviation (SD) is given of the model mean. These variabilities are calculated from the instantaneous lifetimes over each of the time periods. The data are shown in Fig. 5.

\begin{tabular}{|c|c|c|c|c|c|c|}
\hline & \multirow[t]{2}{*}{ Model } & \multicolumn{5}{|c|}{ Instantaneous lifetime $\tau_{\text {inst }}$ (days) } \\
\hline & & $\begin{array}{r}\text { Week } 1 \\
(11-18 \text { Mar; } \\
\text { days } 1-7)\end{array}$ & $\begin{array}{r}\text { Weeks 2-3 } \\
\text { (18 Mar-1 Apr; } \\
\text { days 7-21) }\end{array}$ & $\begin{array}{r}\text { Weeks 4-5 } \\
(1-15 \mathrm{Apr} ; \\
\text { days } 21-35)\end{array}$ & $\begin{array}{l}\text { Weeks 6-7 } \\
\text { (15-29 Apr; } \\
\text { days 35-49) }\end{array}$ & $\begin{array}{r}\text { Weeks 8-9 } \\
\text { (29 Apr-13 May; } \\
\text { days 49-63) }\end{array}$ \\
\hline 1 & NorESM & $1.6 \pm 0.4$ & $6.8 \pm 2.4$ & $8.7 \pm 2.8$ & $6.9 \pm 2.4$ & $9.1 \pm 0.3$ \\
\hline 2 & GISS-ModelE2-TOMAS & $2.5 \pm 0.8$ & $10.1 \pm 3.6$ & $9.5 \pm 3.6$ & $7.4 \pm 1.5$ & $9.9 \pm 0.8$ \\
\hline 3 & GISS-ModelE & $2.2 \pm 1.3$ & $8.7 \pm 5.9$ & $7.9 \pm 3.5$ & $5.5 \pm 0.8$ & $7.9 \pm 0.3$ \\
\hline 4 & ULAQ-CCM & $2.4 \pm 1.5$ & $5.7 \pm 1.0$ & $10.0 \pm 2.5$ & $8.5 \pm 1.4$ & $11.2 \pm 1.3$ \\
\hline 5 & BCC_AGCM & $2.8 \pm 2.0$ & $9.8 \pm 2.3$ & $9.5 \pm 1.7$ & $9.7 \pm 0.8$ & $11.6 \pm 0.4$ \\
\hline 6 & LMDZORINCA & $2.5 \pm 2.1$ & $11.3 \pm 9.0$ & $8.2 \pm 3.6$ & $8.6 \pm 3.6$ & $19.0 \pm 1.3$ \\
\hline 7 & CAM5 & $3.6 \pm 2.6$ & $3.6 \pm 1.7$ & $2.6 \pm 1.3$ & $2.1 \pm 0.8$ & $2.8 \pm 0.3$ \\
\hline 8 & CAM5_PNNL & $2.5 \pm 0.8$ & $11.7 \pm 5.4$ & $10.3 \pm 5.2$ & $11.0 \pm 3.5$ & $17.3 \pm 1.1$ \\
\hline 9 & CAM5_NDG & $2.1 \pm 0.7$ & $6.0 \pm 1.6$ & $7.9 \pm 4.1$ & $6.7 \pm 2.6$ & $12.8 \pm 1.4$ \\
\hline 10 & EMAC-1 & $2.4 \pm 0.7$ & $6.8 \pm 4.1$ & $8.3 \pm 6.1$ & $5.5 \pm 0.8$ & $6.9 \pm 0.7$ \\
\hline 11 & EMAC-2 & $1.7 \pm 1.2$ & $4.4 \pm 2.2$ & $4.4 \pm 3.1$ & $3.0 \pm 0.4$ & $4.2 \pm 0.2$ \\
\hline 12 & ECHAM-HAM2 & $2.8 \pm 1.5$ & $6.9 \pm 4.8$ & $6.4 \pm 3.1$ & $5.1 \pm 1.9$ & $10.4 \pm 0.7$ \\
\hline 13 & ECHAM5-SALSA & $2.2 \pm 0.9$ & $4.1 \pm 0.4$ & $5.3 \pm 1.6$ & $10.4 \pm 1.0$ & $14.4 \pm 2.4$ \\
\hline 14 & GEOS-Chem & $1.4 \pm 0.3$ & $10.7 \pm 8.4$ & $11.8 \pm 5.0$ & $11.6 \pm 2.1$ & $16.4 \pm 0.9$ \\
\hline 15 & EEMEP & $1.0 \pm 0.4$ & $1.4 \pm 0.5$ & $2.7 \pm 1.8$ & $3.0 \pm 1.6$ & $8.1 \pm 1.9$ \\
\hline 16 & OsloCTM2 & $1.3 \pm 0.5$ & $3.7 \pm 2.2$ & $4.6 \pm 3.0$ & $3.9 \pm 1.8$ & $18.1 \pm 1.9$ \\
\hline 17 & OsloCTM3 & $1.5 \pm 0.8$ & $11.9 \pm 6.7$ & $6.3 \pm 3.7$ & $6.0 \pm 1.4$ & $10.4 \pm 2.0$ \\
\hline 18 & NAME & $0.8 \pm 0.3$ & $1.8 \pm 0.7$ & $2.2 \pm 1.4$ & $3.2 \pm 1.2$ & $9.2 \pm 3.6$ \\
\hline \multirow[t]{4}{*}{19} & FLEXPART & $1.5 \pm 0.2$ & $6.6 \pm 4.1$ & $3.7 \pm 1.7$ & $3.7 \pm 1.4$ & $6.3 \pm 0.4$ \\
\hline & Model mean \pm SD & $2.0 \pm 0.7$ & $6.4 \pm 3.6$ & $6.9 \pm 2.9$ & $6.4 \pm 2.9$ & $10.8 \pm 4.6$ \\
\hline & Model median \pm MAD & $2.2 \pm 0.6$ & $6.6 \pm 2.9$ & $7.9 \pm 2.1$ & $6.0 \pm 2.5$ & $10.4 \pm 2.5$ \\
\hline & Observations + box model & NA & NA & $10.9 \pm 4.9$ & $9.3 \pm 1.2$ & $9.6 \pm 0.7$ \\
\hline
\end{tabular}

uous increase in lifetime (Cassiani et al., 2013). The large variations in the steady increase of instantaneous lifetime between models might be related to how the models simulate transport into the upper troposphere and stratosphere. The longest lifetimes at later stages are probably given by models that inject a fraction of the aerosols quickly into the stratosphere (probably even by a single event) and have an efficient removal in the troposphere, which would give a large (and increasing) fraction of the aerosols residing in the upper troposphere and stratosphere. Furthermore, models with diffusive advection schemes may excessively "leak" aerosols into the stratosphere. Thus, the instantaneous lifetimes at later stages are probably more indicative of the upper tropospheric/stratospheric aerosol fraction and are less useful to constrain tropospheric removal. In addition, the well-mixed assumption required for the measurement-derived lifetimes breaks down once a substantial fraction of the material is in the stratosphere. This means that measurement-derived and model-derived instantaneous lifetimes for the later phases are not entirely comparable, as they are not derived in a consistent way. It is expected that the measurement-derived instantaneous lifetimes are systematically lower, since they are based on surface measurements with the assumption of a constant scale height. Calculating the global burdens based on the modelled station data and the box model reveals that for some models, the box-model estimates indeed underestimate the full global burdens (see Appendix C and Fig. C1).

In summary, we find that the modelled instantaneous lifetimes were initially short (about 1-2 days) and the initial removal quicker than for later time periods. At later times (weeks 4-7) the instantaneous lifetimes obtained by measurements were generally longer than obtained from the models, as also seen in Sect. 5.1 from station locations. After that, the modelled instantaneous lifetimes are influenced by mixing into the stratosphere and not representative anymore of scavenging processes in the troposphere.

\section{Discussion}

\subsection{Interpretation of the aerosol lifetime estimates}

To interpret our estimates of aerosol lifetime, we first discuss an exemplified evolution of the aerosol burden after a 

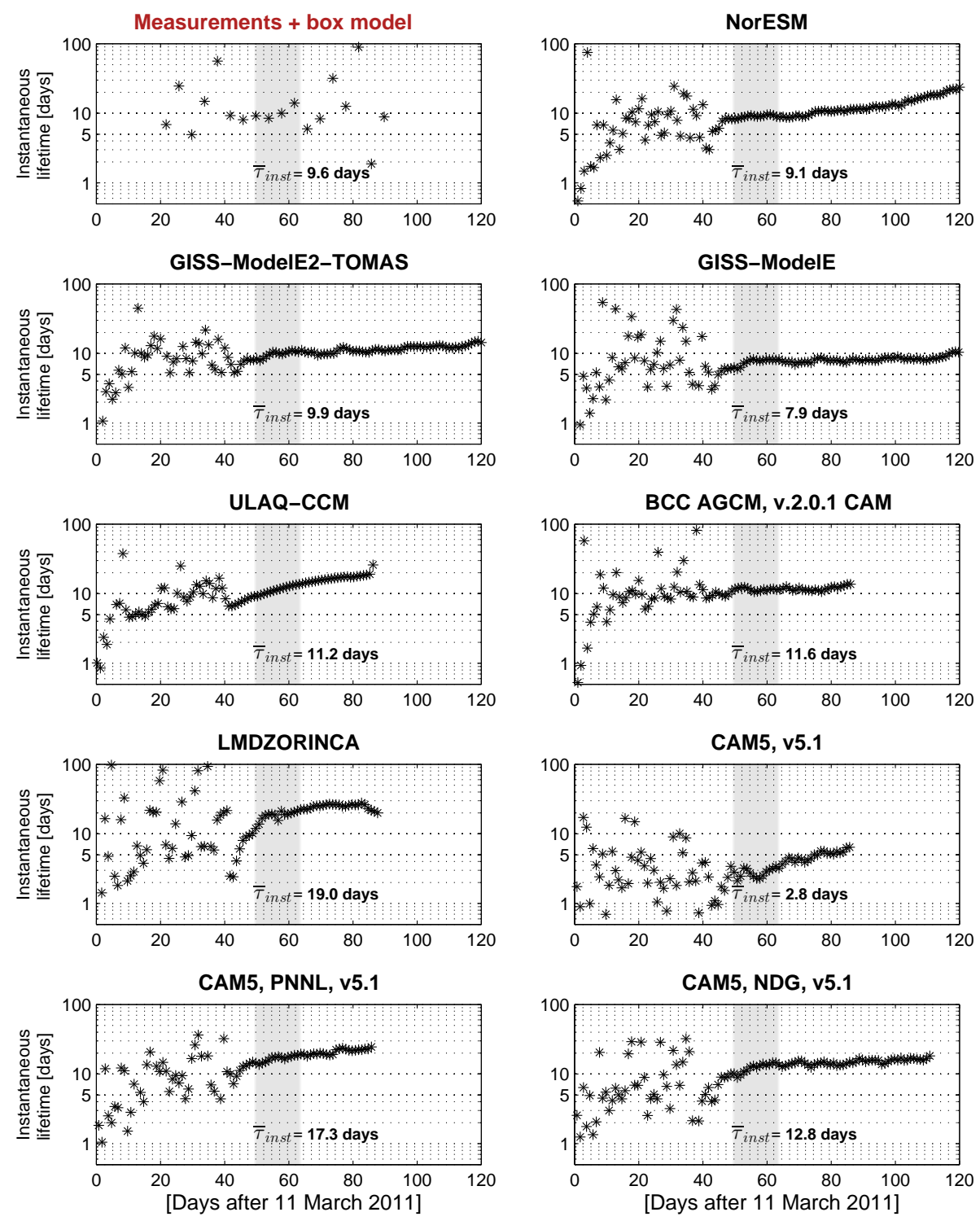

Figure 5.

unit pulse emission (Fig. 6). In our example, the decay of the burden is not perfectly exponential but consists of different characteristic timescales. There is a fast initial removal with a short time decay $\tau_{1}$, which represents the time period when the aerosols are mostly residing in the PBL and are very susceptible to dry and wet deposition. The second period has slower removal with a timescale $\tau_{2}$, and represents the period when most of the aerosols are residing in the free troposphere. The last time period, with the slowest decay timescale $\tau_{3}$, is the period when most of the aerosols are removed from the troposphere and only the fraction that was transported into the stratosphere remains.

The exemplified curve would depend on where on the globe the emissions take place, during which season, and it might differ from year to year. Thus, the timescales will vary greatly for different cases, and also for different models simulating the meteorology for the given case differently. $\tau_{1}$ would be very different for all cases, probably depending on a few precipitation events, while different cases and models would have a smaller spread for $\tau_{2}$ and $\tau_{3}$ which are affected by processes on a more global scale. Global mean lifetimes (e.g. Croft et al., 2014) would be mainly determined by the initial behaviour $\left(\tau_{1}\right)$ and it could be argued that knowing the initial lifetime is important for estimating the aerosol burden, the radiative forcing, and climate sensitivity.

In this study we focus mainly on the intermediate timescale $\tau_{2}$ because sufficient measurement data were only available from about 2 weeks after the start of the release, until about day 65 (Sect. 5.1). We do not have sufficient measurements to constrain $\tau_{1}$, but it is likely that some of the 

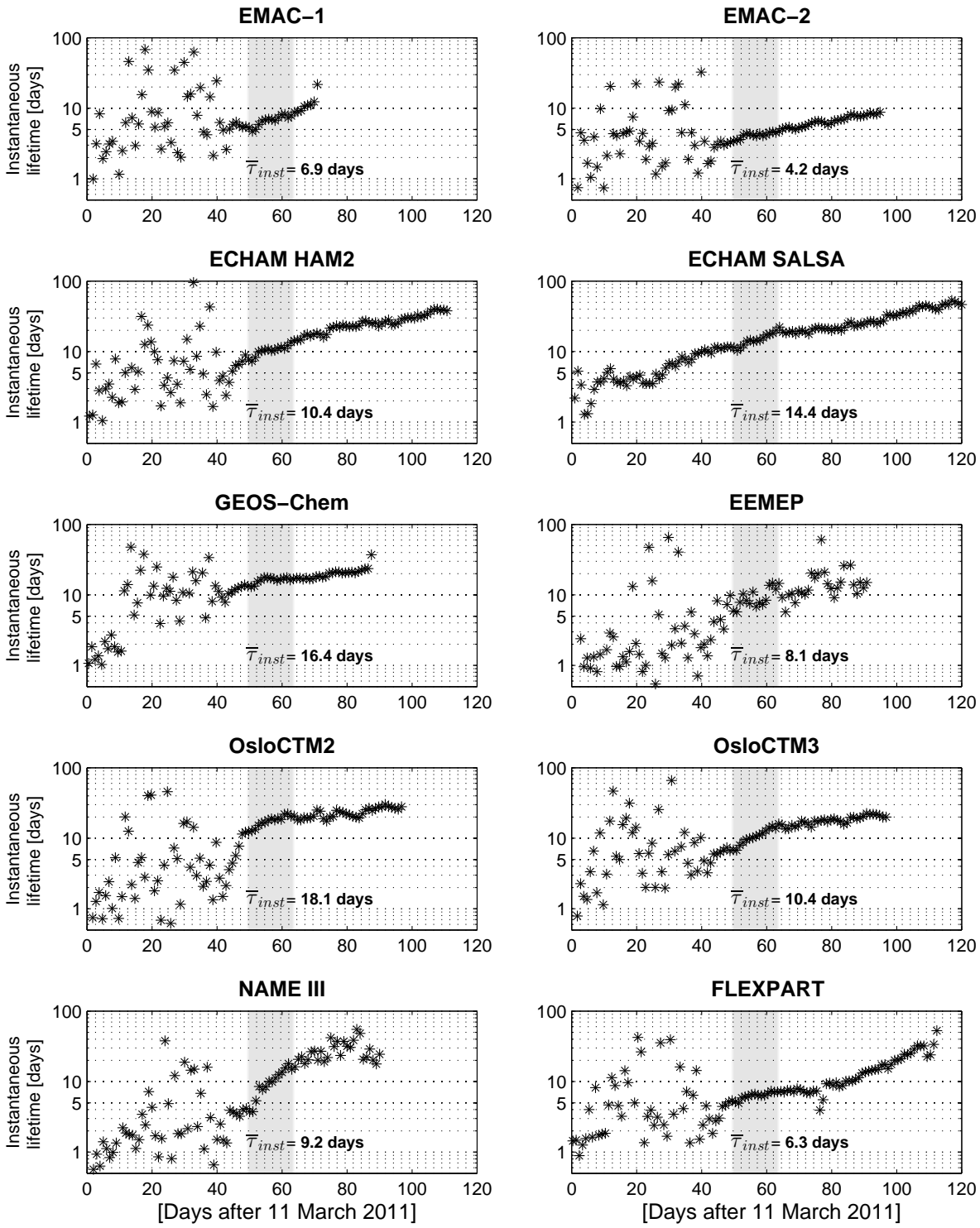

Figure 5. Instantaneous lifetimes calculated from the ratios of the aerosol $\left({ }^{137} \mathrm{Cs}\right)$ to the passive tracer $\left({ }^{133} \mathrm{Xe}\right)$ global burdens. The median instantaneous lifetimes $\tau_{\text {inst }}$ over days 49-63 (weeks 8-9; 29 April-13 May; shaded area) are indicated, and represent the time period when the ratios have reached a quasi-steady state, and influence from transport into the stratosphere is less significant than for later times. The measurement + box model refers to the estimate from Kristiansen et al. (2012) for the burdens using the station measurements and a 1-D box model (see Appendix C and Fig. C1).

same processes contribute to the determination of both $\tau_{1}$ and $\tau_{2}$. While $\tau_{1}$ is probably mainly impacted by processes within the PBL, $\tau_{2}$ is additionally influenced by how the aerosols are mixed out of the PBL, transported in the free troposphere, and finally brought back into the PBL. That way it is possible that models that capture $\tau_{2}$ well also perform well for $\tau_{1}$. In our case, another difference between $\tau_{1}$ and $\tau_{2}$ is that the former was mostly determined by a few individual precipitation events near Fukushima, while the latter is determined by removal occurring worldwide.
The evolution of the burden in Fig. 6 can be approximated by the sum of three exponential functions, i.e.

$f(t)=f_{1} \exp \frac{-t}{\tau_{1}}+f_{2} \exp \frac{-t}{\tau_{2}}+f_{3} \exp \frac{-t}{\tau_{3}}$,

where $f_{1}+f_{2}+f_{3}=1$.

A mean lifetime can be calculated as

$\tau_{\mathrm{m}}=f_{1} \tau_{1}+f_{2} \tau_{2}+f_{3} \tau_{3}$,

which corresponds to the area under the curve $f(t)$.

Using an optimizing convolution approach we can find the coefficients in Eq. (4) which give the best agreement be- 


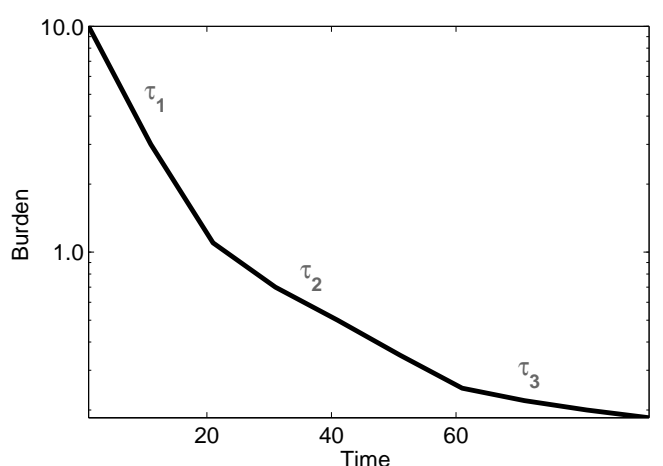

Figure 6. Exemplified evolution of the aerosol burden after a unit emission, with characteristic timescales indicated by $\tau_{1}, \tau_{2}$, and $\tau_{3}$.

tween the aerosol burdens obtained from the model simulations (Appendix C) and the expression in Eq. (4). Table 6 shows the characteristic timescales $\tau_{1}, \tau_{2}$, and $\tau_{3}$ obtained from the convolution approach, calculated for the different models from their aerosol $\left({ }^{137} \mathrm{Cs}\right)$ burdens, as well as the mean lifetime $\tau_{\mathrm{m}}$ (Eq. 5). The initial timescale $\tau_{1}$ is fastest and around 2 days, which is related to the low-altitude emissions of hydrophilic aerosols. The intermediate timescale $\tau_{2}$ is around 12 days, and the longest timescale $\tau_{3}$ about 150 200 days. The estimated $\tau_{3}$ is very uncertain for most models as it is very close to the a priori estimate of 200 days. The exceptions are the NorESM and GISS-ModelE models which had longer time series available. The model mean and median for $\tau_{3}$ are therefore calculated based on these two models only. The mean lifetime $\tau_{\mathrm{m}}$ is rather short, on the order of 2-3 days, and is strongly affected by $\tau_{1}$, which was also demonstrated by Croft et al. (2014). The estimate for $\tau_{2}$ shows good agreement with the instantaneous lifetime $\tau_{\text {inst }}$ over weeks 8-9 from Fig. 5 and Table 5, and for most models the e-folding lifetime $\tau_{\mathrm{e}}$ from Fig. 3 and Table 2 also fits well with $\tau_{2}$. This clearly demonstrates that in this study the focus is on the intermediate timescale $\tau_{2}$.

\subsection{Causes of model-observation deviations and model differences}

Our results show that there are significant deviations between aerosol lifetimes obtained from models and those obtained from observations. The modelled lifetimes have a large spread but are generally shorter than the observed lifetime. In addition, large biases in model to observed surface concentrations were found, with an overall under-prediction of both the aerosol $\left({ }^{137} \mathrm{Cs}\right)$ and passive tracer $\left({ }^{133} \mathrm{Xe}\right)$ concentrations. The model-observation deviations can be due to inaccuracies in the source emissions, errors in scavenging and convective transport, and incorrect diffusivity of the models. These issues are discussed more in the following.

Inaccuracies in the source emissions will affect the absolute model-simulated values and therefore the biases in the model to observed concentrations (Tables 3-4 and Fig. 4). It cannot be ruled out that our ${ }^{137} \mathrm{Cs}$ emissions are too low, or there were errors in the injection heights. However, the ${ }^{137} \mathrm{Cs}$ source term used is rather on the high side compared to others (e.g. Chino et al., 2011). Also, the ${ }^{133}$ Xe source term has been confirmed independently (Stohl et al., 2012b) and has rather low uncertainty. Overall, uncertainties in the assumed source term and its implementation are likely not the main reasons for the general underestimation of the aerosol $\left({ }^{137} \mathrm{Cs}\right)$ and passive tracer $\left({ }^{133} \mathrm{Xe}\right)$ concentrations. The lifetime estimates (Fig. 3 and Table 2) are not affected by the absolute values of the source term used. However, these lifetime estimates would be affected by possible late emissions of radionuclides long after the start of the release. Such late additional releases could be either direct late emissions from FD-NPP or indirect releases by resuspension of deposited radionuclides. Kristiansen et al. (2012) discussed this uncertainty and found no evidence for such late emissions, neither in the measurement data nor in the existing literature on the FD-NPP accident.

Most models have treated cesium solely as sulfate aerosols, while it is possible that some of the cesium attached to other aerosol components with different deposition properties. Initially, many non-soluble aerosols could have been present around the power plant, which might be removed less efficiently from the atmosphere in the first days after emission before mixing internally with soluble aerosol components. The assumption that cesium attached solely to sulfate could result in scavenging that is too strong during the first few days after the release, and can therefore contribute to the overall underestimations of the aerosol $\left({ }^{137} \mathrm{Cs}\right)$ concentrations (Table 4). The e-folding lifetimes (Table 2) should not be affected by errors in the modelled scavenging efficiency in the initial phase ( $\tau_{1}$ in Fig. 6 ), as the e-folding lifetimes have been derived only for later periods (after 15 days, i.e. $\tau_{2}$ in Fig. 6) when the aerosols are likely internally mixed and aerosol components undergo similar removal.

More importantly, the models' treatment of aerosol scavenging is essential for both the modelled lifetime and absolute concentrations. The modelled representation and distribution of clouds, as well as rain patterns and rain intensity, are important factors since they determine where and how much aerosol is removed. Further, the horizontal resolution of the model and meteorological input data might have a large impact in terms of clouds and precipitation (intensity and spatial extent). Higher horizontal resolution can in general lead to more resolved large-scale and less sub-grid convective clouds (Hagemann et al., 2006). The scavenging parameterizations, including cloud and rain definitions and occurrences, differ greatly between the models (Table A1), and are likely the major cause of model differences and deviations between models and observations. This issue is further discussed in Sect. 6.6.

Additionally, the coupling between aerosol scavenging and the convection scheme in the models may represent 
Table 6. Characteristic timescales $\tau_{1}, \tau_{2}$, and $\tau_{3}$ estimated with a convolution approach (Eq. 4) based on the different models' aerosol ( ${ }^{137} \mathrm{Cs}$ ) burdens, as well as the mean lifetime $\tau_{\mathrm{m}}$ (Eq. 5), and the instantaneous lifetime $\tau_{\text {inst }}$ over weeks 8-9 from Fig. 5 and Table 5, and the efolding lifetime $\tau_{\mathrm{e}}$ from Fig. 3 and Table 2 . Values in brackets for $\tau_{3}$ indicate high uncertainty and are discarded in the mean and median calculations.

\begin{tabular}{|c|c|c|c|c|c|c|c|}
\hline & Model & $\tau_{1}$ & $\tau_{2}$ & $\tau_{3}$ & $\tau_{\mathrm{m}}$ & $\begin{array}{r}\tau_{\text {inst }} \\
\text { Week } 8-9 \\
\text { (days 49-63) } \\
(\text { Table 5) }\end{array}$ & $\begin{array}{r}\tau_{\mathrm{e}} \\
\text { Days 15-65, } \\
\text { all stations } \\
(\text { Table } 2)\end{array}$ \\
\hline 1 & NorESM & 1.8 & 10.4 & 192.9 & 2.0 & 9.1 & 10.5 \\
\hline 2 & GISS-ModelE2-TOMAS & 4.1 & 11.4 & [314.8] & 4.4 & 9.9 & 9.6 \\
\hline 3 & GISS-ModelE & 3.8 & 8.5 & 116.8 & 4.1 & 7.9 & 8.0 \\
\hline 4 & ULAQ-CCM & 7.1 & 18.8 & [200.0] & 7.4 & 11.2 & 6.0 \\
\hline 5 & BCC_AGCM & 1.1 & 11.0 & {$[200.2]$} & 2.3 & 11.6 & 16.7 \\
\hline 6 & LMDZORINCA & 2.5 & 20.5 & {$[200.5]$} & 2.6 & 19.0 & 11.5 \\
\hline 7 & CAM5 & 1.1 & 3.0 & [ 11.9] & 1.1 & 2.8 & 4.8 \\
\hline 8 & CAM5_PNNL & 1.7 & 15.9 & [200.2] & 2.2 & 17.3 & 12.5 \\
\hline 9 & CAM5_NDG & 2.8 & 14.3 & [206.2] & 2.9 & 12.8 & 7.7 \\
\hline 10 & EMAC-1 & 1.8 & 7.0 & [200.1] & 2.2 & 6.9 & 11.7 \\
\hline 11 & EMAC-2 & 1.1 & 4.4 & {$[38.2]$} & 1.2 & 4.2 & 8.1 \\
\hline 12 & ECHAM-HAM2 & 2.2 & 18.6 & [224.4] & 2.2 & 10.4 & 6.4 \\
\hline 13 & ECHAM5-SALSA & 2.4 & 19.2 & [472.3] & 2.4 & 14.4 & 6.9 \\
\hline 14 & GEOS-Chem & 1.0 & 15.2 & {$[200.1]$} & 1.7 & 16.4 & 20.4 \\
\hline 15 & EEMEP & 0.6 & 8.2 & [297.1] & 0.7 & 8.1 & 26.7 \\
\hline 16 & OsloCTM2 & 2.3 & 18.9 & [203.0] & 2.4 & 18.1 & 11.2 \\
\hline 17 & OsloCTM3 & 4.5 & 16.3 & [200.1] & 4.6 & 10.4 & 8.8 \\
\hline 18 & NAME & 0.9 & 6.5 & [309.7] & 1.0 & 9.2 & 9.4 \\
\hline \multirow[t]{3}{*}{19} & FLEXPART & 2.0 & 6.8 & [183.9] & 2.1 & 6.3 & 5.8 \\
\hline & Model mean \pm SD & $2.4 \pm 1.6$ & $12.4 \pm 5.6$ & $154.9 \pm 53.8$ & $2.6 \pm 1.6$ & $10.8 \pm 4.6$ & $10.7 \pm 5.4$ \\
\hline & Model median \pm MAD & $2.0 \pm 0.9$ & $11.4 \pm 4.6$ & $154.8 \pm 38.1$ & $2.2 \pm 0.5$ & $10.4 \pm 2.5$ & $9.4 \pm 2.3$ \\
\hline
\end{tabular}

a large source of uncertainty and thus contributes to both model-observation deviations and differences between models. Different aerosol amounts may reach the dry upper troposphere depending on how aerosols are scavenged in convective updrafts and whether updrafts are allowed in the convection scheme to overshoot the level of neutral buoyancy. This has an immediate impact on lifetime via the convective scavenging and also longer term effects, depending on how much aerosol can reach the upper troposphere. Finally, the diffusivity of the models, i.e. either pure numerical diffusivity or apparent diffusivity caused by less representative winds, may be an important cause of the deviations between the models and observations, and the differences between models. If the models are too diffusive, they may unphysically transport aerosols to higher altitudes where they are preserved. Once too much aerosol mass reaches high altitudes, e-folding lifetimes would be very long. At the same time vertical diffusion that is too excessive would mean that the aerosols are not confined sufficiently to the lowest model levels (Koch et al., 2009) and thus the models will probably underestimate mass near the surface. These topics of coupling convection with scavenging, and diffusivity should be investigated further.

\subsection{Modelled aerosol lifetime versus aerosol concentration bias}

Comparing the lifetime estimates in Table 2 and the aerosol concentration bias values in Table 4, it seems that some models have a large bias to the measured aerosol concentrations, yet still have a realistic lifetime. For example, OsloCTM3 has a relatively small bias (ratio 0.76 , i.e. $-24 \%$ relative bias) and a lifetime of 8.8 days, while OsloCTM2 highly underestimates the aerosol concentrations (ratio 0.02, i.e. $-98 \%$ relative bias) and has a lifetime estimate of 11.2 days, closer to the lifetime estimate from the observations (14.3 days). This is probably because the concentrations are strongly influenced by the treatment of the quick removal in the first few days when the plume was at low altitude and co-located with areas of strong precipitation, whereas the lifetimes derived for later time periods are insensitive to this initial removal. Depending on how the models simulate this initial episode (e.g. how the aerosol plume and precipitation areas align), different amounts of aerosols can survive the first few days. This is clearly seen in Fig. 7, which shows how the total atmospheric aerosol $\left({ }^{137} \mathrm{Cs}\right)$ burdens for the different models vary over the first 3 weeks after the initial release. As an example, OsloCTM2 has stronger aerosol removal than 


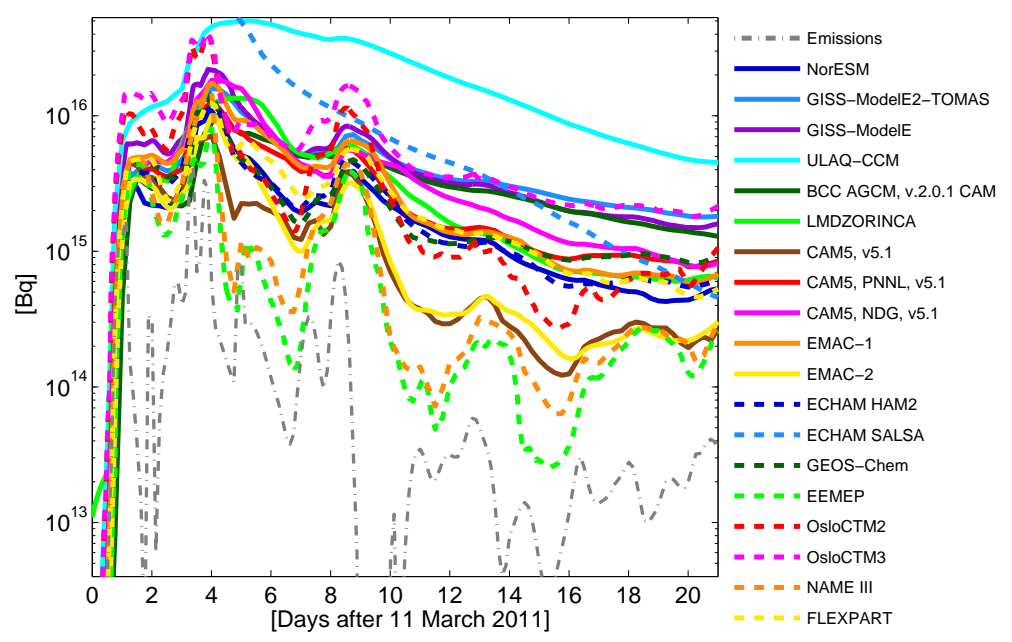

Figure 7. Source emissions of ${ }^{137} \mathrm{Cs}$ and modelled total atmospheric aerosol $\left({ }^{137} \mathrm{Cs}\right)$ burdens, for the initial 3 weeks after the first release.

OsloCTM3 during the first 3 weeks. Further, even relatively small differences in lifetimes can lead to large concentration differences after several multiples of the lifetime. For instance, assume tracers with 6 and 10 days' e-folding lifetimes. After 60 days, total atmospheric burdens of these two tracers will differ by a factor of 50 (reduced to $1 / 403$ and $1 / 22026$, respectively, of the initial burden). This might also explain why aerosol models differ so widely from each other at later times (e.g. in remote regions like the Arctic), whereas they agree much more closely in earlier time periods and closer to the source regions (e.g. Table 4).

Additionally, by comparing the instantaneous lifetimes in Table 5 with the aerosol concentration bias values in Table 4, the models with positive biases (greater than 1, i.e. overestimation of the aerosol concentrations) tend to show longer instantaneous lifetime in the first few weeks (Fig. 8a). The models that strongly underestimate the aerosol concentrations have a shorter instantaneous lifetime in the first weeks. This confirms that the initial quick removal is modelled differently by the various models, which affects the absolute concentrations and bias calculations. Furthermore, there seems to be a positive correlation of lifetimes for different time periods (Fig. 8b). Most models that have short instantaneous lifetimes in the first 3 weeks also have short instantaneous lifetimes for later time periods.

\subsection{Differences in modelled transport and scavenging}

Our results show that there is a large spread in the model results. This is due to the different ways the models simulate transport and scavenging. We note that the range of models in our analysis is quite wide. Many are developed for climate applications and may have been adapted for longer lifetime aspects, while others are more focused on dispersion and transport on a shorter timescale. In addition, some models are related to each other, which will affect the model en- semble. However, as some models are related by driving meteorology, others are related by aerosol module, which makes it difficult to categorize this appropriately.

Sensitivity simulations of the NorESM model (not shown) indicate that between five ensemble members, all simulating their own meteorological conditions, there were no large differences in lifetime. This suggests that the lifetime estimates are independent of the meteorological situation, although the difference between the different models might be greater than a perturbed ensemble of one model, and resolution effects might also play a role. Croft et al. (2014) showed that the e-folding lifetimes do not depend very much on the exact model set-up (emission altitude, location, and time). Therefore, the model's scavenging parameterizations are likely to be the main cause of inter-model differences in e-folding times in this study, especially at time periods around 1565 days after the release start.

The vertical distribution of the modelled aerosols will likely differ substantially between the various model simulations. At later time periods, the troposphere would be mainly cleaned by wet scavenging while aerosols that have been transported into the stratosphere (or upper troposphere) remain, as the removal there is inefficient. The total aerosol mass and the lifetimes are then dominated by the upper tropospheric and stratospheric loading, giving an increase in lifetime (Cassiani et al., 2013). The different stratospheric loadings might therefore be a cause of large model differences. For example, in the OsloCTM2 and OsloCTM3 simulations, about $70-80 \%$ of the burden is stratospheric at the end of the simulation. OsloCTM2 has a higher stratospheric loading than OsloCTM3, which might be related to its coarser resolution and thus stronger diffusion, which partly explains why OsloCTM2 generally has a longer lifetime (Table 2). By calculating tropospheric burdens and the associated lifetimes (burden relative to wet deposition, not shown), this yields the lifetime with respect to scavenging without the ef- 

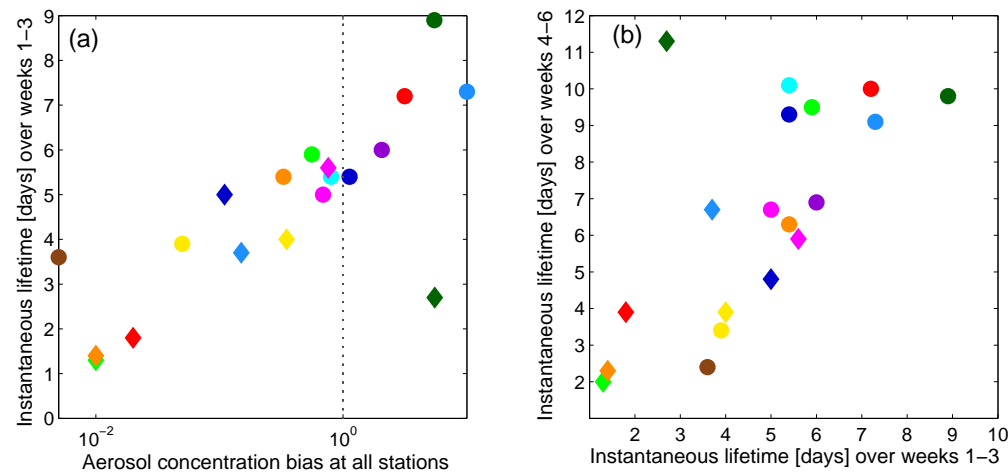

- NorESM

- GISS-ModelE2-TOMAS

- GISS-ModelE

ULAQ-CCM

- BCC AGCM, v.2.0.1 CAM

- LMDZORINCA

- CAM5, PNNL v5.1

- CAM5, NDG, v5.1

- EMAC-1

EMAC-2

- echam ham2

- echam Salsa

- GEOS-Chem

- EEMEP

- OsloctM2

- Osloctm3

- NAME III

Instantaneous lifetime [days] over weeks $1-3 \quad$ FLEXPART

Figure 8. (a) Modelled instantaneous lifetimes averaged over weeks 1-3 (see Fig. 5) versus aerosol concentration bias (modelled to measured aerosol ( ${ }^{137} \mathrm{Cs}$ ) station concentrations; see Table 4). The vertically dotted line is the 1-line (perfect match between modelled and observed aerosol concentrations). (b) Correlation of instantaneous lifetimes at different time periods; modelled instantaneous lifetime averaged over weeks 1-3 versus weeks 4-6 (see Fig. 5).

fect of stratospheric mixing; then the lifetime for OsloCTM3 is longer than for OsloCTM2, highlighting the impact of the different stratospheric aerosol loadings at later times.

The vertical distribution of the aerosols is explored further for four different models which span the range in modelled lifetimes, FLEXPART with a short lifetime ( $\sim 6$ days), EEMEP with the longest ( $\sim 27$ days), and OsloCTM3 and NorESM with lifetimes closer to, but still lower than the measurements (8.8 and 10.5 days, respectively). Figure 9 shows the total aerosol $\left({ }^{137} \mathrm{Cs}\right)$ mass as a function of latitude for these four models, in four different height layers (surface, 0 $5,5-10$, and above $10 \mathrm{~km})$ at three different time steps (14, 28 , and 41 days after the first emissions). The aerosol concentrations in the surface layer (lowest model level) peak around the latitude of the emission pulse for all models. FLEXPART and NorESM generally have more aerosols at the surface than OsloCTM3 and EEMEP and this is particularly evident at the northernmost latitudes. The same trend can be seen in the lower troposphere $(0-5 \mathrm{~km})$ except OsloCTM3 is closer to or above FLEXPART while NorESM has consistently more mass at these heights. At higher altitudes (5-10 and above $10 \mathrm{~km}$ ), OsloCTM3 and NorESM have the most aerosol mass. This indicates that models with lifetimes closer to the measurements have more mass at higher altitudes. The FLEXPART and EEMEP models with lifetimes that deviate more from the observations show lower fractions of the aerosol mass at higher altitudes.

The passive tracer also shows large differences between models (e.g. Table 3). Even models from the same "family" (e.g. GISS, CAM, and ECHAM) give quite different results for the passive tracer. In addition, the four models based on ECHAM5 seem to simulate the passive tracer transport quite differently. This could be due to differences in the driving meteorological fields or advection schemes used in the models. The tracer transport is affected by four processes: (1) large-scale transport, (2) convective transport, (3) turbulent transport, and (4) artificial numerical diffusion. All four processes are sensitive to horizontal and vertical resolution, even if the models are all nudged towards the same reanalysis. Another possibility is that the implementation of the point source was treated differently in the models; e.g. the flux was added at slightly different times (before or after certain physical processes) in the model (see Fig. 7). To identify the exact reasons why there are such large differences warrants a further study.

\subsection{Sensitivity of e-folding times to measurement sampling}

In this study we have used modelled surface concentrations at the times when observation data exist, amounting to 433 data points over all 11 stations and measurement times (March to June 2011) considered. Croft et al. (2014) did a similar lifetime estimate but derived from modelled surface concentrations of ${ }^{137} \mathrm{Cs}$ from continuous time series at the 11 stations during March to June 2011 using about 19000 hourly values. They found a lifetime for GEOS-Chem of about 16.7 days, while in this study the lifetime estimate for GEOS-Chem is longer (20.2 days). For five other models (GISS-modelE, FLEXPART, BCC SGCM CAM, EMAC-1, and EMAC-2) we calculated the difference in the estimated lifetime using continuous (1-hourly or 3-hourly) time series at the stations, compared to using only the 433 data points at the times of the measurements. For all five models, the lifetime is slightly shorter (by 0.2 to 0.9 days) when using the continuous data than when using only data at the measurement times, but the difference is much smaller than for GEOS-Chem (3.5 days). GEOS-Chem is sensitive to the initial scavenging and transport as apparent in Fig. 3 by the anomalous values at Wake Island in the early time period. Insufficient scavenging at midhigh latitudes may also play a role, as seen in the overestimation of aerosol concentrations in Table 4, and this seems to contribute to the longer lifetime for the selection of points 

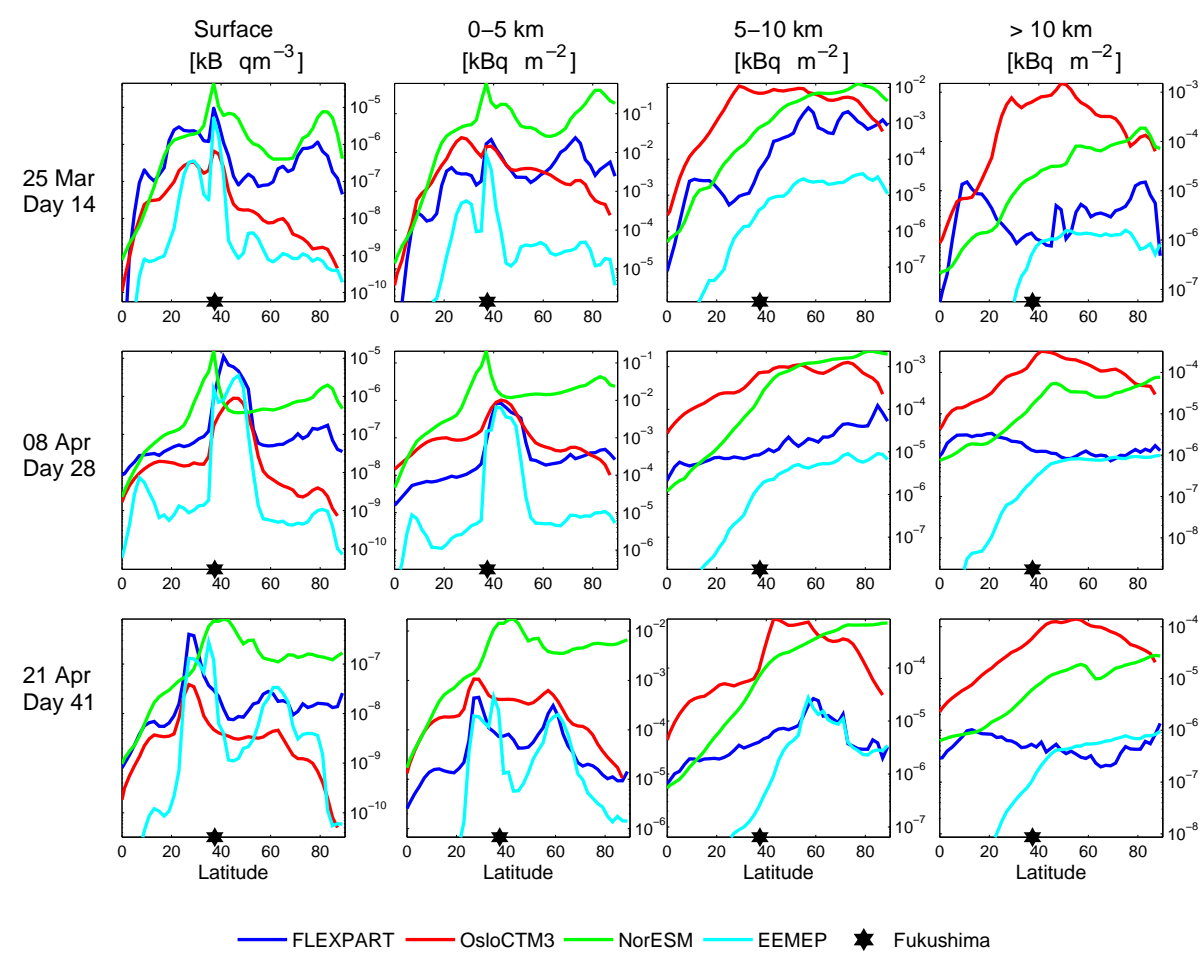

Figure 9. Modelled total aerosol $\left({ }^{137} \mathrm{Cs}\right)$ mass as a function of latitude for four models (FLEXPART, OsloCTM3, NorESM, and EEMEP), in four different height layers (surface, $0-5,5-10$, and $>10 \mathrm{~km}$ ) and at three different time steps $(14,28$, and 41 days after the first emissions). Note the different vertical axes.

used in this study. Further discussion on the scavenging parameterization in GEOS-Chem is given in Sect. 6.6.

Another issue with the measurement sampling is how to deal with measurement values below the detection limit (BDL). In our analysis we have discarded all data BDL, however, this might bias the measurements high. To address this, we did a sensitivity test where all measurement values BDL were set to $1 \%$ of the detection limit, and were included in the analysis. This increased the number of station values from 433 to 495 . The stations with the most data BDL are Ulan Bator, Ashland, and St. Johns, and the BDL values occur mostly between days 40 and 70 . During days 15 to 65 , the time period of the lifetime estimate in Fig. 3, there are $38 \mathrm{BDL}$ values mostly at Ulan Bator and Ashland. Using also BDL values in the analysis, the e-folding lifetime over days 15-65 decreased by 0.7 days (from 14.3 to 13.6 days) compared to when discarding BDL values. This illustrates that a small bias might be present when removing values BDL, but the difference is not significant, indicating that the measurement numbers are robust to BDL values. Besides, since exactly the same stations' data points are used for the derivation of the e-folding lifetimes from the measurement data and the modelled data, it is likely that the same bias is present in both the modelled and measurement data sets, and therefore the comparison of modelled and measured lifetimes remains valid.

\subsection{Sensitivity of e-folding times and aerosol bias to wet removal parameterizations}

A sensitivity test with the NAMEIII model was done (not shown) where the model's scavenging coefficients were decreased by a factor of 10. It is not suggested that the initial scavenging coefficients were a factor of 10 too high, but it was done to demonstrate the results of running the model with different scavenging coefficients. Decreasing the scavenging coefficients by a factor of 10 increased the e-folding lifetime from 5.5 to 13.1 days (not shown), illustrating the dependency of estimated lifetimes on scavenging treatment.

Further, recent revisions to GEOS-Chem that introduce an explicit dependence of wet removal efficiency on (1) cloud liquid and ice water content, (2) cloud temperature, and (3) cloud fraction from the assimilated meteorological fields have yielded about $40 \%$ lower mean lifetimes in the Arctic spring and summer (Croft et al., 2015; Q. Wang et al., 2014). Two revised simulations based on these changes, GEOS-Chem_T258 and GEOS-Chem_allT, are included here (Fig. 10 and Table 7) for comparison to the default scavenging in GEOS-Chem (GEOS-Chem_Orig, same simulation as labelled GEOS-Chem in all previous tables and figures). Simulation GEOS-Chem_T258 updates the scavenging scheme relative to GEOS-Chem_Orig through processes (1)-(3), but preserves the restriction for large-scale in-cloud scavenging of aerosols to temperatures above $258 \mathrm{~K}$. Sim- 
Table 7. Same as Table 2, but including two revised simulations of the GEOS-Chem model, GEOS-Chem_allT and GEOS-Chem_T258 (see text and Fig. 10 for description of simulations).

\begin{tabular}{llrrrrr}
\hline \multirow{2}{*}{ Model } & \multicolumn{5}{c}{ E-folding lifetime $\tau_{\mathrm{e}}$ (days) } \\
\cline { 2 - 7 } & & $\begin{array}{r}\text { Days 15-65 } \\
\text { All stations }\end{array}$ & $\begin{array}{r}\text { Days 15-65 } \\
\text { Stations } \\
\text { below 50 }\end{array}$ & $\begin{array}{r}\text { Days 15-65 } \\
\text { Stations } \\
\text { above 50 N }\end{array}$ & $\begin{array}{r}\text { Days 25-45 } \\
\text { All stations }\end{array}$ & $\begin{array}{r}\text { Days 45-65 } \\
\text { All stations }\end{array}$ \\
\hline 1 & GEOS-Chem_Orig & 20.8 & 17.7 & 30.8 & 19.1 & 21.8 \\
2 & GEOS-Chem_T258 & 19.7 & 16.2 & 32.2 & 13.1 & 19.5 \\
3 & GEOS-Chem_allT & 13.7 & 12.0 & 17.2 & 10.6 & 13.2 \\
\hline & Observations & 14.3 & 13.5 & 15.0 & 15.0 & 14.7 \\
\hline
\end{tabular}
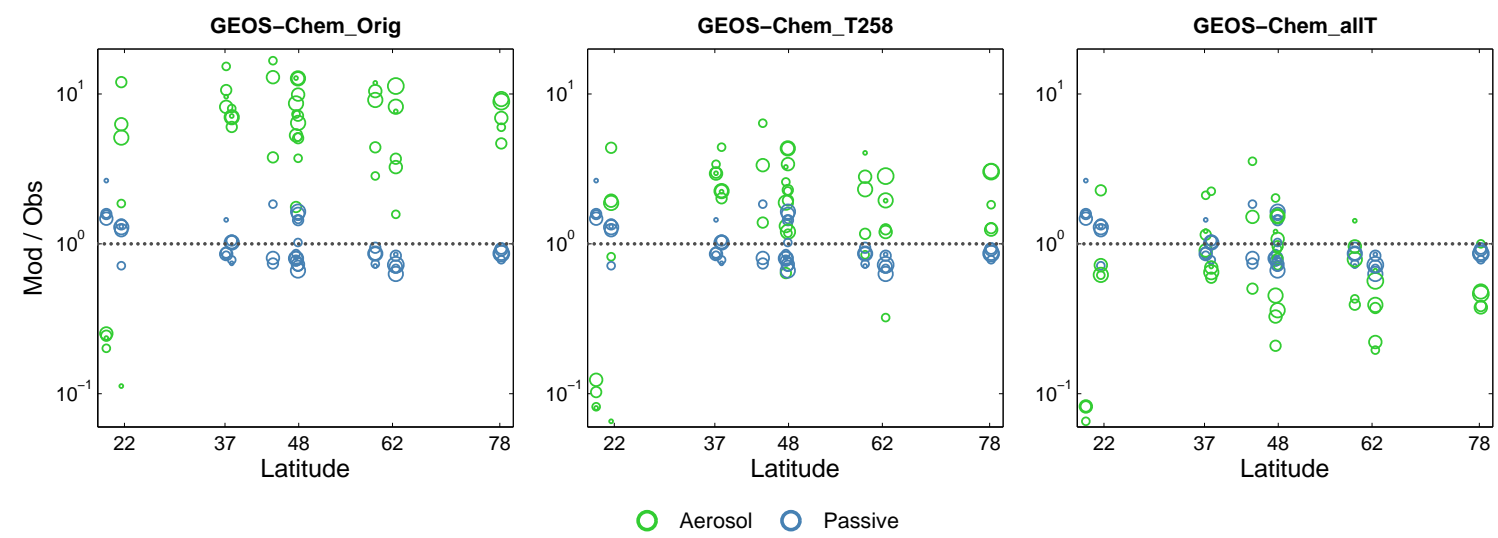

Figure 10. Same as Fig. 4, but including two revised simulations of the GEOS-Chem model. GEOS-Chem_Orig is the same simulation as in Fig. 4; GEOS-Chem_allT has an updated scavenging scheme relative to GEOS-Chem_Orig through processes related to cloud liquid and ice water content, cloud temperature, and using cloud fraction from the assimilated meteorological field. GEOS-Chem_T258 includes the same revisions, but restricts the large-scale in-cloud scavenging of aerosols to temperatures above $258 \mathrm{~K}$; same restriction for simulation GEOS-Chem_Orig.

ulation GEOS-Chem_T258 produces a significantly lower aerosol concentration bias (1.69 vs. 5.53$)$ relative to observations (Fig. 10). In addition, the e-folding lifetimes for the station data are shorter by up to 6 days (Table 7). These improvements imply that using an explicit dependence of wet removal rates on cloud properties may be necessary to properly capture aerosol lifetimes. Simulation GEOSChem_T258 yields the greatest change in the lifetimes for earlier periods (about $30 \%$ for days $25-45$, Table 7), indicating that these scavenging revisions influence removal efficiency in or near the boundary layer more than in the free troposphere. The simulated station e-folding lifetimes for days 45-65 are insensitive to these scavenging revisions at temperatures warmer than $258 \mathrm{~K}$, suggesting that the day 46-65 e-folding lifetimes characterize scavenging efficiency at colder temperatures in the free troposphere. Implementing these large-scale scavenging revisions at all temperatures (simulation GEOS-Chem_allT) yields the closest agreement with the observed day 45-65 e-folding lifetimes (13.2 days vs. 14.7 days), although the aerosol concentration bias relative to observations becomes negative (ratio 48 , i.e. -0.52 relative bias). This illustrates the important control of scavenging efficiency in the free troposphere and at temperatures colder than $258 \mathrm{~K}$ on these e-folding lifetimes.

\subsection{Comparison to other recent studies}

The present study suggests that models generally have too short a sulfate lifetime, while in a recent study Samset et al. (2014) found that models seem to have too long a black carbon (BC) lifetime, in line with other recent studies (Bauer et al., 2013; Q. Wang et al., 2014). These and other studies (e.g. H. Wang et al., 2013) using vertical profiles of BC from aircraft measurements have shown that the models tend to underestimate the concentrations close to ground, while overestimating at higher altitudes, particularly in the upper troposphere. The overall tendency for the atmospheric column is an overestimation and hence a conclusion that models require a shorter lifetime and more wet removal to reproduce the measurements. However, a uniform reduction of the modelled BC lifetime would lead to an even larger underestimation at the surface in the Arctic (Eckhardt et al., 2015). This points to considerable regional and vertical dif- 
ferences in lifetimes, which was clearly illustrated by Croft et al. (2014) using the GEOS-Chem model. They showed that modelled lifetimes were lowest and less than 5 days in the boundary layer below $2 \mathrm{~km}$, and increased by several orders of magnitude with altitude as wet removal mechanisms became increasingly less efficient with altitude. Lastly, transport issues may cause the apparent misfit between surface and higher altitudes. In our study, we have shown that some models underestimate transport particularly to the northernmost stations.

Eckhardt et al. (2015) compared both surface and aircraft measurements of sulfate and black carbon (BC) in the Arctic to model output from 11 different models. They found that the models generally underestimate the surface concentrations of $\mathrm{BC}$ and sulfate in winter/spring, whereas concentrations in summer were overestimated. For sulfate, they found very large differences in the model ensemble, with an apparent anti-correlation between modelled surface concentrations and total atmospheric columns. They also found a strong correlation between surface-measured sulfate and BC concentrations, which indicated that the sources contributing to sulfate and $\mathrm{BC}$ are similar throughout the Arctic, and that the aerosols are internally mixed and undergo similar removal. Neither Eckhardt et al. (2015) nor Samset et al. (2014) found an obvious factor (model type or aerosol treatment) that could explain why some models performed better than others.

Our findings suggest that the models tend to underestimate aerosol lifetimes compared to radionuclide observations, in contrast to what is found for $\mathrm{BC}$ from some of the other studies mentioned above. Of course, the differences may arise from the different properties of sulfate and $\mathrm{BC}$. The removal time of $\mathrm{BC}$ depends strongly on its mixing state and emitted size distribution (Reddington et al., 2013). Specifically, in models, the BC removal timescale is also dependent on the aging parameterizations, which are often very simple and might be a confounding factor. This could mean that our results are not representative of $\mathrm{BC}$ and are certainly not representative of freshly emitted BC. However, the high correlation and similar behaviour of sulfate and BC found by Eckhardt et al. (2015) suggests that their fate in the remote atmosphere is similar. The disagreement between models and observations is particularly evident for the Arctic regions, and there seems to be a mismatch between the surface and at higher altitudes. Therefore, we recommend that radionuclides, in particular ${ }^{133} \mathrm{Xe}$ and ${ }^{137} \mathrm{Cs}$, be measured in the free troposphere in the days and weeks following any detection coming from abnormal atmospheric releases. Such measurement will allow us to understand if the models can reproduce the atmospheric burden and vertical profiles of the aerosols, and better constrain modelled aerosol lifetimes.

\section{Conclusions}

In this study, we have compared measured and modelled accumulation-mode (AM) aerosol lifetimes, using radioactive isotopes released during the Fukushima Dai-Ichi nuclear power plant accident of March 2011. The radioactive isotope ${ }^{137} \mathrm{Cs}$ was released in large quantities during the accident, and attached to particles in the ambient air, approximately according to the particle surface area, which is generally dominated by the accumulation mode (AM). Measurements suggested that sulfate aerosols were the main carriers of cesium, and cesium was therefore used as a tracer for the AM sulfate aerosol's fate in the atmosphere. In contrast, the noble gas xenon $\left({ }^{133} \mathrm{Xe}\right)$, also released during the accident, behaved almost like a passive tracer and served as a reference species for atmospheric transport. Global measurements of the two radioactive isotopes taken over several months allowed the quantification of the lifetime of the carrier aerosols. The lifetimes apply to aerosols that have undergone long-range transport (after about 2-3 weeks); i.e. the results presented cannot directly constrain the lifetime of freshly emitted aerosols or secondary aerosols produced in the boundary layer.

Nineteen global models simulated the transport of the radioactive isotopes using identical emissions. We investigated to what extent the models could reproduce the observations, especially with respect to the observed loss of aerosol mass with time. Model results sampled at exactly the same location and times as station measurements allowed a direct comparison between measured and modelled aerosol decay and provided a strong constraint on modelled aerosol lifetime. Concentrations at measurement sites and global atmospheric burdens were used to evaluate the modelled lifetime of the aerosols.

Our main findings are detailed as follows.

- The e-folding lifetime $\tau_{\mathrm{e}}$, estimated from station measurements taken about 2 to 9 weeks after the start of the emissions, is 14.3 days (95\% confidence interval 13.1-15.7 days), and serves as an estimate for the lifetime of AM sulfate aerosol. The equivalent modelled $\tau_{\mathrm{e}}$ lifetimes have a large spread, varying between 4.8 and 26.7 days with a model median of $9.4 \pm 2.3$ days. Modelled instantaneous lifetimes show that the initial removal was quicker due to the emissions occurring at low altitudes and co-location with strong precipitation. Both e-folding and instantaneous lifetime estimates show that the models generally give a slightly shorter aerosol lifetime than observed. This is in contrast to recent findings for black carbon, which showed modelled lifetimes that are too long compared to aircraft measurements. More measurements of both radionuclides and different aerosol components, particularly in the free troposphere, are needed to better constrain modelled lifetimes, and understand these inconsistencies. 
- Deviations between measured and modelled aerosol lifetimes are largest for the northernmost stations and at later time periods. Comparisons of measured and modelled aerosol $\left({ }^{137} \mathrm{Cs}\right)$ and passive tracer $\left({ }^{133} \mathrm{Xe}\right)$ concentrations at each measurement station show a general underestimation at high latitudes, suggesting that both scavenging and transport are causes for disagreements with observations. The underestimation is largest for the aerosols $\left({ }^{137} \mathrm{Cs}\right)$, suggesting that scavenging and related cloud processes are the major reasons for the deviation from observations.

- Some models have a large bias to the measured aerosol concentrations, while at the same time showing a realistic lifetime. This is likely due to the treatment of the initial quick removal that affects the aerosol concentrations but not the lifetime estimate, which is derived only for later periods (after 2 weeks). Different approaches might be needed for tackling over- or under- scavenging close to the source emission in the early phase, and global-scale scavenging at later time periods. Revisions to one model that introduced an explicit dependence of wet removal efficiency on cloud liquid and ice water content, cloud temperature, and cloud fraction from the assimilated meteorological fields yielded significantly improved results.

- How representative or diffusive the transport schemes of the models are, and to what extent they produce vertical transport that is too fast, should be investigated further. Excessive diffusion in the models would mean that too much aerosol mass would be present at high altitudes, thereby increasing e-folding lifetimes independently of scavenging; while at the same time, the models will likely underestimate aerosol concentrations near the surface. 


\section{Appendix A: Aerosol modules}

Table A1 gives an overview of each model's treatment of the aerosols, i.e. the aerosol module.

Table A1. Specification of the aerosol modules.

\begin{tabular}{|c|c|c|}
\hline & Model & $\begin{array}{l}\text { Aerosol module } \\
\text { size distribution, density, microphysics (external/internal mixing, nucleation, condensation, coagulation), } \\
\text { dry and wet removal (in-cloud, below-cloud) }\end{array}$ \\
\hline 1 & NorESM & $\begin{array}{l}\text { Cesium was modelled as accumulation-mode sulfate, with a median radius of } 0.1 \times 10^{-6} \mathrm{~m} \text {, and a density of } \\
1769 \mathrm{~kg} \mathrm{~m}^{-3} \text {. The aerosol module (Seland et al., 2008; Kirkevåg et al., } 2013 \text { ) calculates mass concentrations } \\
\text { of aerosol species that are tagged according to production mechanisms in clear and cloudy air and four } \\
\text { size classes (nucleation, Aitken, accumulation, and coarse modes). These processes are primary emission, } \\
\text { gaseous and aqueous chemistry (cloud processing), nucleation, condensation, and coagulation. Loss terms } \\
\text { are dry deposition, in-cloud, and below-cloud scavenging. The chemical components included are sulfate } \\
\left(\mathrm{SO}_{4}\right) \text {, black carbon (BC), organic matter (OM), sea salt (SS), and mineral dust (DU). This adds up to } 20 \\
\text { aerosol components in addition to two gaseous precursors ( } \mathrm{SO}_{2} \text { and dimethyl sulfide, DMS). Dry and wet } \\
\text { deposition for aerosols: (i) hygroscopic growth of particles is included. (ii) The dry deposition velocity } \\
\text { depends on particles size, and the relative humidity influences this dependence for hygroscopic particles. } \\
\text { (iii) Gravitational settling is included for coarse particles. (iv) Wet deposition: both in-cloud and below- } \\
\text { cloud scavenging are taken into account for both stratiform and convective clouds. }\end{array}$ \\
\hline 2 & GISS-ModelE2-TOMAS & $\begin{array}{l}\text { TOMAS (TwO-Moment Aerosol Sectional) microphysics model (Adams and Seinfeld, 2002; Lee et al., } \\
\text { 2015) has } 12 \text { bins, covering from } 10 \mathrm{~nm} \text { to } 10 \mu \mathrm{m} \text { in a dry particle diameter, } 10 \text { bins from } 10 \mathrm{~nm} \text { to } 1 \mu \mathrm{m} \text {, } \\
\text { and } 2 \text { bins from } 1 \text { to } 10 \mu \mathrm{m} \text {. We assumed model cesium to follow a size distribution of sulfate particles. } \\
\text { Cesium and sulfate emissions are assumed to have a bimodal log-normal distribution: } 5 \% \text { of emissions } \\
\text { as a nucleation mode with geometric number mean diameter (GMD) of } 10 \mathrm{~nm} \text { and a geometric standard } \\
\text { deviation (GSD) of } 1.6 \text {, and } 95 \% \text { as an Aitken mode with GMD of } 70 \mathrm{~nm} \text { and GSD of } 2 \text {. Coagulation } \\
\text { and condensation are used, but aerosol nucleation is turned off to avoid repartitioning cesium mass to a } \\
\text { smaller size. Density of sulfate is assumed to be } 1.78 \mathrm{~g} \mathrm{~cm}^{-3} \text {. Internal mixing assumption except for wet } \\
\text { deposition. Dry deposition velocity is computed based on a resistance-in-series approach with size-resolved } \\
\text { resistance in the quasi-laminar sublayer and size-resolved gravitational settling velocity. Wet deposition: a } \\
\text { modified Köhler theory is used for in-cloud scavenging, and a size-resolved first-order removal scheme for } \\
\text { below-cloud scavenging. }\end{array}$ \\
\hline
\end{tabular}

3 GISS-ModelE Using the mass-based aerosol scheme one-moment aerosol (OMA), cesium was modelled as accumulationmode sulfate. The model transports sulfate as a mass tracer with a constant mean dry radius of $0.3 \times 10^{-6} \mathrm{~m}$. The wet deposition includes in- and below-cloud scavenging, which depends on the cloud cover, the hygroscopicity of aerosols, sulfate aerosols being assumed to be fully hygroscopic, and the precipitation and evaporation rates. Convective- and large-scale clouds are treated separately, with convective clouds handling individual convective plumes.

4 ULAQ-CCM Size distribution explicitly predicted from a microphysical code with gas-particle interactions (external mixing, homogeneous and heterogeneous nucleation, condensation/evaporation, coagulation, gravitational settling, large-scale transport), dry and wet removal (in-cloud, below-cloud).

5 BCC_AGCM 2.0.1_CAM Canadian Aerosol Module (CAM). The size spectrum of sulfate was discretized into 12 bins from 0.005 to $20.48 \mu \mathrm{m}$. Density of sulfate is about $1.8 \mathrm{~g} \mathrm{~cm}^{-3}$. Internal mixing except for the freshly emitted insoluble components. Coagulation: only binary collisions of particles are considered; coagulation coefficient is calculated from contributions of Brownian, turbulence, and gravitational settling movements. No nucleation and condensation in order to avoid false source of cesium. Dry deposition: a dry deposition velocity for sea-salt on the ocean was modified to treat multicomponent aerosols and complicate land properties. Wet deposition includes in- and below-cloud scavenging, which depend on cloud cover, the properties of both aerosols and hydrometeors, precipitation, and evaporation rates. 
Table A1. Continued.

\begin{tabular}{|c|c|c|}
\hline & Model & $\begin{array}{l}\text { Aerosol module } \\
\text { size distribution, density, microphysics (external/internal mixing, nucleation, condensation, coagulation), } \\
\text { dry and wet removal (in-cloud, below-cloud) }\end{array}$ \\
\hline 6 & LMDZORINCA & $\begin{array}{l}\text { INCA (INteraction with Chemistry and Aerosols) model. Cesium was treated as a submicron (diame- } \\
\text { ters }<1 \mu \mathrm{m} \text { ) aerosol in accumulation mode following a log-normal particle size distribution. No micro- } \\
\text { physics. The dry deposition of cesium was computed using the analogy of surface resistance. The deposition } \\
\text { velocity is defined as the inverse of the sum of an aerodynamic resistance and a surface resistance placed } \\
\text { in series. Wet scavenging for large-scale stratiform precipitation is calculated adopting the falling raindrop } \\
\text { approach. Scavenging by convective precipitation is calculated as part of the upward convective mass flux. }\end{array}$ \\
\hline 7 & CAM5 & $\begin{array}{l}\text { Cesium was assumed to attach to particles in the accumulation mode that includes internally mixed sulfate, } \\
\text { black carbon, primary and secondary organic matter, mineral dust, and sea salt. Particles in this mode are } \\
\text { described by a log-normal size distribution with a prescribed geometric standard deviation of } 1.8 \text { and a } \\
\text { dry diameter size range of } 58-270 \mathrm{~nm} \text {. The evolution of aerosol particles is controlled by various processes } \\
\text { including emission, transport, aerosol microphysics (e.g. nucleation, condensation, and coagulation), cloud } \\
\text { chemistry, and dry/wet removal processes (Liu et al., 2012). Aerosol wet removal is parameterized sepa- } \\
\text { rately for stratiform and convective clouds by in-cloud and below-cloud processes. For stratiform clouds, } \\
\text { the in-cloud removal process involves explicit aerosol activation to form cloud droplets and subsequent } \\
\text { removal of cloud-borne aerosols due to the conversion of cloud droplets to precipitation. Aerosol dry depo- } \\
\text { sition velocities are calculated with model-provided aerodynamic resistance, friction velocity, and surface } \\
\text { properties. Gravitational settling is also treated. }\end{array}$ \\
\hline
\end{tabular}

8 CAM5_PNNL Cesium is treated in the same way as in the CAM5 model. However, a new unified treatment of vertical transport and in-cloud wet removal processes in convective clouds is applied, which has a more detailed treatment of aerosol activation in convective updrafts. Also, a mechanism is added for laterally entrained aerosols to be activated and then removed. In addition, a few other changes have been introduced to wet removal processes to reduce some known biases in the remote aerosol distributions predicted by the default CAM5 model (H. Wang et al., 2013).

\begin{tabular}{ll}
\hline 9 & CAM5_NDG \\
\hline 10 & ECHAM5-MESSy- \\
& Atmospheric Chemistry \\
& Model, v1.92 (EMAC-1)
\end{tabular}

Same as CAM5

Cesium is modelled as a water-soluble aerosol with a standard log-normal distribution with mean radius $0.25 \mu \mathrm{m}$ and a Henry's law coefficient equal to $1.0 \mathrm{~mol} \mathrm{~L}^{-1} \mathrm{~atm}^{-1}$ and a density of $1000.0 \mathrm{~kg} \mathrm{~m}^{-3}$. Scavenging by impaction (below-cloud) and nucleation (in-cloud) by rain and snow/ice. Dry deposition: removal by turbulent transfer and uptake processes onto the earth's surface. The deposition velocity is calculated using a resistance model. Sedimentation: calculated separately based on the mass of the aerosol particles.

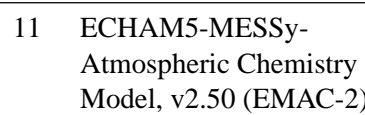

Cesium is treated as quasi-passive aerosol particles with sulfate characteristics, i.e. molar mass of $96 \mathrm{~g} \mathrm{~mol}^{-1}$ and a density of $2 \mathrm{~g} \mathrm{~cm}^{-3}$. The aerosols have an initial diameter of $0.5 \mu \mathrm{m}$ but can grow due to coagulation, coating, and condensation, and are internally mixed. Thus, the aerosols are affected by the background but do not interact with the background. Aerosol microphysics are calculated with GMXe (Pringle et al., 2010). Aerosol removal: scavenging by impaction (below-cloud) and nucleation (in-cloud), depending on aerosol size and solubility and rain intensity and droplet size. Dry deposition: removal by turbulent transfer and uptake processes onto the earth's surface. Dry deposition for aerosols follows the bigleaf approach. The deposition velocity is calculated using a resistance model. Sedimentation: calculated separately based on the mass of the aerosol particles (Kerkweg et al., 2006).

12 ECHAM5-HAM2 M7 modal aerosol microphysics module (Vignati et al., 2004), with modifications described in K. Zhang et al. (2012). Cesium is assumed to attach to accumulation-mode aerosols. In-cloud and below-cloud wet scavenging of cesium is considered for both stratiform and convective clouds. Dry deposition is also considered, but gravitational sedimentation is neglected for cesium. 
Table A1. Continued.

\begin{tabular}{|c|c|c|}
\hline & Model & $\begin{array}{l}\text { Aerosol module } \\
\text { size distribution, density, microphysics (external/internal mixing, nucleation, condensation, coagulation), } \\
\text { dry and wet removal (in-cloud, below-cloud) }\end{array}$ \\
\hline 13 & ECHAM5-SALSA & $\begin{array}{l}\text { SALSA describes aerosol size distribution for diameters ranging from } 3 \mathrm{~nm} \text { to } 10 \mu \mathrm{m} \text { using } 17 \text { internally } \\
\text { and externally mixed sections. The aerosol microphysical processes considered include condensation, co- } \\
\text { agulation, and nucleation, and aerosol particles are removed from the atmosphere by wet and dry deposition } \\
\text { as well as sedimentation (Bergman et al., 2012; Laakso et al., 2016). Wet deposition is based on the size- } \\
\text { and composition-dependent scavenging parameter, rain intensity, and type of precipitation, which are used } \\
\text { to simulate in-cloud and below-cloud scavenging separately (for the coefficients see Bergman et al., 2012). } \\
\text { Dry deposition uses a big-leaf method, which resolves aerosol deposition to surfaces online. Aerosol deposi- } \\
\text { tion velocity is calculated using aerosol number and mass together with wet radius, density, turbulence, and } \\
\text { surface cover (more detailed explanation can be found in Stier et al., 2005, and Kerkweg et al., 2006). Grav- } \\
\text { itational sedimentation is calculated using Stokes' law. Cesium is assumed to have density of } 1.83 \mathrm{~g} \mathrm{~cm}^{-3} \text {. } \\
\text { It attaches to the particles immediately and thus it is allocated to model size bins with diameters ranging } \\
\text { from } 50 \mathrm{~nm} \text { to } 10 \mu \mathrm{m} \text { using a log-normal distribution with a mean diameter of } 150 \mathrm{~nm} \text { and standard deviation } \\
\text { of } 1.59 \text {. }\end{array}$ \\
\hline
\end{tabular}

14 GEOS-Chem v09-01-03 Cesium is treated as accumulation-mode sulfate. No aerosol microphysics. Dry deposition: resistance in series scheme with dry deposition velocity dependent on surface type, as described in Wang et al. (2011). Wet deposition: separate treatment for large-scale and convective clouds (Liu et al., 2001). Below-cloud scavenging depends on precipitation rate, separate scavenging coefficients for accumulation- and coarse-mode aerosols, separate treatment for rain and snow. In-cloud scavenging depends on aerosol hygroscopicity, cloud temperature, and precipitation production rate (Wang et al., 2011).

15 EEMEP v2533 Cesium treated as aerosol particles (PPM2.5) with no sedimentation. No microphysics. Wet deposition depends on precipitation intensity and species-specific scavenging coefficients. Different coefficients are specified for in-cloud (rain out) and below-cloud scavenging. Dry deposition: impaction of particles on surface roughness elements and turbulent diffusion to surface treated using the resistance method to estimate a deposition velocity.

16 OsloCTM2 Cesium is treated as sulfate, following Berglen et al. (2004). Sulfate is assumed very soluble in precipitation. Removed in both convective- and large-scale precipitation. Dry deposition is not included.

17 OsloCTM3 Cesium is treated as sulfate, following Berglen et al. (2004), but large-scale wet scavenging follows Neu and Prather (2012), while convective wet scavenging uses the CTM2 approach. Both are described by Søvde et al. (2012). Dry deposition is not included.

18 NAME III

Cesium is treated as aerosol particles with no sedimentation. No microphysics. Wet deposition depends on precipitation intensity and species-specific scavenging coefficients. Different coefficients are specified for in-cloud (rain out) and below-cloud (wash out) scavenging, and rain and snow (Webster and Thomson, 2014). Dry deposition: impaction of particles on surface roughness elements and turbulent diffusion to surface treated using the resistance method to estimate a deposition velocity.

19 FLEXPART v9.0 Cesium is treated as aerosol particles with a mean particle diameter of $0.4 \mu \mathrm{m}$ and a density of $1.9 \mathrm{~g} \mathrm{~m}^{-3}$. No microphysics. Wet deposition depends on precipitation intensity and determined by species-specific scavenging coefficients. In-cloud (rain out) and below-cloud (wash out) scavenging are treated differently, as well as large-scale and convective-scale precipitation. Dry deposition: impaction of particles on surface roughness elements and turbulent diffusion to the surface treated using the resistance method to estimate a deposition velocity, which also includes a sedimentation velocity dependent on the particle size. 


\section{Appendix B: Confidence intervals and $\boldsymbol{R}^{2}$ statistics for lifetime estimates}

Table B1 gives the $95 \%$ confidence interval (C.I.) for the efolding lifetime $\tau_{\mathrm{e}}$ (Eq. 1) from Table 2. Note that $\tau_{\mathrm{e}}$ is not the centre of the C.I. as explained by Kristiansen et al. (2012). The table also gives the coefficients of determination $R^{2}$ which measure how close the data are to the fitted exponential decay models, with 1.0 indicating a perfect fit.

Table B1. Confidence intervals (days) for the e-folding aerosol lifetimes in Table 2, and the coefficients of determination $R^{2}$. Values that are not statistically significant at the $99.9 \%$ level are marked with an asterisk.

\begin{tabular}{|c|c|c|c|c|c|c|c|c|c|c|c|}
\hline \multirow{3}{*}{\multicolumn{2}{|c|}{ Model }} & \multicolumn{10}{|c|}{ Statistics for e-folding lifetime $\tau_{\mathrm{e}}$ (days) } \\
\hline & & \multicolumn{2}{|c|}{$\begin{array}{l}\text { Days } 15-65 \\
\text { All stations }\end{array}$} & \multicolumn{2}{|c|}{$\begin{array}{l}\text { Days } 15-65 \\
\text { Stations } \\
\text { below } 50^{\circ} \mathrm{N}\end{array}$} & \multicolumn{2}{|c|}{$\begin{array}{l}\text { Days } 15-65 \\
\text { Stations } \\
\text { above } 50^{\circ} \mathrm{N}\end{array}$} & \multicolumn{2}{|c|}{$\begin{array}{l}\text { Days } 25-45 \\
\text { All stations }\end{array}$} & \multicolumn{2}{|c|}{$\begin{array}{l}\text { Days } 45-65 \\
\text { All stations }\end{array}$} \\
\hline & & C.I. & $R^{2}$ & C.I. & $R^{2}$ & C.I. & $R^{2}$ & C.I. & $R^{2}$ & C.I. & $R^{2}$ \\
\hline 1 & NorESM & {$[9.8,11.3]$} & 0.94 & {$[10.3,12.4]$} & 0.91 & {$[8.5,9.6]$} & 0.96 & {$[8.3,13.0]$} & 0.83 & {$[8.5,15.0]$} & 0.77 \\
\hline 2 & GISS-ModelE2-TOMAS & {$[9.2,10.0]$} & 0.98 & {$[8.9,9.8]$} & 0.97 & {$[9.4,10.9]$} & 0.94 & {$[8.2,11.3]$} & 0.91 & {$[8.5,12.7]$} & 0.86 \\
\hline 3 & GISS-ModelE & {$[7.6,8.4]$} & 0.97 & {$[7.3,8.2]$} & 0.96 & {$[7.7,9.5]$} & 0.89 & {$[6.5,8.8]$} & 0.92 & {$[6.9,11.5]$} & 0.79 \\
\hline 4 & ULAQ-CCM & {$[5.7,6.3]$} & 0.97 & {$[5.8,7.1]$} & 0.90 & {$[5.4,6.0]$} & 0.97 & {$[5.2,6.4]$} & 0.96 & {$[3.9,4.7]$} & 0.96 \\
\hline 5 & BCC_AGCM & {$[15.6,18.0]$} & 0.94 & {$[16.1,19.7]$} & 0.90 & {$[16.8,20.4]$} & 0.90 & {$[14.0,24.7]$} & 0.76 & {$[10.8,15.0]$} & 0.90 \\
\hline 6 & LMDZORINCA & {$[10.5,12.8]$} & 0.89 & {$[9.2,11.1]$} & 0.91 & {$[12.9,21.5]$} & 0.57 & {$[6.0,8.2]$} & 0.91 & {$[10.2,61.8]$} & 0.32 \\
\hline 7 & CAM5 & {$[4.4,5.4]$} & 0.88 & {$[4.5,5.9]$} & 0.84 & {$[4.4,6.0]$} & 0.77 & {$[8.3,60.2]$} & $0.30^{*}$ & {$[2.4,3.6]$} & 0.86 \\
\hline 8 & CAM5_PNNL & {$[11.5,13.5]$} & 0.93 & {$[11.7,13.8]$} & 0.93 & {$[15.3,24.0]$} & 0.63 & {$[11.2,21.3]$} & 0.71 & {$[11.0,24.4]$} & 0.63 \\
\hline 9 & CAM5_NDG & {$[7.2,8.2]$} & 0.95 & {$[6.8,7.9]$} & 0.94 & {$[8.1,12.5]$} & 0.64 & {$[5.2,7.3]$} & 0.89 & {$[5.2,7.6]$} & 0.88 \\
\hline 10 & EMAC-1 & {$[10.7,12.8]$} & 0.91 & {$[12.1,16.3]$} & 0.80 & {$[7.4,9.6]$} & 0.84 & {$[7.6,10.3]$} & 0.91 & {$[6.6,10.4]$} & 0.83 \\
\hline 11 & EMAC-2 & {$[7.0,9.6]$} & 0.78 & {$[6.9,9.8]$} & 0.74 & {$[6.6,9.6]$} & 0.70 & {$[11.1,98.8]$} & $0.28^{*}$ & {$[3.2,5.1]$} & 0.82 \\
\hline 12 & ECHAM-HAM2 & {$[5.9,7.0]$} & 0.92 & {$[5.7,7.0]$} & 0.90 & {$[7.4,10.7]$} & 0.72 & {$[4.7,7.3]$} & 0.84 & {$[4.5,10.0]$} & 0.63 \\
\hline 13 & ECHAM5-SALSA & {$[6.1,8.0]$} & 0.81 & {$[6.4,8.9]$} & 0.77 & {$[6.4,9.9]$} & 0.64 & {$[6.4,12.9]$} & 0.68 & {$[11.4,-34.2]$} & $0.06^{*}$ \\
\hline 14 & GEOS-Chem & {$[18.1,23.3]$} & 0.84 & {$[14.8,18.9]$} & 0.86 & {$[25.6,46.4]$} & 0.50 & {$[13.8,28.4]$} & 0.67 & {$[14.6,57.5]$} & 0.41 \\
\hline 15 & EEMEP & {$[20.1,39.7]$} & 0.44 & {$[15.1,30.5]$} & 0.44 & {$[25.5,1233]$} & $0.08^{*}$ & {$[9.3,50.1]$} & 0.34 & {$[10.2,-75.2]$} & $0.12^{*}$ \\
\hline 16 & OsloCTM2 & {$[9.9,12.9]$} & 0.84 & {$[9.6,13.1]$} & 0.79 & {$[13.9,35.4]$} & 0.31 & {$[6.9,24.7]$} & 0.44 & {$[6.0,13.8]$} & 0.61 \\
\hline 17 & OsloCTM3 & {$[8.1,9.5]$} & 0.94 & {$[8.2,10.4]$} & 0.86 & {$[8.1,10.8]$} & 0.80 & {$[10.5,17.0]$} & 0.81 & {$[6.1,10.8]$} & 0.76 \\
\hline 18 & NAME & {$[7.7,11.9]$} & 0.65 & {$[8.9,14.4]$} & 0.61 & {$[6.6,12.6]$} & 0.46 & {$[4.5,19.6]$} & 0.39 & {$[3.2,7.9]$} & 0.57 \\
\hline 19 & FLEXPART & {$[5.5,6.1]$} & 0.97 & {$[5.5,6.3]$} & 0.94 & {$[5.5,6.5]$} & 0.92 & {$[5.6,7.7]$} & 0.91 & {$[4.2,6.4]$} & 0.85 \\
\hline & Observations & {$[13.1,15.7]$} & 0.91 & {$[12.2,15.2]$} & 0.88 & {$[12.9,17.7]$} & 0.77 & {$[11.7,20.9]$} & 0.76 & {$[10.1,26.8]$} & 0.54 \\
\hline
\end{tabular}




\section{Appendix C: Global aerosol burden}

The aerosol lifetime can also be assessed through the decay of the global atmospheric aerosol $\left({ }^{137} \mathrm{Cs}\right)$ burden. Figure $\mathrm{C} 1$ shows different estimates of measured and modelled atmospheric burdens of both the aerosol $\left({ }^{137} \mathrm{Cs}\right)$ and the passive tracer $\left({ }^{133} \mathrm{Xe}\right)$. First, global burdens are estimated with a 1D box model using the station measurements (Kristiansen et al., 2012). The box model assumes that the station concentrations at the ground are representative of the depth of the tropospheric column and of the latitude band a certain station is located in. This requires an assumption of a wellmixed state, which occurs after about 20 days (Kristiansen et al., 2012). The same box-model calculations were performed on the modelled station data (dark green and blue lines in Fig. C1). Second, modelled global burdens were also calculated from the full 3-D model output (light green and turquoise lines in Fig. C1).

Comparing the burdens calculated by applying the box model to the model-simulated station data (dark green and blue lines in Fig. C1) with the modelled global burdens based on the full 3-D model output (bright green and turquoise lines) serves as an evaluation of the box-model assumption. For some models, the global burdens from the surface sites extrapolated with the box model compare well with the burdens from the full model output directly, while for almost half of the models (GISS-ModelE, ULAQ-CCM, CAM5, EMAC-1, ECHAM-HAM2, EEMEP, OsloCTM2, NAME), the box-model estimates do not reconstruct the full global burdens very well and a general underestimation from the box-model estimates is found, which is expected since they are based on surface measurements. When estimating the lifetime from the modelled global burdens, we choose to use the global burdens based on the full model output rather than those based on the modelled station data and the box model, while for the lifetime estimate from the measurements we must rely on the box model and measured station data. This makes the comparison of lifetimes derived from the global burden data not entirely consistent since the measured and modelled burdens are not calculated in exactly the same way.

The modelled passive tracer $\left({ }^{133} \mathrm{Xe}\right)$ burdens (turquoise lines in Fig. C1) increase in the first few days due to xenon emissions, which continue until day 5. Over the next months, the passive tracer burdens stay approximately constant since they are not lost by any physical removal such as wet scavenging (and radioactive decay is corrected for). The passive tracer global burdens based on the station data and box model (dark blue lines) are only shown from day 20 onwards due to the required well-mixed assumption. Some slight decrease seen in the measurements is related to leakage into the stratosphere or outside the domain (i.e. the Southern Hemisphere) considered for the box-model estimates. The modelled global aerosol $\left({ }^{137} \mathrm{Cs}\right)$ burdens (bright green lines) also increase initially due to continuous cesium emissions which peak on day 3 . Until about day 40 , the aerosol burdens vary as they are affected by the emissions. After about 10 days, the cesium emissions drop significantly, but emissions continue between day 10 and 40 at about 2 orders of magnitude lower than the largest emissions. Hence, occasionally the aerosol burdens increase after a decrease up until day 40 . After this day, the cesium burdens decrease as the aerosols are removed from the atmosphere or are lost by mixing into the stratosphere. The ratio of the aerosol $\left({ }^{137} \mathrm{Cs}\right)$ to the passive tracer $\left({ }^{133} \mathrm{Xe}\right)$ burdens (black lines) decreases due to loss of aerosols, mostly dominated by wet deposition.

The e-folding lifetime (Eq. 1) is calculated from the ratio of the aerosol $\left({ }^{137} \mathrm{Cs}\right)$ to the passive tracer $\left({ }^{133} \mathrm{Xe}\right)$ burdens, by fitting an exponential decay model to the ratios between day 45 and day 65 (grey lines). Before day 45, the global aerosol burdens vary due to continuous emissions and reach a quasi-steady state after about $45-50$ days when the burden values are becoming less variable. After day 65, the measurement uncertainty becomes more substantial as the measured concentrations approach the instruments' detection limit. The $\tau_{\mathrm{e}}$ lifetime based on the global burdens from the station measurements and the box model is 12.9 days, while the lifetime based on the modelled global burdens (from the full 3-D model output) varies between 2.6 and 16.3 days with a model mean ( \pm standard deviation) of $10.0 \pm 4.1$ days, and a model median ( \pm MAD, Eq. 3$)$ of $9.4 \pm 2.4$ days.

The lifetime derived from the box-model-based burdens is more uncertain than the lifetime estimate from the station data in Sect. 5.1 due to the required assumption of a well-mixed state of the atmosphere. The assumption is violated due to slow mixing into the stratosphere. Once a large fraction of the material is in the stratosphere the wellmixed assumption breaks down. This effect becomes more prominent at later times as the fraction of aerosols $\left({ }^{137} \mathrm{Cs}\right)$ in the stratosphere increases while most of the tropospheric aerosols $\left({ }^{137} \mathrm{Cs}\right)$ have been removed by scavenging. Loss to the stratosphere cannot be distinguished from tropospheric removal. Errors due to variability caused by the relatively poor representivity of the measurement network may also exist in the box-model estimates. The modelled global burdens calculated from the full 3-D model outputs should not have this problem. That means that measurement-derived and model-derived lifetimes for the later phases are not entirely comparable, as they are not derived in a consistent way.

In summary, the lifetime estimates based on global atmospheric burdens show that the modelled lifetimes are somewhat shorter than those based on the measurements. This is the same trend as seen for the station data in Sect. 5.1. However, the lifetime estimates based on the box-model calculations are more uncertain due to the required well-mixed assumption. 

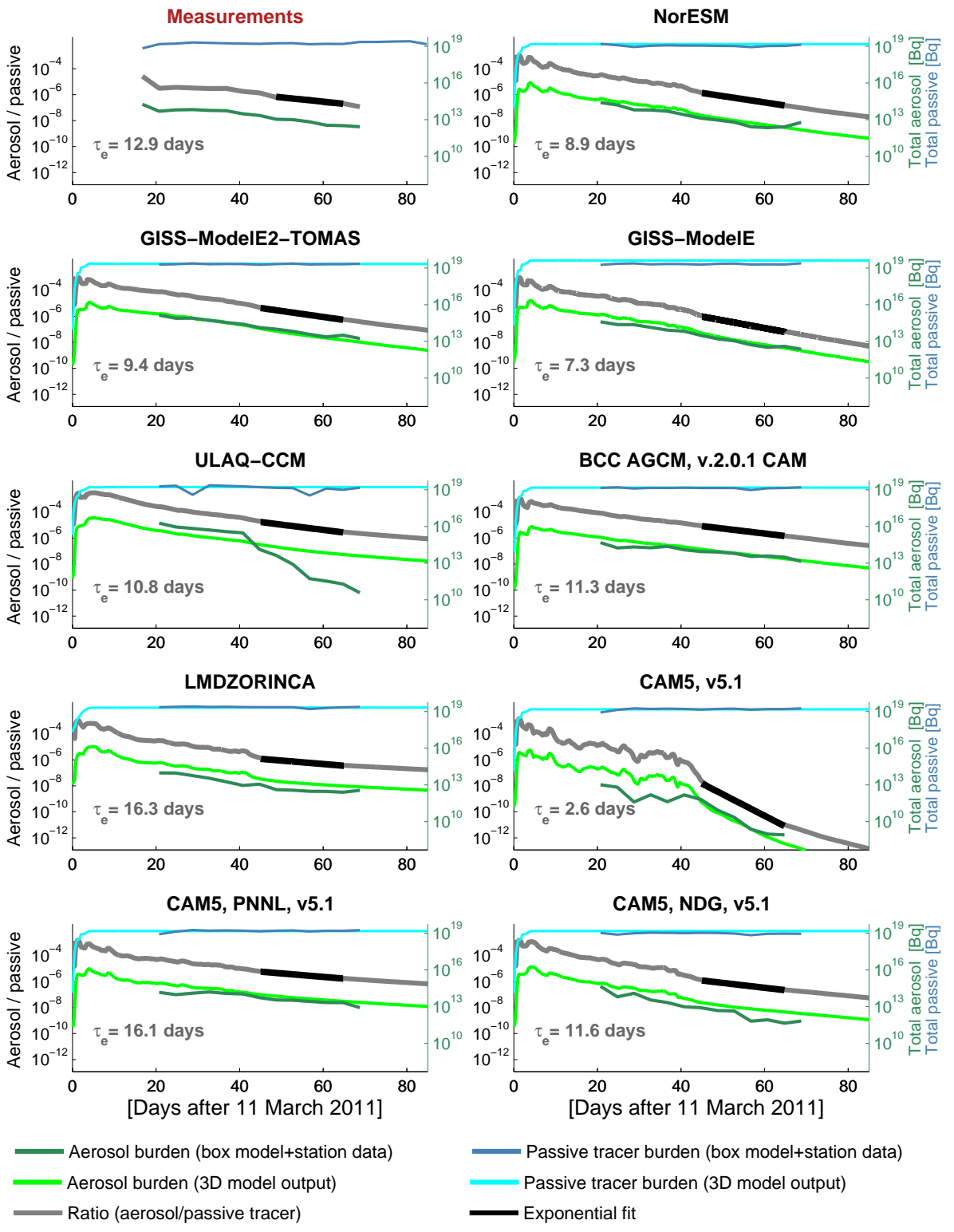

Figure C1. 
EMAC-1

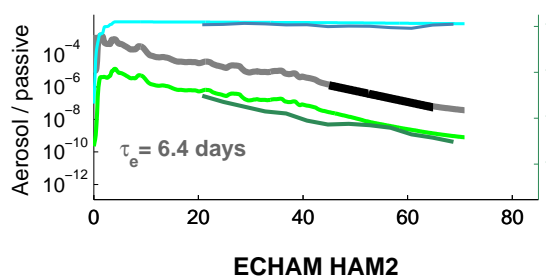

ECHAM HAM2

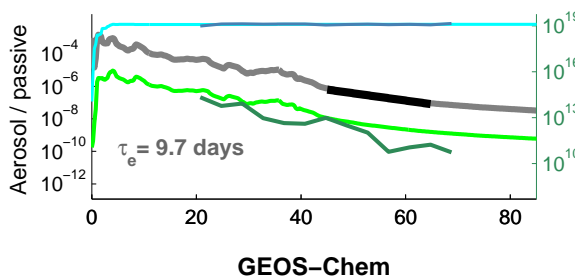

GEOS-Chem

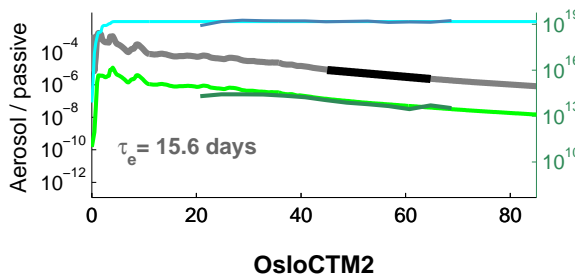

OslocTM2

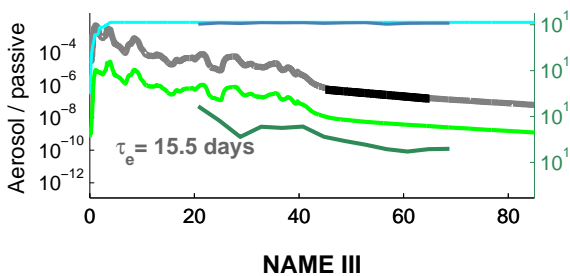

NAME III
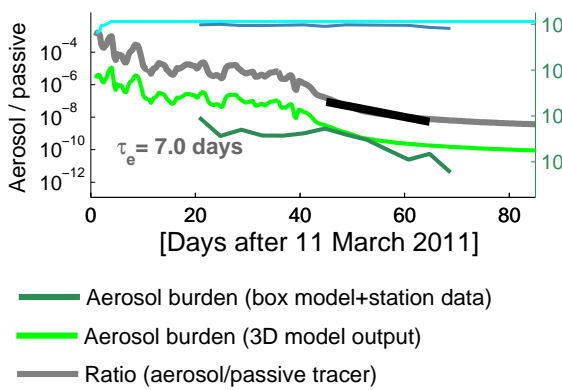

EMAC-2

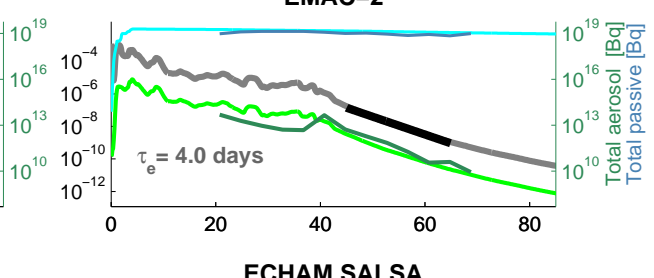

ECHAM SALSA

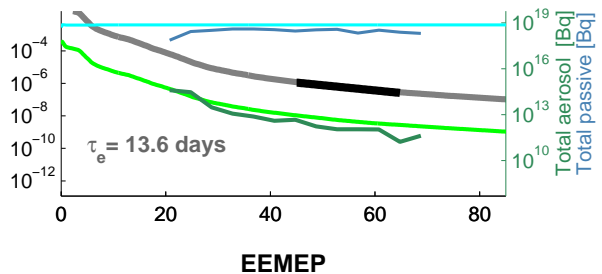

EEMEP

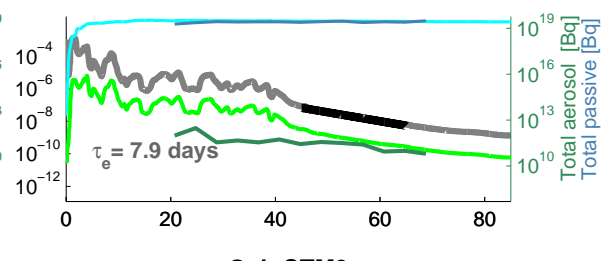

OsloCTM3

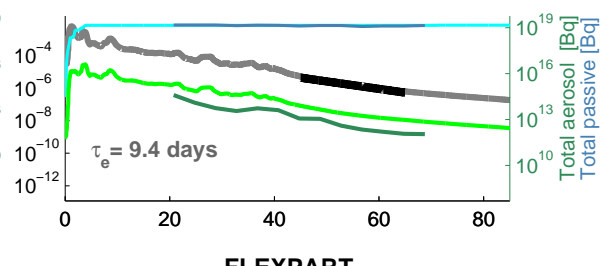

FLEXPART

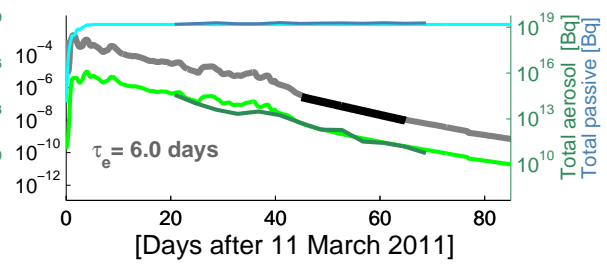

Passive tracer burden (box model+station data)

- Passive tracer burden (3D model output)

Exponential fit

Figure C1. Time series of global atmospheric burdens of aerosol $\left({ }^{137} \mathrm{Cs}\right.$; green lines), passive tracer $\left({ }^{133} \mathrm{Xe}\right.$; blue and turquoise lines), and their ratio (grey lines). Dark green and dark blue lines represent global burdens estimated by applying a 1-D box model to the measured or model-simulated station data. Bright green and turquoise lines show the modelled global atmospheric burdens calculated from the full 3-D model output. Fits of exponential decay models to the ratios between day 45 and 65 are shown as black lines, with e-folding timescales $\tau_{\mathrm{e}}$ (Eq. 1) as indicated. 
Author contributions. N. I. Kristiansen and A. Stohl designed the experiment, performed the FLEXPART simulations, and prepared the manuscript. The NorESM simulations and the optimizing convolution approach calculations were done by D. J. L. Olivié. The GEOS-Chem simulations were conducted by B. Croft with input from J. R. Pierce and R. V. Martin. The OsloCTM2 and OsloCTM3 simulations were done by O. A. Søvde, while the EEMEP simulations were carried out by $\mathrm{H}$. Klein. The EMAC-1 simulations were done by T. Christoudias and the EMAC-2 simulations by D. Kunkel with help from $\mathrm{H}$. Tost. The NAMEIII simulations were performed by S. J. Leadbetter, and the GISS-ModelE2-TOMAS simulations by Y. H. Lee with input from D. Shindell. The ECHAM5-HAM2 calculations were done by $\mathrm{K}$. Zhang, and $\mathrm{K}$. Tsigaridis completed the GISS-ModelE simulations with input from S. E. Bauer. The ECHAM5-SALSA simulations were conducted by T. Bergman with guidance from H. Kokkola, and the LMDZORINCA simulations were done by N. Evangeliou with input from Y. Balkanski. The CAM5 and CAM5_PNNL simulations were carried out by H. Wang together with P.-L. Ma, R. C. Easter, and P. J. Rasch, and the CAM5_NDG simulations were done by K. Zhang, H. Wang, and X. Liu. The ULAQ-CCM simulations were completed by G. Pitari and G. Di Genova, and the BCC_AGCM_2.0.1_CAM simulations were conducted by S. Y. Zhao with guidance from H. Zhang. Additional input to the interpretation of the analysis was provided by M. Schulz and Y. Balkanski. The analysis of model results and preparation of all figures and tables were done by N. I. Kristiansen. All authors provided input to the manuscript.

Acknowledgements. We would like to thank all the scientists who produced the CTBTO measurement data and made them available to us. The research leading to these results has received partial funding from the Norwegian Research Council under the NORKLIMA and KLIMAFORSK program (project "AeroCom-P3"). H. Zhang and S. Y. Zhao are supported by the National Basic Research Program of China (grant no.: 2011CB403405). H. Wang, R. C. Easter, P.-L. Ma, and P. J. Rasch acknowledge support from the US Department of Energy (DOE), Office of Science, Biological and Environmental Research as part of the Earth System Modeling Program. T. Bergman and H. Kokkola were supported by the Academy of Finland Centre of Excellence (project no. 272041). The ECHAM-HAMMOZ model is developed by a consortium composed of ETH Zurich, Max Planck Institut für Meteorologie, Forschungszentrum Jülich, University of Oxford, the Finnish Meteorological Institute, and the Leibniz Institute for Tropospheric Research, and managed by the Center for Climate Systems Modeling (C2SM) at ETH Zurich. The GISS model group acknowledges resources supporting this work, provided by the NASA High-End Computing (HEC) Program through the NASA Center for Climate Simulation (NCCS) at the Goddard Space Flight Center.

Edited by: E. Harris

\section{References}

Adams, P. J. and Seinfeld, J. H.: Predicting global aerosol size distributions in general circulation models, J. Geophys. Res., 107, doi:10.1029/2001JD001010, 2002.

Andreae, M. O.: Atmospheric aerosols versus greenhouse gases in the twenty-first century, Philos. T. R. Soc. A, 365, 1915-1923 doi:10.1098/rsta.2007.2051, 2007.

Bauer, S. E., Bausch, A., Nazarenko, L., Tsigaridis, K., Xu, B. Q., Edwards, R., Bisiaux, M., and McConnell, J.: Historical and future black carbon deposition on the three ice caps: ice core measurements and model simulations from 1850 to 2100 , J. Geophys. Res., 118, 7948-7961, doi:10.1002/Jgrd.50612, 2013.

Bentsen, M., Bethke, I., Debernard, J. B., Iversen, T., Kirkevåg, A., Seland, Ø., Drange, H., Roelandt, C., Seierstad, I. A., Hoose, C., and Kristjánsson, J. E.: The Norwegian Earth System Model, NorESM1-M - Part 1: Description and basic evaluation of the physical climate, Geosci. Model Dev., 6, 687-720, doi:10.5194/gmd-6-687-2013, 2013.

Berglen, T. F., Berntsen, T. K., Isaksen, I. S. A., and Sundet, J. K.: A global model of the coupled sulfur/oxidant chemistry in the troposphere: The sulfur cycle, J. Geophys. Res., 109, D19310, doi:10.1029/2003JD003948, 2004.

Bergman, T., Kerminen, V.-M., Korhonen, H., Lehtinen, K. J., Makkonen, R., Arola, A., Mielonen, T., Romakkaniemi, S., Kulmala, M., and Kokkola, H.: Evaluation of the sectional aerosol microphysics module SALSA implementation in ECHAM5HAM aerosol-climate model, Geosci. Model Dev., 5, 845-868, doi:10.5194/gmd-5-845-2012, 2012.

Bey, I., Jacob, D. J., Logan, J. A., and Yantosca, R. M.: Asian chemical outflow to the Pacific in spring: Origins, pathways and budgets, J. Geophys. Res., 106, 23097-23113, doi:10.1029/2001JD000806, 2001.

Bourgeois, Q. and Bey, I.: Pollution transport efficiency toward the Arctic: Sensitivity to aerosol scavenging and source regions, J. Geophys. Res., 116, D08213, doi:10.1029/2010JD015096, 2011.

Browse, J., Carslaw, K. S., Arnold, S. R., Pringle, K., and Boucher, O.: The scavenging processes controlling the seasonal cycle in Arctic sulfate and black carbon aerosol, Atmos. Chem. Phys., 12, 6775-6798, doi:10.5194/acp-12-6775-2012, 2012.

Cambray, R. S., Cawse, P. A., Garland, J. A., Gibson, J. A. B., Johnson, P., Lewis, G. N. J., Newton, D., Salmon, L., and Wade, B. O.: Observations on radioactivity from the Chernobyl accident, Nucl. Energy, 26, 77-101, 1987.

Cassiani, M., Stohl, A., and Eckhardt, S.: The dispersion characteristics of air pollution from the world's megacities, Atmos. Chem. Phys., 13, 9975-9996, doi:10.5194/acp-13-9975-2013, 2013.

Chin, M., Jacob, D. J., Gardner, G. M., Foreman-Fowler, M. S., Spiro, P. A., and Savoie, D. L.: A global three-dimensional model of tropospheric sulfate, J. Geophys. Res., 101, 18667-18690, doi:10.1029/96JD01221, 1996.

Chino, M., Nakayama, H., Nagai, H., Terada, H., Katata, G., and Yamazawa, H.: Preliminary estimation of release amounts of ${ }^{131} \mathrm{I}$ and ${ }^{137}$ Cs accidentally discharged from the Fukushima Daiichi nuclear power plant into the atmosphere, J. Nuc. Sci. Tech., 48, 1129-1134, doi:10.1080/18811248.2011.9711799, 2011.

Christoudias, T. and Lelieveld, J.: Modelling the global atmospheric transport and deposition of radionuclides from the Fukushima Dai-ichi nuclear accident, Atmos. Chem. Phys., 13, 1425-1438, doi:10.5194/acp-13-1425-2013, 2013. 
Chung, S. H. and Seinfeld, J. H.: Global distribution and climate forcing of carbonaceous aerosols, J. Geophys. Res., 107, 4407, doi:10.1029/2001JD001397, 2002.

Croft, B., Pierce, J. R., and Martin, R. V.: Interpreting aerosol lifetimes using the GEOS-Chem model and constraints from radionuclide measurements, Atmos. Chem. Phys., 14, 4313-4325, doi:10.5194/acp-14-4313-2014, 2014.

Croft, B., Martin, R. V., Leaitch, W. R., Tunved, P., Breider, T. J., D'Andrea, S. D., and Pierce, J. R.: Processes controlling the seasonal cycle of Arctic aerosol number and size distributions, Atmos. Chem. Phys. Discuss., 15, 29079-29124, doi:10.5194/acpd-15-29079-2015, 2015.

Eckhardt, S., Quennehen, B., Olivié, D. J. L., Berntsen, T. K., Cherian, R., Christensen, J. H., Collins, W., Crepinsek, S., Daskalakis, N., Flanner, M., Herber, A., Heyes, C., Hodnebrog, Ø., Huang, L., Kanakidou, M., Klimont, Z., Langner, J., Law, K. S., Lund, M. T., Mahmood, R., Massling, A., Myriokefalitakis, S., Nielsen, I. E., Nøjgaard, J. K., Quaas, J., Quinn, P. K., Raut, J.-C., Rumbold, S. T., Schulz, M., Sharma, S., Skeie, R. B., Skov, H., Uttal, T., von Salzen, K., and Stohl, A.: Current model capabilities for simulating black carbon and sulphate concentrations in the Arctic atmosphere: a multi-model evaluation using a comprehensive measurement data set, Atmos. Chem. Phys., 15, 9413-9433, doi:10.5194/acp-15-9413-2015, 2015.

Evangeliou, N., Balkanski, Y., Cozic, A., and Møller, A. P.: Global Transport and Deposition of ${ }^{137} \mathrm{Cs}$ Following the Fukushima Nuclear Power Plant Accident in Japan: Emphasis on Europe and Asia Using High-Resolution Model Versions and Radiological Impact Assessment of the Human Population and the Environment Using Interactive Tools, Environ. Sci. Technol., 47, 58035812, doi:10.1021/es400372u, 2013.

Feichter, J., Kjellstrom, E., Rodhe, H., Dentener, F., Lelieveld, J., and Roelofs, G.-J.: Simulation of the tropospheric sulphur cycle in a global climate model, Atmos. Environ., 30, 1693-1707, 1996.

Friedlander, S. K.: Smoke, dust and haze: Fundamentals of aerosol behavior, New York, Wiley-Interscience, 333 pp., doi:10.1016/1352-2310(95)00394-0, 1977.

Giorgi, F. and Chameides, W. I.: Rainout lifetimes of highly soluble aerosols and gases as inferred from simulations with a General Circulation Model, J. Geophys. Res., 91, 14367-14376, doi:10.1029/JD091iD13p14367, 1986.

Gong, S. L., Barrie, L. A., Blanchet, J.-P., von Salzen, K., Lohmann, U., Lensins, G., Spacek, L., Zhang, L. M., Girard, E., Lin, H., Leaitch, R., Leighton, H., Chylek, P., and Huang, P.: Canadian Aerosol Module: A size-segregated simulation of atmospheric aerosol processes for climate and air quality models 1. Module development, J. Geophys. Res., 108, 4007, doi:10.1029/2001JD002002, 2003.

Hagemann, S., Arpe, K., and Roeckner E.: Evaluation of the Hydrological Cycle in the ECHAM5 Model, J. Climate, 19, 38103827, doi:10.1175/JCLI3831.1, 2006.

Iversen, T., Bentsen, M., Bethke, I., Debernard, J. B., Kirkevåg, A., Seland, Ø., Drange, H., Kristjansson, J. E., Medhaug, I., Sand, M., and Seierstad, I. A.: The Norwegian Earth System Model, NorESM1-M - Part 2: Climate response and scenario projections, Geosci. Model Dev., 6, 389-415, doi:10.5194/gmd-6-3892013, 2013.
Kaneyasu, N., Ohashi, H., Suzuki, F., Okuda, T., and Ikemori, F. Sulfate aerosol as a potential transport medium of radiocesium from the Fukushima nuclear accident, Environ. Sci. Technol., 46, 5720-5726 doi:10.1021/es204667h, 2012.

Kerkweg, A., Buchholz, J., Ganzeveld, L., Pozzer, A., Tost, H., and Jöckel, P.: Technical Note: An implementation of the dry removal processes DRY DEPosition and SEDImentation in the Modular Earth Submodel System (MESSy), Atmos. Chem. Phys., 6, 4617-4632, doi:10.5194/acp-6-4617-2006, 2006.

Kirkevåg, A., Iversen, T., Seland, Ø., Hoose, C., Kristjánsson, J. E., Struthers, H., Ekman, A. M. L., Ghan, S., Griesfeller, J., Nilsson, E. D., and Schulz, M.: Aerosol-climate interactions in the Norwegian Earth System Model - NorESM1-M, Geosci. Model Dev., 6, 207-244, doi:10.5194/gmd-6-207-2013, 2013.

Koch, D. and Hansen, J.: Distant origins of Arctic black carbon, A Goddard Institute for Space Studies ModelE experiment, J. Geophys. Res., 110, D04204, doi:10.1029/2004jd005296, 2005.

Koch, D., Schmidt, G. A., and Field, C. V.: Sulfur, sea salt, and radionuclide aerosols in GISS ModelE, J. Geophys. Res., 111, D06206, doi:10.1029/2004jd005550, 2006.

Koch, D., Schulz, M., Kinne, S., McNaughton, C., Spackman, J. R., Balkanski, Y., Bauer, S., Berntsen, T., Bond, T. C., Boucher, O., Chin, M., Clarke, A., De Luca, N., Dentener, F., Diehl, T., Dubovik, O., Easter, R., Fahey, D. W., Feichter, J., Fillmore, D., Freitag, S., Ghan, S., Ginoux, P., Gong, S., Horowitz, L., Iversen, T., Kirkevåg, A., Klimont, Z., Kondo, Y., Krol, M., Liu, X., Miller, R., Montanaro, V., Moteki, N., Myhre, G., Penner, J. E., Perlwitz, J., Pitari, G., Reddy, S., Sahu, L., Sakamoto, H., Schuster, G., Schwarz, J. P., Seland, Ø., Stier, P., Takegawa, N., Takemura, T., Textor, C., van Aardenne, J. A., and Zhao, Y.: Evaluation of black carbon estimations in global aerosol models, Atmos. Chem. Phys., 9, 9001-9026, doi:10.5194/acp-9-9001-2009, 2009.

Kristiansen, N. I., Stohl, A., and Wotawa, G.: Atmospheric removal times of the aerosol-bound radionuclides ${ }^{137} \mathrm{Cs}$ and ${ }^{131} \mathrm{I}$ measured after the Fukushima Dai-ichi nuclear accident - a constraint for air quality and climate models, Atmos. Chem. Phys., 12, 10759-10769, doi:10.5194/acp-12-10759-2012, 2012.

Kunkel, D.: Global modeling of pollutant transport and deposition from anthropogenic emission hot spots on global scale, PhD Dissertation, Johannes Gutenberg-Universität in Mainz, 2012.

Kunkel, D., Tost, H., and Lawrence, M. G.: Aerosol pollution potential from major population centers, Atmos. Chem. Phys., 13, 4203-4222, doi:10.5194/acp-13-4203-2013, 2013.

Laakso, A., Kokkola, H., Partanen, A.-I., Niemeier, U., Timmreck, C., Lehtinen, K. E. J., Hakkarainen, H., and Korhonen, H.: Radiative and climate impacts of a large volcanic eruption during stratospheric sulfur geoengineering, Atmos. Chem. Phys., 16, 305-323, doi:10.5194/acp-16-305-2016, 2016.

Leadbetter, S., Hort, M., Jones, A., Webster, H., and Draxler R.: Sensitivity of the deposition of Caesium-137 from Fukushima Dai-ichi nuclear power plant on the wet deposition parameterisation in NAME, J. Environ. Radioactiv., 139, 200-211, doi:10.1016/j.jenvrad.2014.03.018, 2015.

Lee, Y. H., Adams, P. J., and Shindell, D. T.: Evaluation of the global aerosol microphysical ModelE2-TOMAS model against satellite and ground-based observations, Geosci. Model Dev., 8, 631-667, doi:10.5194/gmd-8-631-2015, 2015. 
Liu, H., Jacob, D. J., Bey, I., and Yantosca, R. M.: Constraints from ${ }^{210} \mathrm{~Pb}$ and ${ }^{7} \mathrm{Be}$ on wet deposition and transport in a global threedimensional chemical tracer model driven by assimilated meteorological fields, J. Geophys. Res., 106, 12109-12128, 2001.

Liu, X., Penner, J. E., and Herzog, M.: Global modeling of aerosol dynamics: Model description, evaluation, and interactions between sulfate and nonsulfate aerosols, J. Geophys. Res., 110, D18206, doi:10.1029/2004JD005674, 2005.

Liu, X., Easter, R. C., Ghan, S. J., Zaveri, R., Rasch, P., Shi, X., Lamarque, J.-F., Gettelman, A., Morrison, H., Vitt, F., Conley, A., Park, S., Neale, R., Hannay, C., Ekman, A. M. L., Hess, P., Mahowald, N., Collins, W., Iacono, M. J., Bretherton, C. S., Flanner, M. G., and Mitchell, D.: Toward a minimal representation of aerosols in climate models: description and evaluation in the Community Atmosphere Model CAM5, Geosci. Model Dev., 5, 709-739, doi:10.5194/gmd-5-709-2012, 2012.

Ma, P.-L., Rasch, P. J., Wang, H., Zhang, K., Easter, R. C., Tilmes, S., Fast, J. D., Liu, X., Yoon, J.-H., and Lamarque, J.-F.: The role of circulation features on black carbon transport into the Arctic in the Community Atmosphere Model version 5 (CAM5), J. Geophys. Res.-Atmos., 118, 4657-4669, doi:10.1002/jgrd.50411, 2013.

Masson, O., Ringer, W., Malá, H., Rulik, P., Dlugosz-Lisiecka, M., Eleftheriadis, K., Meisenberg, O., De Vismes-Ott, A., and Gensdarmes, F.: Size Distributions of Airborne Radionuclides from the Fukushima Nuclear Accident at Several Places in Europe, Environ. Sci. Technol., 47, 10995-11003, doi:10.1021/es401973c, 2013.

Medici, F.: The IMS radionuclide network of the CTBT, Radiat. Phys. Chem., 61, 689-690, doi:10.1016/S0969-806X(01)003759, 2001.

Miyamoto, Y., Yasuda, K., and Magara, M.: Size distribution of radioactive particles collected at Tokai, Japan 6 days after the nuclear accident, Environ. Sci. Technol., 132, 1-7, doi:10.1016/j.jenvrad.2014.01.010, 2014.

Moore, H. E., Poet, S. E., and Martell, E. A.: ${ }^{222} \mathrm{Rn},{ }^{210} \mathrm{~Pb},{ }^{210} \mathrm{Bi}$, and ${ }^{210}$ Po profiles and aerosol residence times versus altitude, J. Geophys. Res., 78, 7065-7075, doi:10.1029/JC078i030p07065, 1973.

Neu, J. L. and Prather, M. J.: Toward a more physical representation of precipitation scavenging in global chemistry models: cloud overlap and ice physics and their impact on tropospheric ozone, Atmos. Chem. Phys., 12, 3289-3310, doi:10.5194/acp-12-32892012, 2012.

Papastefanou, C.: Residence time of tropospheric aerosols in association with radioactive nuclides, Appl. Radiat. Isotopes, 64, 93-100, doi:10.1016/j.apradiso.2005.07.006, 2006.

Papastefanou, C.: Radioactive aerosols, Radioactivity in the environment, Volume 12, edited by: Baxter, M. S., Elsevier, ISBN: 978-0-08-044075-0, 2008.

Paris, J.-D., Stohl, A., Nédélec, P., Arshinov, M. Yu., Panchenko, M. V., Shmargunov, V. P., Law, K. S., Belan, B. D., and Ciais, P.: Wildfire smoke in the Siberian Arctic in summer: source characterization and plume evolution from airborne measurements, Atmos. Chem. Phys., 9, 9315-9327, doi:10.5194/acp-9-9315-2009, 2009.

Pitari, G., Aquila, V., Kravitz, B., Robock, A., Watanabe, S., Cionni, I., De Luca, N., Di Genova, G., Mancini, E., and Tilmes, S.: Stratospheric Ozone Response to Sulfate Geoengi- neering: Results from the Geoengineering Model Intercomparison Project (GeoMIP), J. Geophys. Res., 119, 2629-2653, doi:10.1002/2013JD020566, 2014.

Pöschl, U.: Atmospheric Aerosols: Composition, Transformation, Climate and Health Effects. Angew. Chem. Int. Ed., 44, 7520 7540, doi:10.1002/anie.200501122, 2005

Pringle, K. J., Tost, H., Message, S., Steil, B., Giannadaki, D., Nenes, A., Fountoukis, C., Stier, P., Vignati, E., and Lelieveld, J.: Description and evaluation of GMXe: a new aerosol submodel for global simulations (v1), Geosci. Model Dev., 3, 391-412, doi:10.5194/gmd-3-391-2010, 2010.

Ramanathan, V., Crutzen, P. J., Kiehl, J. T., and Rosenfeld, D.: Aerosols, Climate, and the Hydrological Cycle, Science, 294, 2119-2124, doi:10.1126/science.1064034, 2001.

Reddington, C. L., McMeeking, G., Mann, G. W., Coe, H., Frontoso, M. G., Liu, D., Flynn, M., Spracklen, D. V., and Carslaw, K. S.: The mass and number size distributions of black carbon aerosol over Europe, Atmos. Chem. Phys., 13, 4917-4939, doi:10.5194/acp-13-4917-2013, 2013.

Saey, P. R. J. and de Geer, L.-E.: Notes on radioxenon measurements for CTBT verification purposes, Appl. Radiat. Isotopes, 63, 765773, doi:10.1016/j.apradiso.2005.05.035, 2005.

Samset, B. H., Myhre, G., Herber, A., Kondo, Y., Li, S.-M., Moteki, N., Koike, M., Oshima, N., Schwarz, J. P., Balkanski, Y., Bauer, S. E., Bellouin, N., Berntsen, T. K., Bian, H., Chin, M., Diehl, T., Easter, R. C., Ghan, S. J., Iversen, T., Kirkevåg, A., Lamarque, J.-F., Lin, G., Liu, X., Penner, J. E., Schulz, M., Seland, Ø., Skeie, R. B., Stier, P., Takemura, T., Tsigaridis, K., and Zhang, K.: Modelled black carbon radiative forcing and atmospheric lifetime in AeroCom Phase II constrained by aircraft observations, Atmos. Chem. Phys., 14, 12465-12477, doi:10.5194/acp14-12465-2014, 2014.

Schmale, J., Schneider, J., Ancellet, G., Quennehen, B., Stohl, A., Sodemann, H., Burkhart, J. F., Hamburger, T., Arnold, S. R., Schwarzenboeck, A., Borrmann, S., and Law, K. S.: Source identification and airborne chemical characterisation of aerosol pollution from long-range transport over Greenland during POLARCAT summer campaign 2008, Atmos. Chem. Phys., 11, 1009710123, doi:10.5194/acp-11-10097-2011, 2011.

Schmidt, G. A., Kelley, M., Nazarenko, L., Ruedy, R., Russell, G. L., Aleinov, I., Bauer, M., Bauer, S. E., Bhat, M. K., Bleck, R., Canuto, V., Chen, Y.-H., Cheng, Y., Clune, T. L., Del Genio, A., de Fainchtein, R., Faluvegi, G., Hansen, J. E., Healy, R. J., Kiang, N. Y., Koch, D., Lacis, A. A., LeGrande, A. N., Lerner, J., Lo, K K., Matthews, E. E., Menon, S., Miller, R. L., Oinas, V., Oloso, A. O., Perlwitz, J. P., Puma, M. J., Putman, W. M., Rind, D., Romanou, A., Sato, M., Shindell, D. T., Sun, S., Syed, R. A., Tausnev, N., Tsigaridis, K., Unger, N., Voulgarakis, A., Yao, M.-S., and Zhang, J.: Configuration and assessment of the Giss ModelE2 contributions to the CMIP5 archive, J. Adv. Model. Earth Syst., 6, 141-184, doi:10.1002/2013MS000265, 2014.

Schulze, J., Auer, M., and Werzi, R.: Low level radioactivity measurement in support of the CTBTO, Appl. Radiat. Isotopes, 53, 23-30, doi:10.1016/j.apradiso.2005.05.035, 2000.

Seinfeld, J. H. and Pandis, S. N.: Atmospheric Chemistry and Physics: From Air Pollution to Climate Change, New York, John Wiley and Sons, 1998. 
Seland, Ø., Iversen, T., Kirkevåg, A., and Storelvmo, T.: Aerosolclimate interactions in the CAM-Oslo atmospheric GCM and investigation of associated basic shortcomings, Tellus, 60A, 459951, doi:10.1111/j.1600-0870.2008.00318.x, 2008.

Shindell, D. T., Chin, M., Dentener, F., Doherty, R. M., Faluvegi, G., Fiore, A. M., Hess, P., Koch, D. M., MacKenzie, I. A., Sanderson, M. G., Schultz, M. G., Schulz, M., Stevenson, D. S., Teich, H., Textor, C., Wild, O., Bergmann, D. J., Bey, I., Bian, H., Cuvelier, C., Duncan, B. N., Folberth, G., Horowitz, L. W., Jonson, J., Kaminski, J. W., Marmer, E., Park, R., Pringle, K. J., Schroeder, S., Szopa, S., Takemura, T., Zeng, G., Keating, T. J., and Zuber, A.: A multi-model assessment of pollution transport to the Arctic, Atmos. Chem. Phys., 8, 5353-5372, doi:10.5194/acp-85353-2008, 2008.

Stier, P., Feichter, J., Kinne, S., Kloster, S., Vignati, E., Wilson, J., Ganzeveld, L., Tegen, I., Werner, M., Balkanski, Y., Schulz, M., Boucher, O., Minikin, A., and Petzold, A.: The aerosol-climate model ECHAM5-HAM, Atmos. Chem. Phys., 5, 1125-1156, doi:10.5194/acp-5-1125-2005, 2005.

Stohl, A., Forster, C., Frank, A., Seibert, P., and Wotawa, G.: Technical note: The Lagrangian particle dispersion model FLEXPART version 6.2, Atmos. Chem. Phys., 5, 2461-2474, doi:10.5194/acp-5-2461-2005, 2005.

Stohl, A., Seibert, P., Wotawa, G., Arnold, D., Burkhart, J. F., Eckhardt, S., Tapia, C., Vargas, A., and Yasunari, T. J.: Xenon133 and caesium-137 releases into the atmosphere from the Fukushima Dai-ichi nuclear power plant: determination of the source term, atmospheric dispersion, and deposition, Atmos. Chem. Phys., 12, 2313-2343, doi:10.5194/acp-12-2313-2012, 2012a.

Stohl, A., Seibert, P., and Wotawa, G.: The total release of xenon-133 from the Fukushima Dai-ichi nuclear power plant accident. J. Environ. Radioactiv., 112, 155-159, doi:10.1016/j.jenvrad.2012.06.001, 2012b.

Søvde, O. A., Gauss, M., Smyshlyaev, S., and Isaksen, I. S. A.: Evaluation of the chemical transport model Oslo CTM2 with focus on Arctic winter ozone depletion, J. Geophys. Res., 113, D09304, doi:10.1029/2007JD009240, 2008.

Søvde, O. A., Prather, M. J., Isaksen, I. S. A., Berntsen, T. K., Stordal, F., Zhu, X., Holmes, C. D., and Hsu, J.: The chemical transport model Oslo CTM3, Geosci. Model Dev., 5, 1441-1469, doi:10.5194/gmd-5-1441-2012, 2012.

Textor, C., Schulz, M., Guibert, S., Kinne, S., Balkanski, Y., Bauer, S., Berntsen, T., Berglen, T., Boucher, O., Chin, M., Dentener, F., Diehl, T., Easter, R., Feichter, H., Fillmore, D., Ghan, S., Ginoux, P., Gong, S., Grini, A., Hendricks, J., Horowitz, L., Huang, P., Isaksen, I., Iversen, I., Kloster, S., Koch, D., Kirkevåg, A., Kristjansson, J. E., Krol, M., Lauer, A., Lamarque, J. F., Liu, X., Montanaro, V., Myhre, G., Penner, J., Pitari, G., Reddy, S., Seland, $\varnothing$., Stier, P., Takemura, T., and Tie, X.: Analysis and quantification of the diversities of aerosol life cycles within AeroCom, Atmos. Chem. Phys., 6, 1777-1813, doi:10.5194/acp-6-1777-2006, 2006.

Tsigaridis, K., Koch, D., and Menon, S.: Uncertainties and importance of sea spray composition on aerosol direct and indirect effects, J. Geophys. Res.-Atmos., 118, 220-235, doi:10.1029/2012jd018165, 2013.
Vignati, E., Wilson, J., and Stier, P.: M7: An efficient size-resolved aerosol microphysics module for large-scale aerosol transport models, J. Geophys. Res., 109, D22202, doi:10.1029/2003JD004485, 2004.

Wang, H., Easter, R. C., Rasch, P. J., Wang, M., Liu, X., Ghan, S. J., Qian, Y., Yoon, J.-H., Ma, P.-L., and Vinoj, V.: Sensitivity of remote aerosol distributions to representation of cloud-aerosol interactions in a global climate model, Geosci. Model Dev., 6, 765-782, doi:10.5194/gmd-6-765-2013, 2013.

Wang, H., Rasch, P. J., Easter, R. C., Singh, B., Zhang, R., Ma, P. L., Qian, Y., and Beagley, N.: Using an explicit emission tagging method in global modeling of source-receptor relationships for black carbon in the Arctic: Variations, Sources and Transport pathways, J. Geophys. Res.-Atmos., 119, 12888-12909, doi:10.1002/2014JD022297, 2014.

Wang, Q., Jacob, D. J., Mao, J., Leibensperger, E. M., Carouge, C. C., Sager, P. L., Kondo, Y., Jimenez, J. L., Cubison, M. J., and Doherty, S. J.: Sources of carbonaceous aerosols and deposited black carbon in the Arctic in winter-spring: implications for radiative forcing, Atmos. Chem. Phys., 11, 12453-12473, doi:10.5194/acp-11-12453-2011, 2011.

Wang, Q., Jacob, D. J., Spackman, J. R., Perring, A. E., Schwarz, J. P., Moteki, N., Marais, E. A., Ge, C., Wang, J., and Barrett, S. R. H.: Global budget and radiative forcing of black carbon aerosol: Constraints from pole-to-pole (HIPPO) observations across the Pacific, J. Geophys. Res.-Atmos., 119, 195-206, doi:10.1002/2013jd020824, 2014.

Webster H. and Thomson, D.: The NAME wet deposition scheme, Forecasting Research Technical Report 584, Met Office, UK, available at: http://www.metoffice.gov.uk/media/pdf/c/ a/FRTR584.pdf (last access: 15 March 2016), 2014.

Wernsberger, B. and Schlosser, C.: Noble gas monitoring within the international monitoring system of the Comprehensive $\mathrm{Nu}$ clear Test-Ban Treaty, Radiat. Phys. Chem., 71, 775-779, doi:10.1016/j.radphyschem.2004.04.088, 2004.

Williams, J., de Reus, M., Krejci, R., Fischer, H., and Ström, J.: Application of the variability-size relationship to atmospheric aerosol studies: estimating aerosol lifetimes and ages, Atmos. Chem. Phys., 2, 133-145, doi:10.5194/acp-2-133-2002, 2002.

Wotawa, G., Becker, A., Kalinowski, M., Saey, P., Tuma, M., and Zähringer, M.: Computation and analysis of the global distribution of the radioxenon isotope 133133 based on emissions from nuclear power plants and radioisotope production facilities and its relevance for the verification of the Nuclear-Test-Ban treaty, Pure Appl. Geophys., 167, 541-557, 2010.

Zhang, H., Wang, Zh., Wang, Za., Liu, Q., Gong, S., Zhang, X., Shen, Z., Lu, P., Wei, X., Che, H., and Li, L.: Simulation of direct radiative forcing of aerosols and their effects on East Asian climate using an interactive AGCM-aerosol coupled system, Clim. Dynam., 38, 1675-1693, doi:10.1007/s00382-011-1131-0, 2012.

Zhang, H., Jing, X., and Li, J.: Application and evaluation of a new radiation code under McICA scheme in BCC_AGCM2.0.1, Geosci. Model Dev., 7, 737-754, doi:10.5194/gmd-7-737-2014, 2014.

Zhang, K., O’Donnell, D., Kazil, J., Stier, P., Kinne, S., Lohmann, U., Ferrachat, S., Croft, B., Quaas, J., Wan, H., Rast, S., and Feichter, J.: The global aerosol-climate model ECHAM-HAM, version 2: sensitivity to improvements in process representations, 
Atmos. Chem. Phys., 12, 8911-8949, doi:10.5194/acp-12-89112012, 2012.

Zhang, K., Wan, H., Liu, X., Ghan, S. J., Kooperman, G. J., Ma, P.-L., Rasch, P. J., Neubauer, D., and Lohmann, U.: Technical Note: On the use of nudging for aerosol-climate model intercomparison studies, Atmos. Chem. Phys., 14, 8631-8645, doi:10.5194/acp-14-8631-2014, 2014.
Zhang, R., Wang, H., Qian, Y., Rasch, P. J., Easter, R. C., Ma, P.L., Singh, B., Huang, J., and Fu, Q.: Quantifying sources, transport, deposition, and radiative forcing of black carbon over the Himalayas and Tibetan Plateau, Atmos. Chem. Phys., 15, 62056223, doi:10.5194/acp-15-6205-2015, 2015. 